\title{
Improving hospital-based quality of care in Vietnam by reducing HIV-related stigma and discrimination
}

Khuat Thi Hai Oanh

Kim Ashburn

Julie Pulerwitz

Jessica Ogden

Laura Nyblade

Follow this and additional works at: https://knowledgecommons.popcouncil.org/departments_sbsr-hiv

Part of the Demography, Population, and Ecology Commons, Health Policy Commons, Immune System Diseases Commons, International Public Health Commons, Medicine and Health Commons, Public Health Education and Promotion Commons, and the Virus Diseases Commons How does access to this work benefit you? Let us know!

\section{Recommended Citation}

Khuat Thi Hai Oanh, Kim Ashburn, Julie Pulerwitz, Jessica Ogden, and Laura Nyblade. 2008. "Improving hospital-based quality of care in Vietnam by reducing HIV-related stigma and discrimination," Horizons Final Report. Washington, DC: Population Council. 


\section{Improving Hospital-based Quality of Care in Vietnam by Reducing HIV-related Stigma and Discrimination}
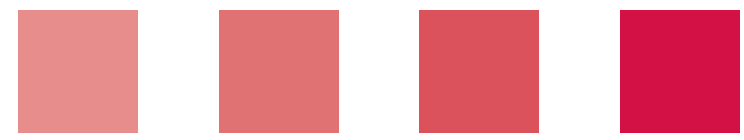

Institute for Social Development Studies International Center for Research on Women Horizons Program 


\section{Improving Hospital-based Quality of Care in Vietnam by Reducing HIV-related Stigma and Discrimination}

Khuat Thi Hai Oanh, Institute for Social Development Studies (ISDS) Kim Ashburn, International Center for Research on Women (ICRW) Julie Pulerwitz, Horizons/PATH Jessica Ogden, ICRW Laura Nyblade, ICRW
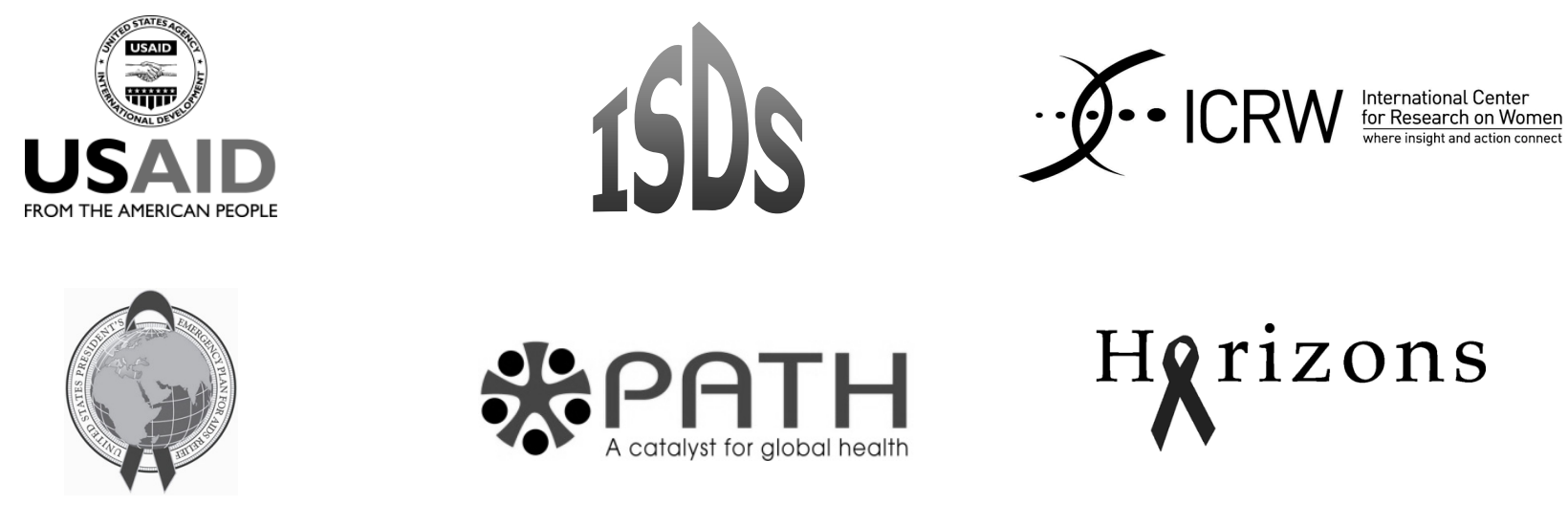


\section{Hgrizons}

\section{Acknowledgments}

This work and resulting report was only possible through the contributions of many individuals and through the collaboration of our various institutions. In particular, we would like to acknowledge Pham Duc Muc, of Department of Therapy, Vietnam Ministry of Health, who provided expert guidance and valuable insights on infection control and implementation of universal precautions in the hospital setting; Ross Kidd for documenting the stigma training content and process; and to Joseph Abraham, Sc.D., independent consultant, who provided input into the statistical analysis plan. We would also like to thank Jane Hughes, Population Council/Vietnam, for being supportive of this project from its inception.

Finally, we give special thanks to all of those in the hospital study sites who so willingly shared their time and experiences with us on such a sensitive topic. Without their generous involvement, this work would not have been possible.

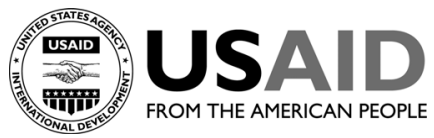

This study and final report were made possible by the President's Emergency Plan for AIDS Relief and the generous support of the American people through the United States Agency for International Development (USAID) under the terms of Cooperative Agreement No. HRN-A00-97-00012-00. The contents are the responsibility of the Horizons Program and do not necessarily reflect the views of USAID or the United States Government.

Published in February 2008.

\section{(P) Population Council}

The Population Council is an international, non-profit, nongovernmental institution that seeks to improve the well-being and reproductive health of current and future generations around the world and to help achieve a humane, equitable, and sustainable balance between people and resources. The Council conducts biomedical, social science, and public health research and helps build research capacities in developing countries. Established in 1952, the Council is governed by an international board of trustees. Its New York headquarters supports a global network of regional and country offices.

Copyright (C) 2008. The Population Council Inc.

Suggested citation: Oanh, Khuat Thi Hai, Kim Ashburn, Julie Pulerwitz, Jessica Ogden, and Laura Nyblade. 2008. "Improving hospital-based quality of care in Vietnam by reducing HIV-related stigma and discrimination," Horizons Final Report.

Washington, DC: Population Council.

This document may be reproduced in whole or in part without permission of the Population Council provided full source citation is given and the reproduction is not for commercial purposes. 


\section{Table of Contents}

Executive Summary 1

Introduction $\quad 5$

HIV/AIDS in Vietnam $\quad 5$

HIV-related stigma and discrimination $\quad 5$

$\begin{array}{ll}\text { Methods } & 9\end{array}$

Study design $\quad 9$

Study sites $\quad 9$

$\begin{array}{ll}\text { Ethical procedures } & 10\end{array}$

$\begin{array}{ll}\text { Quantitative data dollection } & 10\end{array}$

$\begin{array}{ll}\text { Qualitative data collection } & 11\end{array}$

$\begin{array}{ll}\text { Monitoring visits and observations } & 12\end{array}$

$\begin{array}{ll}\text { Measures } & 12\end{array}$

$\begin{array}{ll}\text { Data analysis } & 13\end{array}$

$\begin{array}{ll}\text { Intervention Design and Activities } & 15\end{array}$

$\begin{array}{ll}\text { Development of the intervention package } & 15\end{array}$

$\begin{array}{ll}\text { Intervention components } & 16\end{array}$

$\begin{array}{ll}\text { Results } & \mathbf{2 0}\end{array}$

$\begin{array}{ll}\text { Profile of hospital workers at baseline } & 20\end{array}$

Post-intervention changes in stigma and discrimination 25

Differential impacts of arm 1 and arm 2 interventions 35

Additional findings and insights $\quad 39$

$\begin{array}{ll}\text { Conclusions } & \mathbf{4 0}\end{array}$

$\begin{array}{ll}\text { Program implications } & 41\end{array}$

$\begin{array}{ll}\text { Policy implications } & 41\end{array}$

Research implications $\quad 42$

$\begin{array}{ll}\text { References } & 43\end{array}$ 



\section{Executive Summary}

To address HIV-related stigma and discrimination, and improve the quality of care in the healthcare setting in Vietnam, the Institute for Social and Development Studies (ISDS), the International Center for Research on Women (ICRW), and the Horizons Program conducted intervention research in four hospitals. The study team conceptualized two fundamental causes of HIV-related stigma: 1) fear of casual transmission; and, 2) negative values/social judgments and associations between HIV and certain behaviors and groups, such as sex workers and injecting drug users.

The intervention that was implemented in the four study hospitals included six key components: establishment of a hospital steering committee, staff training, hospital policy development, provision of material supplies to facilitate the practice of universal precautions, provision of educational materials, and monthly monitoring. However, the type and intensity of the training differed by study arm. Staff from one hospital in the north and one in the south (Arm 1) received a half-day training on basic HIV/AIDS information that included testimonials from HIV-positive individuals, and a full day on Universal Precautions. Staff from the other northern and southern hospitals (Arm 2) received the same training, but also participated in an extra half-day training on social stigma. Training sessions on HIV and stigma were co-facilitated by people living with HIV.

The study sought to determine the extent to which the Arm 1 intervention alone could reduce stigma and improve the quality of care for patients living with HIV in the intervention sites, and what added value the Arm 2 intervention contributed.

\section{Methods}

Two hospitals were selected in Quang Ninh and Hai Phong provinces in northern Vietnam and two hospitals in Can Tho province in the south. Baseline and endline survey data were collected among all hospital staff. The sample sizes at baseline and endline, respectively, in the northern sites were Arm 1, $\mathrm{n}=$ 218 and 205; Arm 2, $n=126$ and 128. In the southern sites the figures were Arm 1: $n=275$ and 277; Arm $2: \mathrm{n}=176$ and $187 .^{1}$

The study team also conducted 43 qualitative interviews both at baseline and endline among staff from the different study hospitals. In addition, regular structured observations of hospital practices and monthly monitoring visits were used to track changes.

\footnotetext{
${ }^{1}$ See appendices for the quantitative survey instrument for hospital workers; in-depth interview guides (4 different ones - one for patient and one for staff each at baseline and endline); observation checklists (one for hospital staff and one for hospital facility; safe and friendly hospital codes of practice (one for each hospital); and quantitative survey instrument for patients. The Safe and Friendly Health Facility manual is available on the web at www.popcouncil.org/pdfs/horizons/Vietnam_SafeFriendlyHealthFacility.pdf or www.isds.org.vn.
} 


\section{Hgrizons}

\section{Key Findings}

\section{At baseline, hospital workers reported high levels of both fear-based and value-based stigma.}

Results from survey data show high levels of fear of casual contact with HIV-positive individualscontact that would not lead to HIV infection. For example, almost half of hospital workers (48 percent) feared sharing utensils with HIV-positive individuals, and 37 percent feared touching the skin of a person who was infected with HIV. Hospital workers with high exposure to bodily fluids in their daily work reported the highest level of fear-based stigma.

Stigmatizing attitudes reflecting negative value judgments were also common. At least 40 percent of all hospital workers in each of the hospitals reported that HIV was a punishment for bad behavior, and nearly 40 percent reported that HIV-positive individuals should be ashamed of themselves. More than a third of hospital workers in each hospital also felt that they would feel ashamed if they were infected with HIV.

Qualitative interviews also demonstrate a substantial amount of stigma at baseline, as in this description of the protective measures used in attending patients with HIV versus other patients:

I use long gloves, coat, boots. My coat is quite long, which covers part of my thigh. I am provided with five coats by the hospital.... I put it on when I have contact with TB and HIV infected patients. I use short or normal coats (and short gloves) when I have contact with normal patients.

Orderly, Arm 2 hospital site

\section{Discriminatory behaviors and hospital practices were also common at baseline, and associated with fear-based stigma.}

At baseline, discriminatory practices were common, such as signs on the bed or outside patient files indicating a patient's HIV status, or the clothes of HIV-positive patients being burned when no longer being used by the patient. Further, approximately half (48 percent) of hospital workers reported that fear of HIV transmission and related stigmatizing attitudes led them to treat HIV-positive patients differently, such as by avoiding touching them, or by avoiding them altogether. Almost half (42 percent) of hospital workers reported using gloves, goggles, or a mask at all times while attending a patient with HIV, even during casual contact with patients. In each of the four hospitals, workers who reported high levels of fear-based stigma were more likely to report overusing barrier protections $(p<.001)$.

In qualitative interviews hospital workers often described situations in which patients with HIV were treated in a discriminatory way in an effort to "protect" themselves or other patients from becoming infected with HIV. The interviews also revealed that many hospital workers felt bad about their discriminatory practices.

\section{Lack of hospital policies fosters stigma and discrimination, which affects the quality of care.}

Quality patient care can be influenced by both national- and hospital-level policies, or the absence of such policies. Analysis of qualitative data showed how stigma and discrimination often occurred in the absence 
of specific hospital policies on, for example, HIV testing and providing care and treatment to patients with HIV, creating heightened uncertainty about HIV risk among hospital workers and, consequently, discriminatory patient care practices.

\section{Both interventions were successful in reducing both fear- and value-based stigma.}

Following the intervention, there were reductions in both fear and value-based stigma. For example, hospital workers in the Arm 2 hospitals reported significantly less fear about changing the clothes of a patient with HIV (from 30 percent to 23 percent in the north and 30 percent to 16 percent in the south; $\mathrm{p}<$ $.001)$. Hospital workers in the Arm 2 hospitals who felt that HIV/AIDS is a punishment for bad behavior declined, from 43 percent before the intervention to 26 percent at end line in the south $(\mathrm{p}<.001)$ and from 44 percent to 19 percent in the north $(\mathrm{p}<.001)$.

Four items that measured fear-based stigma and five items that measured value-based stigma were each summed to create a composite score (Fear: Cronbach's alpha $=.74$; Value: Cronbach's alpha $=.81$ ). Following the intervention, the mean score on both the fear- and value-based stigma indices had significantly decreased in all 4 hospitals $(\mathrm{p}<.05)$.

\section{Both interventions were successful in reducing various discriminatory behaviors and hospital practices.}

At endline, there was a significant reduction in reporting of discriminatory behaviors and practices by hospital workers. For example, in the Arm 1 hospitals, the percentage of hospital workers reporting labels indicating HIV status on files declined from 56 percent to 31 percent in the south $(\mathrm{p}<.001)$ and from 68 percent to 41 percent in the north $(\mathrm{p}<.001)$. Labels on files also decreased significantly in Arm 2 hospitals, declining from 46 percent to 12 percent $(\mathrm{p}<.000)$ in the north, and from 31 percent to 17 percent in the south $(\mathrm{p}<.002)$.

Significant decreases in the frequency of discriminatory behaviors reported by health workers about other health workers (i.e., "observed" discrimination) were found in the Arm 1 hospital in the south $(\mathrm{p}<.001)$ but not in the north. During the monitoring visits, various positive changes were observed (e.g., improvements in the use of Universal Precautions, increased voluntary HIV testing of patients and informing patients of their HIV status, and a reduction in the marking of files and beds).

\section{The impact of the Arm 2 intervention was greater than the Arm 1 intervention.}

In multivariate regression analyses at endline, controlling for age, education, and type of hospital facility, results from the combined intervention (Arm 2) showed more impact than Arm 1. Mean scores were significantly lower on both the fear-based stigma and value-based stigma indices $(\mathrm{p}<.001)$. Further, hospital workers in the combined intervention group were 4.7 times less likely to report marking HIV patient files $(\mathrm{p}<.001)$ and 2.3 times less likely to report placing signs on beds indicating HIV status $(\mathrm{p}<$ .001) than hospital workers in Arm 1. Hospital workers who participated in the Arm 2 intervention were also less likely to report overuse of gloves, masks, and goggles $(p<.008)$. Monitoring visits supported this finding as well. 


\section{Hgrizons}

\section{Key intervention elements included involving all cadres of staff in training and policy development, improving the structural environment, and involving HIV-positive individuals in staff training.}

Based on the monitoring visits, structured observations, and interviews with hospital and program staff, there were certain key elements that led to success. The study team found that including each hospital as a partner to review the baseline findings and design the intervention was crucial for building support. Furthermore, involving all categories of hospital staff (e.g., doctors, guards) in training and policy development helped create a stigma-free environment at all levels. Also, addressing the structural environment itself to bring about small improvements (e.g., adding more hand-washing stations) was an important component. Lastly, including people living with HIV as instructors during the education sessions was a key component of the intervention.

\section{Conclusions}

Both intervention strategies successfully reduced stigma and discrimination toward HIV-positive patients in these health care settings. The combined fear-based, plus social stigma reduction intervention (Arm 2) often was more effective than the intervention that primarily focused on fear alone (Arm 1). These findings show that addressing stigma and discrimination in the health care setting can contribute to improving the quality of health care for HIV-positive patients. Further, effective approaches to reduce stigma and discrimination in health care settings need to address the hospital environment and reach all hospital workers. 


\section{Introduction}

\section{HIV/AIDS in Vietnam}

Cases of HIV infection have been reported in all 64 provinces of Vietnam. According to the Ministry of Health, the number of people living with HIV dramatically increased from 120,000 in 2000 to 293,000 at the end of 2007 (Ministry of Health Viet Nam 2005). Vietnam is experiencing a concentrated epidemic with highest prevalence rates among injecting drug users (IDUs) (23 percent), men who have sex with men (9 percent), and sex workers (4.2 percent) (Socialist Republic of Viet Nam 2008). The epidemiological data, however, indicate an increase in HIV prevalence in all groups of the population (National Committee for AIDS, Drugs and Prostitution Prevention and Control (NCADP 2004). In 2007, the government estimated that 0.53 percent of the Vietnamese population had been infected with HIV (Socialist Republic of Viet Nam 2008). In some high-prevalence provinces like Quang Ninh and Hai Phong, the prevalence among the adult population crossed the threshold of one percent (Ministry of Health 2004).

The Vietnamese National Strategy on HIV/AIDS (2005 - 2010) includes a target of providing "appropriate" care for 90 percent of people living with HIV and antiretroviral (ARV) medications to 70 percent of HIV-positive people who require them. During the last few years, HIV voluntary counseling and testing (VCT) services have been made available throughout Vietnam, including at the district level. The number of individuals who take the test, however, is still limited, as are the number of people with HIV who access services. Stigma and discrimination toward people living with HIV has been recognized as an important barrier to HIV interventions, as noted in a speech by President Tran Duc Luong during his first visit to AIDS patients in Bach Mai hospital (JVnet 2004).

\section{HIV-related Stigma and Discrimination}

The definition of stigma that has often been applied to HIV/AIDS describes stigma as a "discrediting attribute" that an individual or group possesses and thus results in societal labeling as different or deviant (Goffman 1963). Discrimination (e.g., denial of services, employment, etc.) is often thought of as enacted stigma - behaviors that result from stigma at an institutional level. More recently, authors have advocated for the need to locate HIV-related stigma and discrimination within a broader social, cultural, political, and economic framework (Link and Phelan 2001; Horizons 2002). These writers describe stigma and discrimination as social processes that involve identifying and using differences between groups of people or individuals to create and legitimize social hierarchies and inequalities.

More than 20 years after the first AIDS case was diagnosed, stigma and discrimination against those with the illness, and often their close contacts, remain a pervasive problem. Various studies have established that AIDS-related stigma and discrimination are widespread and occur in contexts such as the family, community, workplace, and health care system (UNAIDS 2001). Studies have further elucidated that the health care sector is one of the main sites where HIV-positive individuals experience stigma and discrimination, often for the first time. It has also been documented that stigma inhibits individuals from learning their serostatus (Kalichman et al. 2005; Madan et al. 2006), accessing health services and adhering to medicines (Campbell et al. 2005; Liu et al. 2006; Mills 2006), and taking preventive measures (Kalichman et al. 2006). 


\section{Hgrizons}

In Vietnam, an ordinance prohibiting stigma and discrimination against people living with HIV was created in 1995 (Ordinance on HIV/AIDS Prevention and Control, National Assembly), yet people infected with HIV have frequently suffered from stigma and ill-treatment in the community in general, and in health settings in particular (Hong, Van Anh, and Ogden 2004). Recently, the government has responded more actively to address stigma and discrimination in speeches and in decrees. In late 2004, President Tran Duc Luong gave a speech calling for the elimination of stigma and discrimination. In April 2005, a decree was issued by the government that stipulates concrete punitive sanctions against institutional stigma and discrimination. Specific acts that are subject to sanctions include disclosing another person's HIV status involuntarily, denying treatment for any HIV-infected person, and recruiting employees or students on the basis of an HIV test or firing employees or students on the basis of their HIV-positive status (Decree 45/CP 2005). In 2006 the National Assembly passed a law, Law on HIV/AIDS Prevention and Control, that makes HIV-related stigma and discrimination an offense, and clearly promotes full human rights of people living with HIV (National Assembly of the Socialist Republic of Viet Nam 2006).

An in-depth study on stigma and discrimination in Vietnam conducted by Hong et al. (2004) identified two fundamental causes of stigma:

1. Fear of casual transmission stemming from incomplete and sometimes vague information that is delivered to people about the modes of transmission. This fear is pervasive in communities and within the healthcare system.

2. The close associations made in policy, the public imagination, and within the health care system between HIV, injecting drug use, and sex work. Known throughout Vietnam as "social evils," these behaviors are considered to be immoral within Vietnamese culture. The researchers found that in fact HIV is linked almost synonymously with these "social evils."

The study also identified the health care setting as an important site for the enactment and experience of HIV-related stigma and discrimination in Vietnam. Experiences of stigma in the health sector reported by study respondents, including those living with HIV and health workers, included the following:

- Women in labor were turned away from a public hospital once diagnosed with HIV. These same women, forced to seek care at private maternity clinics, would rarely disclose their newly discovered HIV status to the delivering doctor or midwife for fear of being sent away again.

- Some hospital workers used excessive preventive measures, making HIV-positive patients in their care feel ashamed.

- Many health care workers were aware of their own stigmatizing attitudes and actions toward HIVpositive patients, but confessed that fear of becoming infected often stood in the way of more equitable treatment.

- Many also admitted giving HIV-positive patients sub-standard care due to this fear, and the fear of exposing other patients to possible infection.

A survey of HIV/AIDS knowledge, attitudes, and practices among physicians in Quang Ninh province, Vietnam (Quach et al. 2005) echoes these findings. Three-quarters of physicians worried about becoming infected with HIV on the job, 40 percent felt uncomfortable touching HIV-positive patients during examination and treatment, and 35 percent agreed with the statement that healthcare workers should have the right to refuse to provide care for HIV-positive patients. Only a little over a third of those surveyed felt positively about providing care to people with HIV, and 68 percent were likely to exclude HIVpositive patients from their practices. While general knowledge of HIV transmission was high, the study noted the presence of several misconceptions about transmission (e.g., 12 percent thought HIV could be 
transmitted by sharing the toilet with an infected person), and showed that knowledge of HIV biology was low.

Similarly, studies in Nigeria (Adebajo et al. 2003), Mexico (National Institute of Public Health of Mexico 2004), Ethiopia (Banteyerga et al. 2004), and Tanzania (Mbwambo et al. 2004; Kohi and Horrocks 1994) reported high levels of fear of contagion among health care providers, which often appeared to be related to a lack of understanding of HIV transmission and the practice of universal precautions. For example, in a study with Tanzanian nurses (Kohi and Horrocks 1994), 54 percent incorrectly stated that HIV can be transmitted through contact with saliva, and 51 percent said casual contact with HIV-positive people puts others at risk of HIV. That this fear can translate directly into discriminatory behavior is illustrated by the fact that 22 percent of the nurses with these misconceptions indicated they would refuse to care for patients with HIV. In Nigeria, results of a study among nurses and laboratory technicians showed that 35 percent felt that HIV-positive people deserve it as punishment for their "sexual misbehaviors" (Adebajo et al. 2003). In Mexico, three-quarters of health providers surveyed thought people with HIV bore responsibility ("were guilty") for having HIV (INSP 2004).

Similar results were found in an intervention study conducted in three large hospitals in New Delhi, India (Mahendra et al. 2006). A key finding of the baseline research was that a range of institutional and individual factors, including misconceptions about HIV transmission and fear of infection among health workers, as well as a lack of hospital policies protecting people living with HIV and ensuring staff safety, contributed to stigma and discrimination in the study hospitals. Using the baseline data, the study team developed and tested the impact of an intervention package that put into place policies, training, and services to reduce stigma and discrimination, and make the hospitals "friendly to people living with HIV."

Following the intervention, hospital workers reported significant improvements in their attitudes and practices. Specifically, there was an increased understanding of HIV prevention and transmission, improved attitudes toward patients living with HIV in the hospital context, more appropriate HIV testing and counseling practices among doctors, greater understanding and correct practice of universal precautions and infection control, and increased respect for patient confidentiality.

Studies have also shown that stigma and discrimination can take many forms in health care settings. A study in Tanzania documented a wide range of discriminatory practices (enacted stigma) observed in health care settings, and categorized them broadly into neglect (e.g., making a client wait longer in hope of avoiding treating them), differential treatment (e.g., requiring HIV testing before providing care), denial of care/unnecessary referrals, testing and disclosing HIV status without consent, and verbal abuse/gossip (Tanzania Stigma-indicators Field Testing Group 2005). Similarly, a study in Ethiopia found that common forms of stigma and discrimination occurring in health care settings included marking or labeling patients as HIV positive on charts or in wards, gossip, verbal harassment, avoidance and isolation, and referrals for testing without counseling (Banteyerga et al. 2004).

These studies clearly indicate that in a great variety of health settings globally, there is an urgent need to address health workers' fear of contracting HIV in the workplace, as well as dealing with the social stigma that permeates client-provider interactions. In response, the Institute for Social Development Studies (ISDS), the International Center for Research on Women (ICRW), and the Horizons Program assessed the effectiveness of two interventions designed to reduce fear-based and value-based stigma and discrimination within the health care setting in Vietnam. The study took an ecological approach to 


\section{Hgrizons}

understanding and addressing stigma and discrimination by focusing on structural and environmental factors that influence stigma and discrimination in the settings observed. 


\section{Methods}

\section{Study Design}

The study used a quasi-experimental design to compare two interventions for reducing fear-based and value-based stigma in the health care setting. The underlying hypotheses were that:

- Increased knowledge of modes of HIV transmission, risks related to HIV transmission, and risk prevention; and improved knowledge and practices of universal precautions will reduce stigma and discrimination based on fear of HIV infection; and

- Increased awareness of the needs and rights of people living with HIV will reduce the stigma and discrimination associated with value judgments made against those infected with HIV, which are based in part on moral assumptions about marginalized populations such as injecting drug users and sex workers.

Two hospitals, one in the north and one in the south, were assigned to each intervention arm: Arm 1 included activities that primarily focused on reducing fear-based stigma and Arm 2 included the same activities carried out in Arm 1 but also included additional staff training that addressed value-based stigma. Sessions on HIV and stigma were co-facilitated by HIV-positive individuals.

The study team used quantitative and qualitative methods to assess attitudes and practices related to stigma and discrimination, and the key factors hypothesized to influence stigma in these settings.

Research methods included baseline and endline surveys with hospital staff, structured observations of hospital staff and environmental conditions in the hospitals, and in-depth interviews with hospital staff and administrators. ${ }^{2}$

\section{Study Sites}

Two government hospitals with a focus on treating TB patients were selected in northern Vietnam, one in Quang Ninh province and one in Hai Phong province. These provinces were selected because HIV prevalence there was estimated to be the highest and second highest in the country. The two hospitals selected were comparable in size, had similar patient populations, and the hospital administrators at these facilities expressed interest in the study. These TB hospitals serve a large clientele of patients with HIV, as well as prisoners and injecting drug users.

In the south, two hospitals of comparable size and patient population were selected within the province of Can Tho. Can Tho is one of the provinces with the highest HIV prevalence and incidence in southern Vietnam.

As part of the process to select the study hospitals in the north and the south, the project team consulted with HIV/AIDS authorities in both regions of the country.

\footnotetext{
${ }^{2}$ See the appendices for the quantitative survey instrument for hospital workers; in-depth interview guides (4 different ones-one for patient and one for staff each at baseline and endline); observation checklists (one for hospital staff and one for hospital facility; safe and friendly hospital codes of practice (one for each hospital); and quantitative survey instrument for patients. The Safe and Friendly Health Facility manual is available on the web at www.popcouncil.org/pdfs/horizons/Vietnam_SafeFriendlyHealthFacility.pdf or www.isds.org.vn.
} 


\section{Hgrizons}

\section{Ethical Procedures}

This study protocol received approval from the Population Council's Institutional Review Board and the Research Advisory Committee in Vietnam, a committee convened with representative membership from each of the study subgroups (patients with HIV and hospital workers, including hospital administrators). All study participants provided informed written consent before any data collection activities began. A referral system was also established to provide support and referrals to necessary services for unexpected events directly related to study participation that could not be addressed by study staff. No unexpected events were reported during the research project period.

\section{Quantitative Data Collection}

The sample sizes for the quantitative survey administered at each site to hospital workers at baseline and endline is presented in Table 1. Sampling of hospital workers was by census in each hospital and cross sectional at each data collection point in time. Staff with diverse roles and responsibilities within each hospital participated in the study: clinical, administrative, and support staff.

Hospital workers at each of the four hospital sites completed a self-administered, baseline questionnaire prior to the start of the intervention. Although participants read and completed the questionnaire on their own, project staff supervised the administration of the questionnaire so that participants could ask questions and seek clarification if needed. A self-administered questionnaire rather than a structured interview was used to ensure greater confidentiality and comfort for the participants. The questionnaire contained items to measure fear of HIV transmission, and attitudes and behaviors toward HIV-infected patients. Quantitative measures for stigma and discrimination were developed and adapted from measures used in previous Horizons and ICRW research projects, as well as from recommendations from the USAID-convened Interagency Stigma and Discrimination Indicators Working Group, of which both Horizons and ICRW are active members (Tanzania Stigma Indicators Field Testing Group 2005). Three variables were developed to measure attitudes specifically related to the construct of "social evils," referred to here as compounded stigma. Participants also provided information on knowledge of HIV transmission and prevention, knowledge and practice of universal precautions, and quality of care for patients.

Additionally, patients at each of the four study facilities were approached by hospital workers to complete questionnaires. ${ }^{1}$ As a result of a relatively small number of HIV-positive patients in the wards at the time of baseline and endline data collection, as well as refusal rates, the resulting sample sizes are small and the data from these questionnaires are not reported on in this report. 
Table 1 Quantitative survey sample sizes of hospital workers at baseline and endline by site and intervention arm

\begin{tabular}{lcccc}
\hline & \multicolumn{2}{c}{ Baseline } & \multicolumn{2}{c}{ Endline } \\
& Arm 1 & Arm 2 & Arm 1 & Arm 2 \\
\hline $\begin{array}{l}\text { Northern hospitals } \\
\text { \# of hospital workers } \\
\begin{array}{c}\text { Southern hospitals } \\
\text { \# of hospital workers }\end{array}\end{array}$ & 218 & 126 & 205 & 128 \\
\hline
\end{tabular}

\section{Qualitative Data Collection}

Qualitative interviews were conducted with hospital workers before and after the intervention (see Table 2). Field guides were developed based on the key goals of the intervention: reduction of fear-based stigma, reduction of value-based stigma, improved knowledge and practice of Universal Precautions, development and implementation of policies and codes of conduct, and improved quality of care for patients with HIV. Interviews were tape-recorded and transcribed verbatim, all in Vietnamese with a selection translated into English as well. ISDS analyzed all transcripts, and ICRW further analyzed the selection of transcripts in English.

There were also attempts to conduct qualitative interviews with patients; however, the data collected were limited, and the results are not included in this report.

Table 2 Qualitative data collection and observations at baseline and endline by study site and intervention arm

\begin{tabular}{lcccc}
\hline Method & \multicolumn{2}{c}{ Baseline } & \multicolumn{2}{c}{ Endline } \\
& Arm 1 & Arm 2 & Arm 1 & Arm 2 \\
\hline $\begin{array}{l}\text { Northern hospitals } \\
\text { In-depth interviews with } \\
\text { hospital workers } \\
\begin{array}{l}\text { Observations with } \\
\text { monitoring checklist }\end{array}\end{array}$ & 10 & 11 & 10 & 11 \\
$\begin{array}{l}\text { Southern hospitals } \\
\text { In-depth interviews with } \\
\text { hospital workers } \\
\begin{array}{l}\text { Observations with } \\
\text { monitoring checklist }\end{array}\end{array}$ & 7 & 7 & 7 & 7 \\
\hline
\end{tabular}




\section{Hgrizons}

\section{Monitoring Visits and Observations}

Study staff conducted monthly monitoring visits throughout the implementation of the project. During each monitoring visit, hospital administrators received feedback from the study staff and had the opportunity to discuss challenges or particular issues and concerns that had arisen during the previous period. An observation checklist was also completed, and a series of process indicators was used to monitor implementation of activities, which included indicators for measuring three main areas: practice, quality assurance, and policy. ${ }^{1}$

More in-depth structured observations using a checklist were conducted in each facility at baseline and endline (see Table 2). They were used to assess practices at each hospital with a focus on universal precautions, waste management, confidentiality of HIV-positive patients, and hospital workers' interactions and communication with patients. Photography was also used to capture evidence of change in key areas of hospital practices and conditions of facility infrastructure addressed by the objectives of the study.

\section{Measures}

Measures were developed to assess key dimensions of stigma: fear of casual transmission, and negative value judgments due to associations with certain behaviors and marginalized groups, including sex workers and injecting drug users. Discrimination (or enacted stigma) - such as the refusal to treat patients with HIV—was also measured.

\section{Fear-based stigma}

An additive index was developed to measure fear-based stigma using four items. These items were statements about conducting certain low HIV risk patient care procedures without gloves (e.g., taking blood pressure), and they had sufficient internal consistency (alpha $=.74)$. Each item had four possible responses $(0=$ no fear; $1=$ a little fear; $2=$ some fear; $3=$ a lot of fear $)$, which were dichotomized into two response categories $(0=$ no fear and $1=$ some fear $)$. The responses were summed to obtain a fearbased stigma score for each respondent.

\section{Value-based stigma}

Factor analysis was used to create a scale to measure dimensions of value-based stigma. Value-based stigma was conceptualized as having three main dimensions: 1) feelings of shame associated with having HIV; 2) feelings of blame toward people infected with HIV; and, 3) attitudes about the rights of HIVpositive people. Items were selected for each corresponding domain, and a total of eight items were factor analyzed using principal components analysis with promax rotation. One main factor-with 5 itemsemerged $($ alpha $=.81)$. 


\section{Compounded stigma}

A third measure was created to specifically measure the concept of compounded stigma, in which certain marginalized groups experience stigma in response to HIV and their group identity (e.g., injecting drug users). This is a very relevant construct in Vietnamese culture, as certain groups are associated with "social evils." Three "social evil" variables were created to measure this, in the form of statements: 1) It is the women prostitutes that spread HIV; 2) It is the drug users that spread HIV; and, 3) It is promiscuous men that spread HIV in our community. These items were considered to be reliable and have sufficient internal consistency $($ alpha $=.79)$. Items were summed to provide a composite score ranging from 0 to 3 for compounded stigma.

\section{Discrimination or enacted stigma}

A variable was created to measure hospital workers' observations of at least one out of three scenarios involving discriminatory behaviors of hospital staff toward patients. Statements used to describe these provider-patient interactions included: 1) A health provider avoids treating a patient and instead passes the patient to another provider because the patient is HIV-positive; 2) A health provider discloses a patient's HIV status to the patient's family without the patient's consent; and, 3) Health providers gossip about a patient's HIV status. Measures were also created to capture whether fear of contracting HIV at work changed hospital workers' behaviors with patients, and specifically what those changes were (e.g., overuse of barrier protections, such as gloves, or avoidance of patients). Finally, measures were created about discriminatory hospital practices, including marking patient files with their HIV status, putting signs on beds indicating patients' HIV status, or locating patients in specific beds to indicate their HIV status.

\section{In-depth knowledge}

A total of nine items were combined to create an additive index of in-depth knowledge. The nine items measured knowledge of which bodily fluids have a high enough concentration of HIV to transmit the virus. Response categories were dichotomized $(0=$ incorrect; $1=$ correct $)$. Each respondent was given a score ranging from 0 to 9 with one point given for each correct response.

\section{Data Analysis}

Survey and in-depth interview data from both hospital workers and patients, and findings from the structured observations and monitoring visits, were triangulated in the analyses.

We examined changes from baseline to endline in the main outcome measures of stigma and discrimination among hospital workers by intervention arm using chi-square tests for categorical variables and t-tests for continuous variables.

Multivariate analyses using ordinary least squares linear regression for continuous outcome variables and logistic regression for binary outcome variables were used to examine the impact of the Arm 1 intervention versus the Arm 2 intervention while controlling for hospital facility type (two hospitals were 


\section{Hgrizons}

specialized disease facilities and two hospitals were district hospitals), and sociodemographic characteristics of respondents including education level and age, at endline.

A total of 795 surveys at baseline and 797 surveys at endline were included in the analysis for a total sample of 1,592. Six hundred seventy-seven of these surveys came from study sites in the north and 915 came from study sites in the south. Eighty-two surveys were omitted from the endline sample, because respondents did not attend or did not remember attending any of the intervention training sessions $(\mathrm{n}=$ 35 ) or because they were new staff members and joined the hospital after the initial training course ( $\mathrm{n}=$ 47).

Qualitative in-depth interviews were analyzed using an analytical framework to guide the identification of major themes and salient concerns in the data. A total of 86 transcripts were included in the analysis.

As part of the analysis, quantitative and qualitative data from health workers, as well as data from the observations and monitoring visits, were triangulated to provide a clearer picture of the outcomes of the interventions. 


\section{Intervention Design and Activities}

\section{Development of the Intervention Package}

To design the intervention activities, ISDS and the study team drew upon strategies and tools developed and implemented by Horizons and partners in hospitals in India (Mahendra et al. 2006). They also used the resource, "Understanding and Challenging HIV Stigma: A Toolkit for Action" (Kidd et al. 2007), which was developed by ICRW and partners. ISDS developed and adapted the intervention activities for the Vietnamese setting, in collaboration with study hospital staff, an ICRW training consultant with expertise in stigma reduction, and an infectious diseases specialist. The resulting "Safe and Friendly Health Facility" manual was developed in Vietnamese and English to document the training curriculum for health workers and the stigma reduction activities implemented in the study hospitals. ${ }^{3}$

After baseline data collection was completed and some preliminary data analysis had been done, the study team convened a workshop that included representatives from the hospitals. The baseline preliminary findings were presented and discussed, and in response, workshop participants established a set of objectives for the intervention:

- Create a safe and friendly hospital environment, one in which hospital workers feel safe from transmission and abuse from patients, and patients feel they are appropriately treated.

- Build more respect, care, and support for people living with HIV.

- Develop the practical skills to implement universal precautions in a systematic way.

- Develop a code of practice for each hospital for implementing stigma-free practices and universal precautions.

Using participatory methods, the study team also identified six major intervention components: establishment of hospital steering committees, staff training, hospital policy development, provision of material supplies to facilitate the practice of universal precautions, educational materials, and monthly monitoring. These are discussed more in-depth in the next section.

Both study arms included all six components. However, the type and intensity of the training differed. Hospital staff in both arms received a half-day training on basic HIV/AIDS information that included testimonials from HIV-positive individuals about their experiences, and a full day on Universal Precautions. Hospital staff in Arm 2 received the same training but participated in an extra half-day training on social stigma co-facilitated by HIV-positive individuals (see Box 1).

\footnotetext{
${ }^{3}$ The manual is available on the web only at www.popcouncil.org/pdfs/horizons/Vietnam_SafeFriendlyHealthFacility.pdf or www.isds.org.vn.
} 


\section{Hgrizons}

\section{Intervention Components}

\section{Hospital steering committee}

After the initial workshop, each hospital appointed three to four members of the management team to be on the steering committee. Membership of the steering committee included hospital directors and/or vice directors, and chief nurses and/or heads of the infection control departments. The head of the Planning Department was also a member of the steering committee in one of the study sites.

The steering committee proved to be a key mechanism for feedback between the hospital staff and the project team. The steering committee members played a central role in designing the intervention activities and acted as liaisons between hospital staff and the project team during project implementation. They were involved in the process of developing and implementing the intervention, so they thoroughly understood the project concept. At the same time, their positions as respected leaders of the hospitals enabled positive changes at institutional and individual levels to occur.

\section{Staff training}

Training was provided for all staff including doctors, nurses, and administrative and support staff. Partners in the kick-off workshop agreed that hospital workers at all levels have fears about HIV and may stigmatize patients living with HIV, consciously or subconsciously. During training it was emphasized that each staff member has a role to play in creating a safe and friendly environment. Therefore, the training was provided for all staff. Involving all staff also helped to build the synergy that created a hospital environment supportive of change.

The training was implemented without disruption of normal hospital services and activities; staff were divided into different training groups to ensure the continuity of services. Participants were grouped by their roles and positions within the hospital into three main categories:

- Doctors and nurses

- Auxiliary nurses (ward staff)

- Administration and support staff

\section{Box 1 Staff training by study arm}

\section{Arm 1}

Section A: HIV and AIDS Basic Knowledge

Duration: Half day

Modules:

- Personal experience with HIVIAIDS

- Who is infected?

- Basic knowledge of HIVIAIDS

- Testimonials from people living with HIV

Section B: Universal Precautions

Duration: One day

Modules:

- Overview of hospital infection and risk for occupational exposure

- Principles of Universal Precautions

- Hand washing

- Protective barriers

- Injecting safely

- Equipment processing

- Linen processing

- Hospital hygiene

- Waste management

- Handling occupational exposure

\section{Arm 2}

Sections A and B from above, plus: Section C: HIV Stigma and Discrimination Duration: Half day Modules:

- Naming stigma through pictures

- What is the meaning of stigma

- Naming stigma in the hospital-Forms and causes

- How it feels to be stigmatizedTestimonials 
Each training group ranged in size from 25 to 45 people, depending on the number of staff, and from six to ten training groups were organized in each facility. The training workshops, particularly for those in Arm 2, aimed to:

- Review and update knowledge on HIV/AIDS, especially HIV transmission.

- Address fears and misconceptions about becoming infected with HIV through casual contact, and what it means to live with HIV.

- Update and expand knowledge about antiretroviral therapy, prevention of mother-to-child transmission, post-exposure prophylaxis, etc.

- Develop practical skills to adopt Universal Precautions, e.g., hand washing.

- Develop a deeper understanding of HIV stigma - its forms, effects, and causes.

- Instill a greater understanding of HIV-related issues, how stigma affects people living with HIV, and a commitment to ending stigma.

Five trainers, each with expertise in HIV, Universal Precautions, or stigma and discrimination, and familiarity with participatory methods, facilitated the training of hospital workers in both arms. In the southern hospitals they were joined by two additional trainers from a local AIDS Center. Four people living with HIV were also trained to be co-facilitators. Contributions of the co-facilitators significantly enhanced the training in both intervention arms not only through sharing personal stories and experiences, but simply through their presence and by allowing participants the opportunity to interact with people living with HIV outside of the patient/provider relationship.

\section{Hospital policy development}

At the end of the training, each group of participants in each hospital developed their own draft of a safe and friendly hospital policy that reflected what they had discussed during the training and be in line with the newly released AIDS law. ${ }^{4}$ Overall, six components emerged from this exercise:

1. Access to services by people living with HIV

2. HIV counseling and testing

3. Confidentiality

4. Universal Precautions

5. Training on HIV/AIDS

6. Dissemination of HIV/AIDS-related policy

After each training group had developed their own draft, each hospital convened a plenary meeting with all staff to present and discuss the policy drafts. Each hospital's steering committee then incorporated all comments and integrated all drafts into one final Safe and Friendly Hospital Policy for each hospital. A monitoring checklist was provided to every Steering Committee for the purpose of self-monitoring.

\footnotetext{
${ }^{4}$ The Safe and Friendly Hospital Policy documents developed in each of the hospitals are included in the appendices.
} 


\section{Hgrizons}

\section{Material supplies for practicing universal precautions}

Observations at baseline and discussion during the training revealed that hand washing was not practiced nearly as often as it should be. Apart from the lack of hand washing practiced in the hospitals, access to running water for hand washing was an issue in all four hospitals. In one hospital, there was no running water for most of the working hours. While water was available in the other hospitals, water taps were not easily accessible in patient wards and had old twist tap fittings that required use of hands to operate rather than the preferable (from the perspective of infection control) fittings that can be used with an elbow. At the recommendation of the Universal Precautions consultant, dispensers for an alcohol-based solution, which can be used to disinfect hospital workers' hands without soap and water, were supplied to hospitals to facilitate hand washing practices. The dispensers can be refilled with an inexpensive, home-made, alcohol-based solution using a simple formula. The solution was introduced during the training and hospital workers found it a practical and realistic solution. Taps and water containers were requested by the hospital that did not have running water at the start of the project. These were provided to the hospital by the project.

At baseline, sharps containers were not available in any of the study's four hospitals, forcing hospital workers to use water or soda bottles for disposal of needles. Sharps containers were introduced during the Universal Precautions training and were well received by hospital workers. Locally made, reusable sharps containers were supplied to hospitals, to support changes in sharp disposal practices. The containers are long-lasting and inexpensive to replace when damaged or worn.

Other supplies were provided based on the different needs of the hospitals, which included chairs for patients to be able to gather to socialize. These chairs were provided with the aim of fostering solidarity among patients with HIV and those who are HIV-negative. Trash bins were provided to keep hospitals clean, and cleaning trolleys were made available to support cleaners in their work.

\section{Educational materials}

The project produced posters on hand washing to be strategically displayed in all locations where hospital workers wash their hands. The Safe and Friendly Hospital Worker in the Presence of HIV/AIDS manuals were printed and distributed to all hospital workers. The manual introduces the concept of "safe and friendly" hospital workers and hospitals, points out unsafe and unfriendly practices, provides basic information on HIV and Universal Precautions, and the 2006 AIDS law. The project also helped the hospitals print their Safe and Friendly Hospital Policy in poster-size to display in all department and waiting areas, reminding hospital workers and patients about their rights and obligations.

\section{Monthly monitoring}

Monthly monitoring visits were made jointly by the Universal Precautions consultant, project team, and hospital's steering committee. A monitoring checklist was used to assess practices, mechanisms for quality assurance, and policy for four domains: admission and care and treatment of HIV-positive patients, HIV testing and counseling, confidentiality, and Universal Precautions. A score was given to each hospital during each monitoring trip. The project team provided feedback to the steering committee during each monitoring trip and discussed strategies for improvement. Monitoring activities were 
considered to be an essential component of the intervention to ensure the transfer of knowledge and skills acquired during the training into everyday practice. 


\section{Hgrizons}

\section{Results}

\section{Profile of Hospital Workers at Baseline}

Hospital workers ranged in age from 20 to 59 years, with an overall median of 40 years. Approximately 70 percent of hospital workers surveyed were women. Hospital workers tended to be employed in the same facility for long periods of time, up to 36 years for some, but averaging significantly longer in the north as compared to the south (14 vs. 11 years; $\mathrm{p}<.001)$.

Levels of education did not differ by type of facility. Half of all hospital workers surveyed had post-high school education, 23 percent had university or post-graduate education, and 10 percent had not yet completed high school. The majority of staff in all hospitals were nurses, which accounted for 31 percent of all hospital workers surveyed, followed by administrative staff (14 percent), auxiliary and ward staff (13 percent), physicians (12 percent), managers (11 percent), technicians and lab staff ( 6 percent), pharmacists ( 5 percent), and other staff ( 8 percent), including guards, cooks, and drivers, among others. Hospitals in the south had significantly more physicians, clinical nurses, and lab technicians than hospitals in the north $(\mathrm{p}<.001)$.

Based on staff positions and the nature of the responsibilities that corresponded to these positions, hospital workers were classified into three categories of exposure to bodily fluids: high, medium, and low. The majority of hospital workers, about 50 percent overall, were classified as having high exposure to bodily fluids in their daily work. This group included auxiliary ward staff, clinical nurses, and lab technicians. Physicians and physician managers were classified as medium level exposure, which made up about 20 percent of the sample. A third of all workers were classified as having low exposure, including pharmacists, administrative and management nurses, administrative staff, and other staff.

\section{In-depth HIV transmission knowledge}

Nearly all hospital workers surveyed were aware that HIV can be transmitted through semen, blood, and vaginal fluid; however, only approximately half of all hospital workers knew HIV could also be transmitted through breast milk. A relatively high proportion of hospital workers in all sites incorrectly believed HIV transmission was possible through saliva, sweat, and urine. Approximately 21 percent of hospital workers in the north and slightly more, 27 percent, in the south incorrectly identified urine; 20 percent and 23 percent, respectively, identified saliva; and, 15 percent of hospital workers in the north as compared to 9 percent in the south identified sweat as fluids with a high enough concentration of HIV to transmit the virus. These differences were not statistically significant across regions.

\section{Stigma and discrimination in the hospital setting}

\section{Fear-based stigma}

Results of survey data show nearly half of all hospital workers surveyed across all hospitals expressed fear of sharing eating utensils with patients who have HIV. In the north, more than half of all workers reported some fear in changing the clothes of patients with HIV, as compared to 30 percent of hospital 
workers in the south. More than half of all workers in the north were also afraid to touch the skin of a person with HIV, versus 21 percent of hospital workers in the south. Hospital workers with high exposure to bodily fluids in their daily work also scored among the highest on the fear-based stigma scale. Half of all workers with the highest scores on fear-based stigma were also among high exposure category workers, primarily auxiliary ward staff and clinical nurses.

Looking at the combined items in the composite scores on fear-based stigma at baseline, study sites in the south had statistically significantly lower mean scores on the fear-based stigma measure than hospitals in the north $(1.15$ vs. $1.85 ; \mathrm{p}<.001)$.

This fear was described indirectly in qualitative interviews and manifested in the over-use of protective measures by nurses - which in itself can be stigmatizing if it is very obvious to the person being treated as well as to other patients. For example, in one hospital an orderly was asked whether she experienced any difficulties looking after HIV-positive patients in her care.

Yes, I have some and I also tell doctors about that... It is our protective measures... That means the long gloves. They are quite expensive. I request the hospital to provide me with sufficient long gloves... I also have boots, long gloves, hats... [which] I wear when I contact every patient, but I put on long gloves when I take care of HIV-infected patients. I even sometimes put on both normal and long gloves. I only put on normal gloves when I take care of normal patients...

\section{Compounded stigma}

The vast majority of all hospital workers agreed with all three statements developed to quantitatively measure compounded stigma. Over 90 percent of all hospital workers across all hospitals agreed with the statement, "It is promiscuous men spreading HIV in our community." Nearly 90 percent of hospital workers in all hospitals agreed with the statements, "It is women prostitutes who spread HIV" and "Drug users spread HIV." Average mean scores on the compounded stigma index measure were significantly higher in the north $(2.80$ vs. $2.69 ; \mathrm{p}<.020)$ at baseline.

This relationship also emerged in the qualitative data. For example, a surgeon explained that he tended to worry because not all his patients were tested for HIV. He said he uses a simple formula to decide when to be "more careful."

We see some tattoos on their body or if they are too thin. Or for those women we suspect to be sex workers when looking at their dressing...

However, he also said this system could let him down. Once he operated on a woman and she failed to heal properly, at which time she was tested for HIV and found to be positive.

She was a tailor, so we didn't suspect... we just feel suspicious when we receive those who have tattoos, or we suspect some just on the basis of our intuition and then we are more careful.

These results likely reflect not only the cultural concept of "social evils" but also the HIV epidemic in Vietnam, where HIV was initially transmitted among IDUs and sex workers but has recently started to spread to the general population. 


\section{Hgrizons}

Value-based stigma

Among all of the hospital workers surveyed, 34 percent said they would feel ashamed if they were infected with HIV, and 46 percent would feel ashamed if someone in their family had HIV. Another 45 percent felt that HIV was a punishment for bad behavior, and 44 percent said people with HIV should feel ashamed of themselves.

In combined composite measures of these items, mean scores on the value-based stigma measures among all hospital workers across all hospitals were relatively high. Mean scores were significantly higher among hospital workers in the north, at 8.70, as compared to hospital workers in the south, at 8.06 ( $\mathrm{p}<$ $.005)$. Between each intervention arm, scores were also significantly different, with higher scores for fearbased stigma in the north $(\mathrm{p}<.001)$ and the south $(\mathrm{p}<.045)$, respectively.

Despite these high levels of reported fear- and value-based stigma, hospital workers also uniformly expressed a great deal of compassion for patients with HIV. As one orderly explained:

They [HIV-positive patients] are treated in the same way [as everyone else]; there is no discrimination... It is partly the hospital regulations, it partly comes from our sincere desire to provide comfortable care for them.

Among hospital workers surveyed, at least 84 percent of all workers in all hospitals agreed that people with HIV deserve sympathy and at least 92 percent agreed they should be treated the same as anyone else.

\section{Discrimination or enacted stigma}

Patient-provider interactions: Nearly 20 percent of hospital workers in the Arm 1 hospital in the south, 25 percent in the Arm 2 hospital in the north, and nearly 15 percent in the Arm 1 hospital in the north reported observing a health provider disclosing a patient's status to their family without the patient's consent, by far the most frequently observed of the three types of discrimination measured. In the Arm 1 hospital in the south, workers more frequently observed health providers gossiping about a patient's HIV status, as reported by 13 percent of all staff. More than 10 percent of hospital workers in each of the hospitals in the north observed health providers gossiping about a patient's HIV status.

The importance of gossip as a form of stigma emerges clearly from the qualitative data as well. For example, a senior nurse in one hospital made the following observation:

Other nurses talk in whispers, e.g,, you are in this Department, I am in other one. Of course we talk in whispers; we dare not to inform members of patients' families.

Awareness of HIV testing policy: At baseline, none of the four hospitals in the study had concrete policies or guidelines for testing patients for HIV. Correct awareness of this lack of a policy was only indicated by 12 percent of hospital workers surveyed across all hospitals, at baseline.

Hospital-wide practices: Observations revealed that signs on beds and marked files indicating a patient's HIV status were prevalent in varying degrees across all hospitals. At baseline, the percentage of hospital workers reporting signs on beds indicating a patient's HIV status ranged from a high of 46 percent to a 
low of 12 percent in the north, and from 38 percent to 19 percent in the south. Marked files also varied from 46 percent to 56 percent in the north, and 31 percent to 68 percent in the south.

Fears affecting interactions: At baseline, approximately half of all hospital workers surveyed reported having fears about HIV that affected their interactions with HIV-positive patients.

Use of barrier protections: There was extensive evidence in both the quantitative and qualitative data of the inappropriate use of barrier protections such as gloves, masks, and goggles at baseline. Of those who reported having fears that affected their interactions with patients, 42 percent reported overuse of barrier protections (use of gloves, mask, or goggles at all times while attending patients with HIV). Overuse of any barrier protection had a significant positive association with higher levels of fear-based stigma in all hospitals, but was only significantly associated with higher mean scores on the value-based stigma measure in the Arm 1 hospital in the north $(\mathrm{p}<.044)$. Although fear of casual transmission seemed relatively high, very few hospital workers, about 4 percent, reported trying to completely avoid HIVpositive patients. Furthermore, overuse of barrier protections was most often reported by those with high exposure to bodily fluids - auxiliary nurses, ward staff, and clinical nurses. The greatest proportion of those overusing barrier protections, about 35 percent, was among clinical nurses.

In qualitative interviews, staff described how they use double gloves for washing linens and clothes, while handing non-injected medications to patients, when changing a patient's clothes, or during other patient care procedures not requiring the use of gloves. These precautions were mainly due to fear of contagion.

When asked about extra care taken with the use of barrier protection when washing clothes of HIVpositive patients, a nurse explained,

Nurse: We will wear one thick pair of gloves as normal and one thin pair for sure because the javel [disinfectant] water will easily tear them out.

Interviewer: What about other types of clothing?

Nurse: When we wash other types of clothes we wear only one pair of gloves. The hospital wants to save and we do not have many gloves here so we only wear two pairs of gloves when we wash clothes of HIV patients.

During the observations conducted pre-intervention, researchers noticed an almost universal inappropriate use of gloves in hospitals. Hospital workers often wore the same pair of gloves throughout the work day, only removing them to eat lunch. Hospital workers attended one patient after another without changing gloves or washing hands in between patients, increasing the potential risk of spreading infections from patient to patient and among hospital workers.

Handling of linens: Another key area of discrimination not captured in the survey but that emerged in the qualitative interviews was the separation of hospital clothing and linens used by HIV-positive patients. These procedures were largely based on fear of becoming infected with HIV but manifested themselves in discriminatory identification and separation of patients with HIV. In three hospitals, specially marked clothing was used for patients with HIV or bags of a particular color were used to collect their clothes. Hospital workers described procedures for laundering clothing and linens used by patients with HIV, which was often separately treated with detergents or chemicals before washing. In one hospital, clothing was not marked and was not different in any way from hospital clothing of other patients, but when the patients left the hospital the used clothes and linens were incinerated. According to a physician in this 


\section{Hgrizons}

particular hospital, "HIV infected [sic] stuff is burnt after being used. Other patients don't reuse their stuff." An orderly from the same hospital provided more detail about how decisions are made on what items to burn depending on the level of illness of a patient:

If HIV-infected patients are at stage one their stuff is sterilized...if they are at stage two and we are aware of their infection through HIV tests, their stuff is incinerated...It is both the hospital regulation and what we think should be done.

Later in the same interview the orderly contradicted his previous explanation:

Orderly: ...no [it does not] matter what stage they are at. All of their stuff is incinerated.

Interviewer: Is their mat also incinerated?

Orderly: Yes even if it is a new mat...it is still incinerated although it is new.

An interesting point in this series of interviews is that during the course of a third interview with an administrator from this same hospital, the administrator denied that any clothing or linens were burned. This suggests that hospital workers at various levels of experience understand hospital policy and hospital practice in different ways.

Linens and clothing from HIV-positive patients were almost always gathered in separate bags or in bags of a different color than bags used with other patients in order to alert laundry staff to the linens and clothing of HIV-positive patients. In some cases, linens and clothing were gathered simultaneously along with clothing and linens of other patients. Hospital workers often said they took extra care not to show the patients that they were treating them any differently than other patients. As one orderly explained:

...we wrap their stuff in a yellow bag separately without letting them know. We should be handling it delicately so as not to let them feel inferiority complex. We mark the yellow bag 'infected' with a pen so that the laundry will know. So yellow is a signal.

When asked how patients felt about having their laundry put in yellow bags while other patients had blue bags, a nurse in the same hospital said, "Most of them do not care and do not know. What we do can't usually be recognized."

Other staff expressed some concern for patients being aware of differential treatment but seemed satisfied that if patients were unquestioning, they were not aware of the distinct treatment.

The separation of linens was justified as "protection" of other staff as well as other patients from HIV, even if this is the manner in which a patient becomes informed of his or her status, as may be the case according to this deputy director:

Frankly speaking...it [separation of linens] is only difficult when the patients are not prepared to know or do not know their status. Those who know their infection will not question. They know this practice is to protect other patients.

Separation of linens was also described as a practical measure to quell the concerns of patients more so than protection for staff, as suggested by a nurse:

Nurse: ...when we issued the clothes to the patients...they said that they were afraid 
of the HIV patients wearing the same clothes as them. So we told them not to worry, the clothes from Ward D have signs so that they can be distinguished.... We had to explain it like that so that they'd make less fuss.

Interviewer: But HIV isn't transmitted through clothing?

Nurse: But people were still worried.

\section{Post-intervention Changes in Stigma and Discrimination}

\section{Changes in fear-based stigma in Arm 1 hospitals}

Results show significant declines among hospital workers in the Arm 1 intervention hospital in the north who reported fear of performing certain patient care procedures with HIV-positive patients without gloves (see Figure 1). For example, hospital workers in the north reporting fear of touching the skin of a person with HIV declined from 57 percent at baseline to 13 percent at endline, and fear of serving food to a patient with HIV also dropped from 26 percent at baseline to 9 percent at endline. These changes were significant $(\mathrm{p}<.001)$. Significant changes were noted in all fear-based stigma items in the north but not in the south.

Figure 1 Percent of hospital workers in Arm 1 hospitals reporting some fear in certain patient care procedures

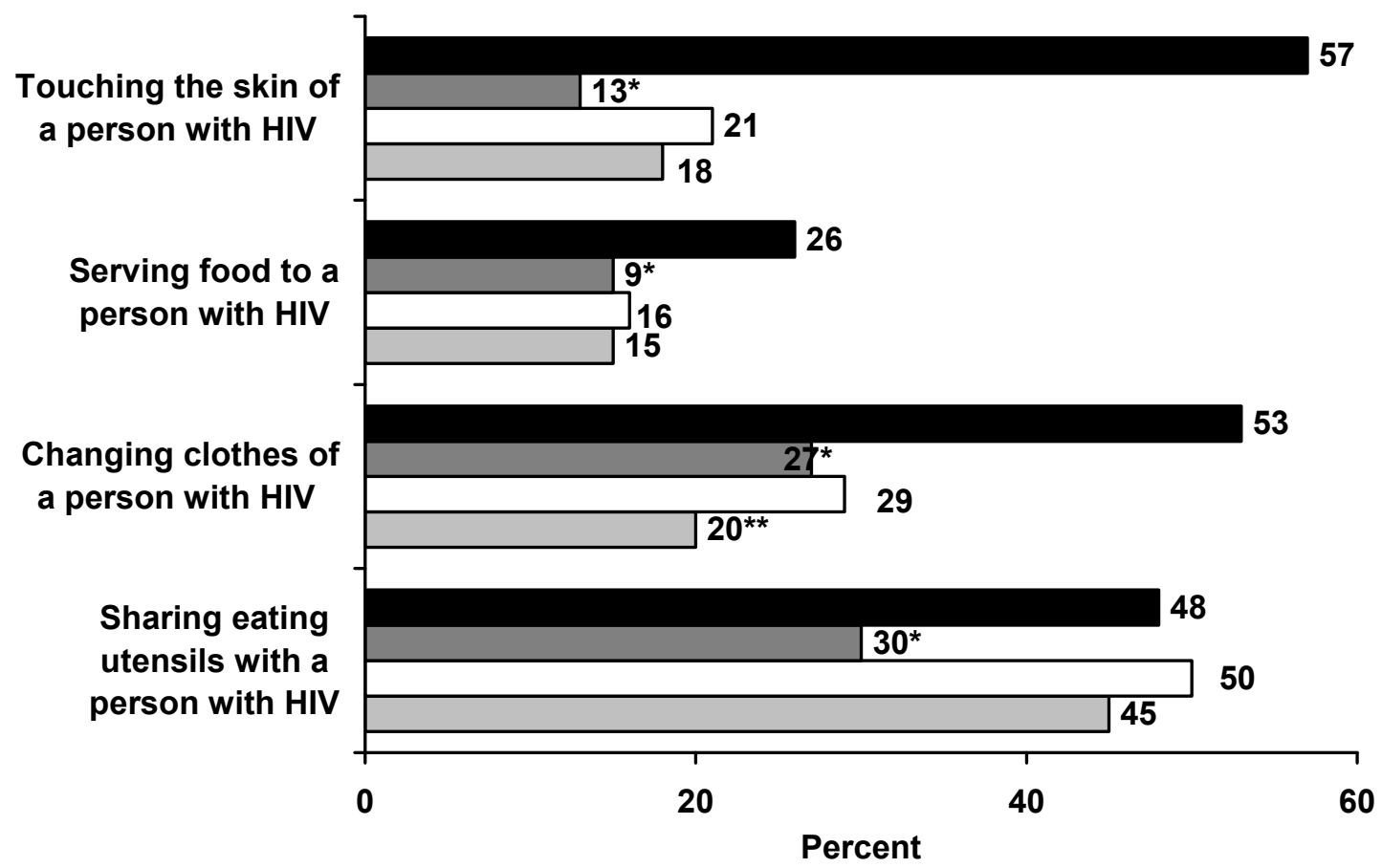

$\square$ Endline, south $\square$ Baseline, south $\quad \square$ Endline, north $\quad$ Baseline, north

${ }^{*} p<.001 ;{ }^{* *} p<.01$ 


\section{Hgrizons}

Means of composite scores of fear-based stigma also declined significantly in the north, from 1.84 to 0.81 $(\mathrm{p}<.001)$. Although the mean score on fear-based stigma also decreased in the south, from a mean score of 1.16 to 1.01 , this was not a statistically significant change.

\section{Changes in fear-based stigma in Arm 2 hospitals}

In the Arm 2 hospitals there were also significant decreases in reported fear while performing specific procedures without gloves with HIV-positive patients (see Figure 2). Hospital workers reported significantly less fear of sharing eating utensils with a person with HIV, which decreased from 45 percent at baseline to 13 percent at endline in the north, and from 49 percent to 31 percent in the south. The number of hospital workers who said they feared changing the clothes of a patient with HIV went down from 30 percent to 23 percent in the north, and from 30 percent to 16 percent in south. These are statistically significant changes $(\mathrm{p}<.001)$.

\section{Figure 2 Percent of hospital workers in Arm 2 reporting some fear in certain patient care procedures}

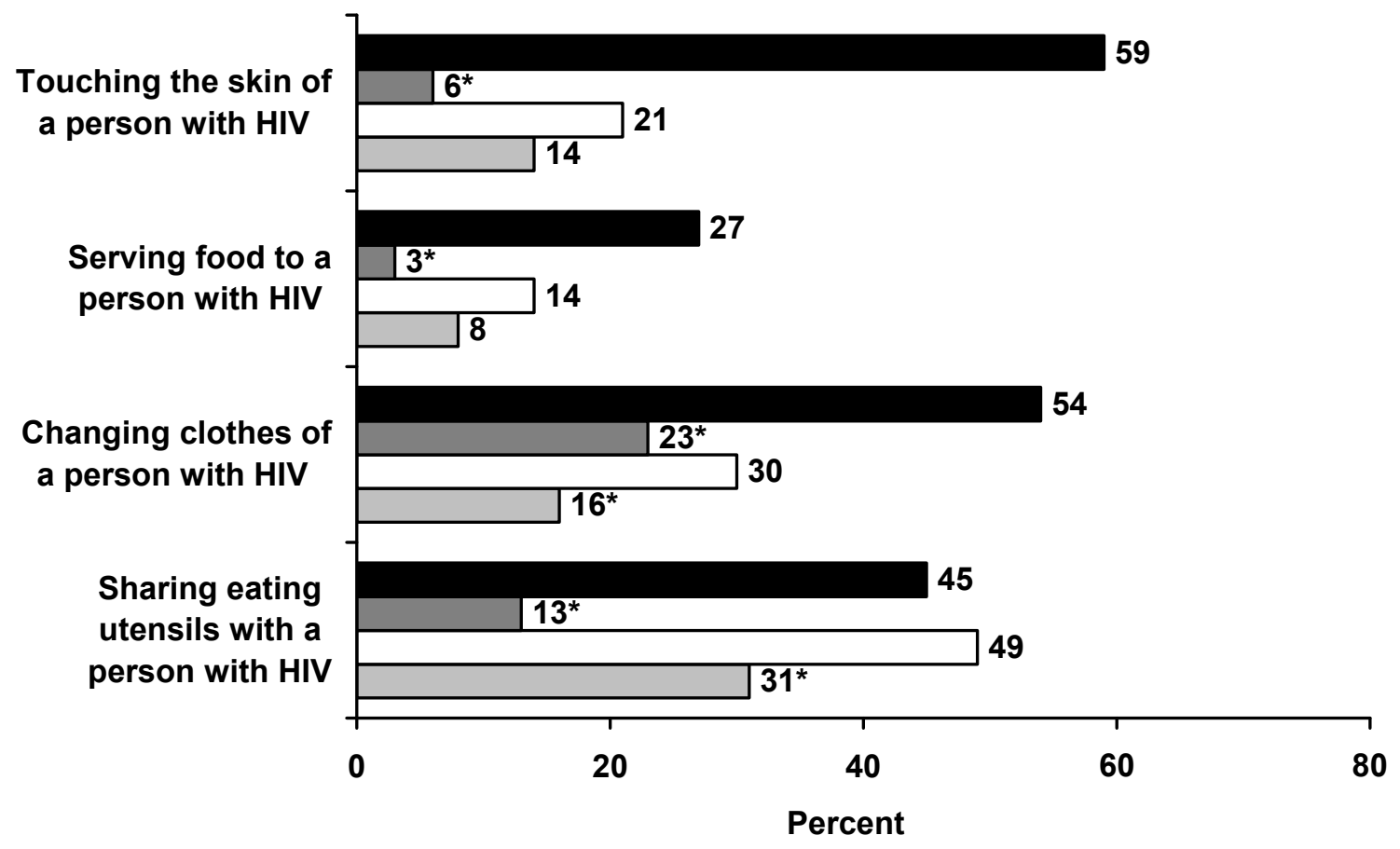

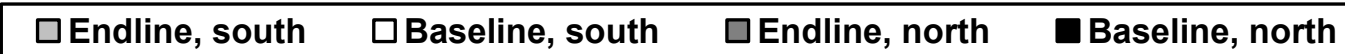

${ }^{*} p<.001$

Mean composite scores also decreased significantly in both regions. In the north, mean scores were reduced from 1.85 at baseline to 0.44 at endline $(\mathrm{p}<.001)$, and in the south from 1.14 to $0.69(\mathrm{p}<.001)$, baseline to endline. 


\section{Changes in compounded stigma in Arm 1 hospitals}

Agreement with negative statements about sex workers, IDUs, and men with multiple partners declined significantly from baseline to endline. Opinions about IDUs spreading HIV decreased most significantly among Arm 1 hospitals, from 93 percent to 82 percent in the north $(\mathrm{p}<.001)$ and 92 percent to 85 percent in the south $(\mathrm{p}<.004)$. Agreement with the statement, "It is promiscuous men who spread HIV in our community" did not decrease in the south but significantly declined in the north, from 95 percent to 82 percent $(\mathrm{p}<.001)$. In terms of the composite index scores, the most significant changes were recorded among hospital workers in the Arm 1 hospitals, where mean scores on the compounded stigma index decreased from 2.83 to $2.45(\mathrm{p}<.001)$ in the north. In the south the mean scores on the composite index decreased from 2.72 to $2.58(\mathrm{p}<.05)$.

\section{Changes in compounded stigma in Arm 2 hospitals}

After the intervention, significantly fewer hospital workers in both hospitals reported agreeing with the statement, "It is drug users who spread HIV," from 94 percent to 83 percent $(p<.007)$ in the north and 87 percent to 73 percent $(p<.001)$ in the south. There was no significant change in agreement with the statement, "It is promiscuous men that spread HIV in our community" in either hospital assigned to the Arm 2 intervention. Mean scores on the composite index for compounded stigma also fell significantly in the Arm 2 hospitals. In the north, mean scores among hospital workers declined from 2.76 to 2.51 (p $<$ $.01)$, and from 2.65 to 2.27 in the south $(\mathrm{p}<.001)$.

\section{Changes in value-based stigma in Arm 1 hospitals}

Agreement with statements of value judgments also declined significantly in the Arm 1 hospital in the north but not in the south (see Figure 3). At baseline, 54 percent of hospital workers agreed that AIDS was a punishment for bad behavior, decreasing significantly to 34 percent $(p<.001)$ at endline in the north. Significantly fewer hospital workers in the north agreed with the statement, "I would feel ashamed if I was infected with HIV," decreasing from 52 percent to 32 percent $(p<.001)$ baseline to endline. Changes in agreement with these statements among hospital workers in the south were not significant. 


\section{Hgrizons}

Figure 3 Percent of hospital workers in Arm 1 hospitals reporting agreement
with stigmatizing attitude statements

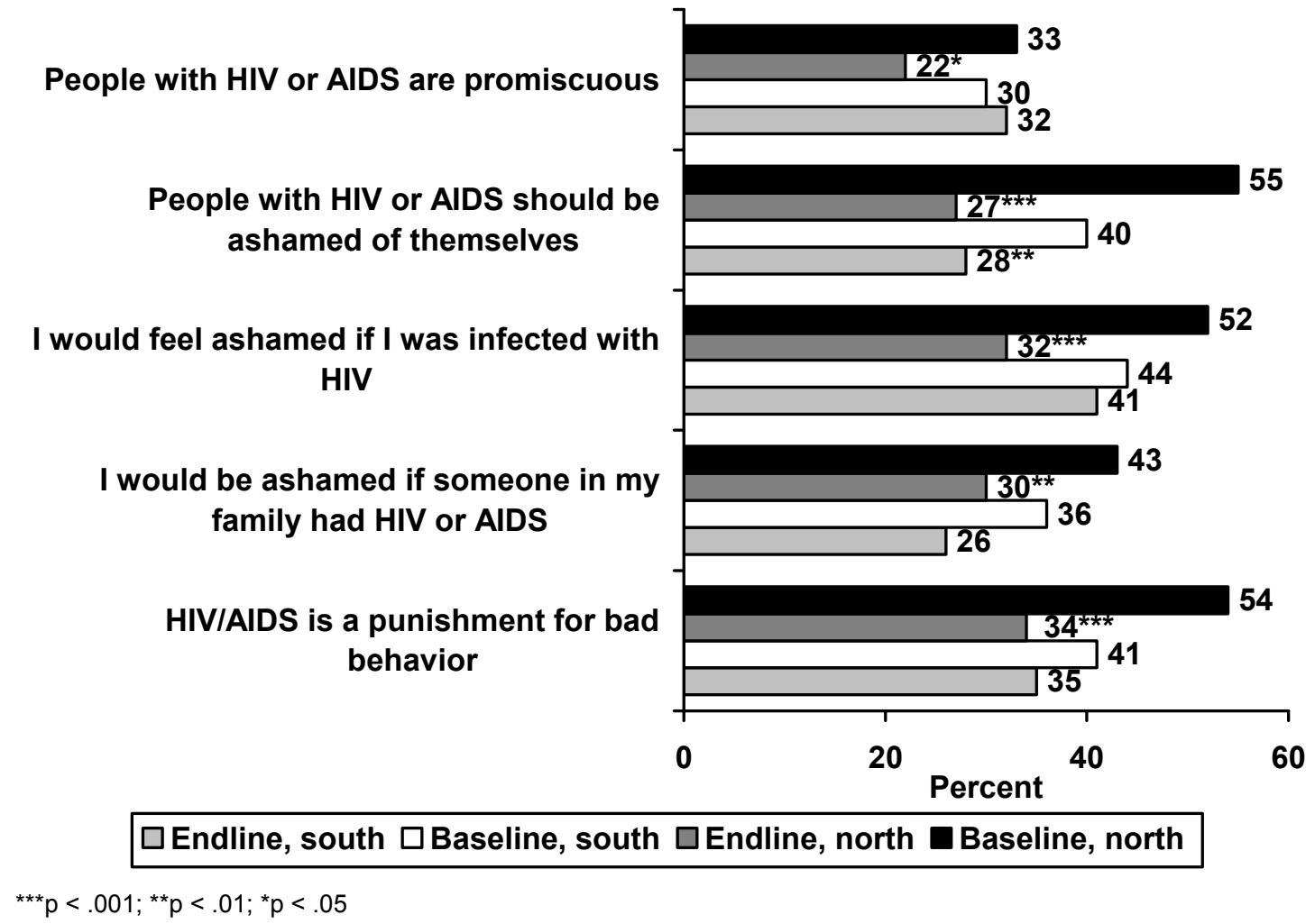

Looking at the composite score for value-based stigma in the Arm 1 hospitals, a significant change was detected both in the north, where the average score dropped from 9.78 to $7.35(\mathrm{p}<.001)$, and in the south, where this change went from 8.10 to $7.57(\mathrm{p}<.001)$.

\section{Changes in value-based stigma in Arm 2 hospitals}

Results of pre- and post-intervention change in the Arm 2 hospitals are shown in Figure 4. Hospital workers who felt that HIV/AIDS is a punishment for bad behavior declined from 43 percent before the intervention to 26 percent after the intervention in the south $(\mathrm{p}<.001)$. In the north, 44 percent of hospital workers at baseline agreed with this statement, declining to 19 percent at endline $(\mathrm{p}<.001)$. 
Figure 4 Percent of hospital workers in Arm 2 hospitals reporting agreement with stigmatizing attitude statements

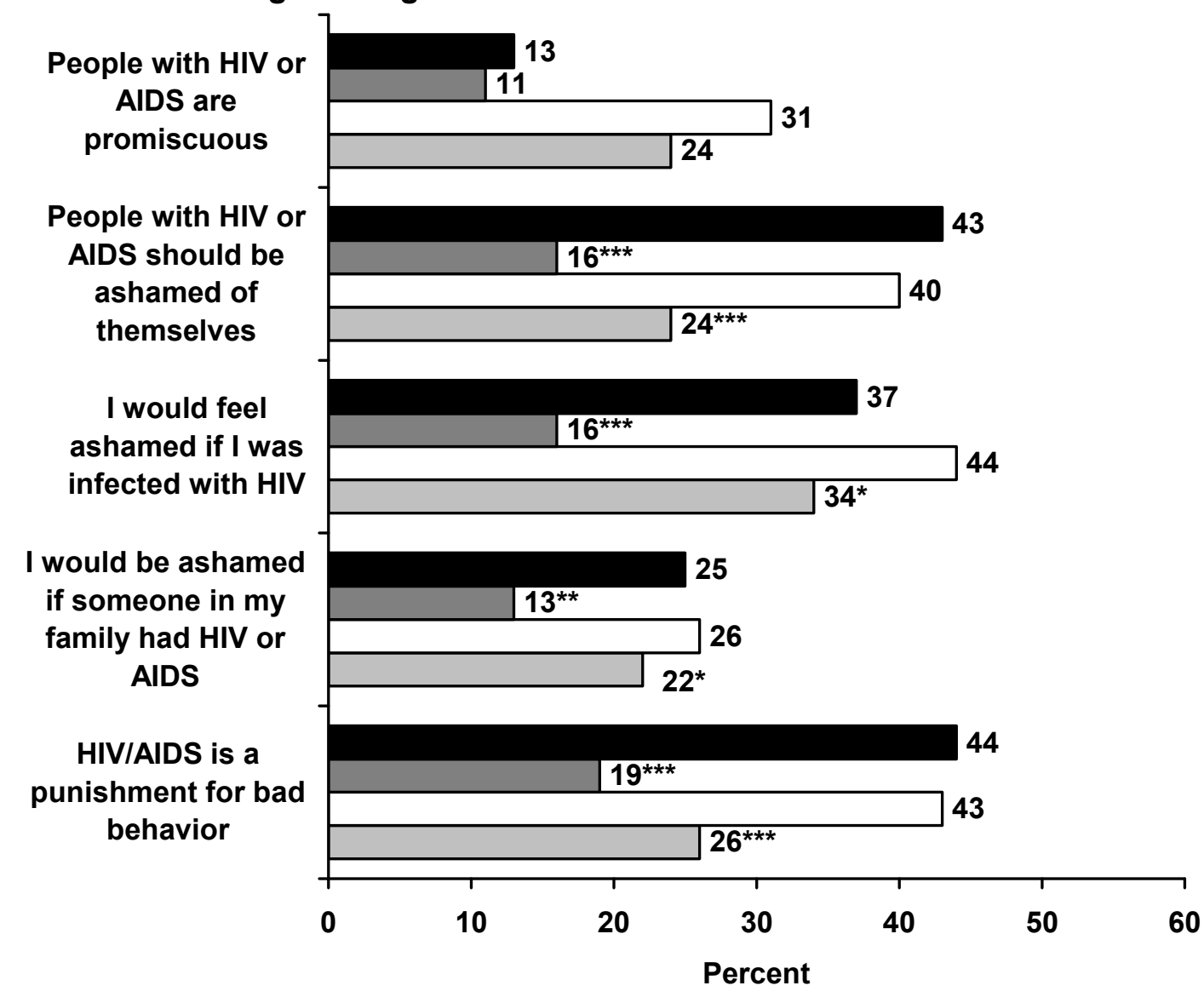

$\square$ Endline, south $\square$ Baseline, south $\quad \square$ Endline, north $\quad$ Baseline, north

${ }^{* * *} p<.001 ;{ }^{* *} p<.01 ;{ }^{*} p<.05$

Mean stigma scores in the composite value-based stigma measure also decreased in the Arm 2 hospital in the north, from 7.70 to 6.19 ( $\mathrm{p}<.001)$, and in the south, from 7.99 to $6.93(\mathrm{p}<.05)$.

\section{Changes in discrimination or enacted stigma}

Patient-provider interactions in Arm 1 hospitals

Hospital workers reported fewer observations of enacted stigma in both hospitals. Results of this analysis are shown in Figure 5. Significantly fewer hospital workers reported observing discrimination in patientprovider interactions among hospitals in the south but not in the north $(\mathrm{p}<.001)$. 
Figure 5 Changes in percentage of hospital workers in Arm 1 hospitals who observed at least one of three situations of discrimination

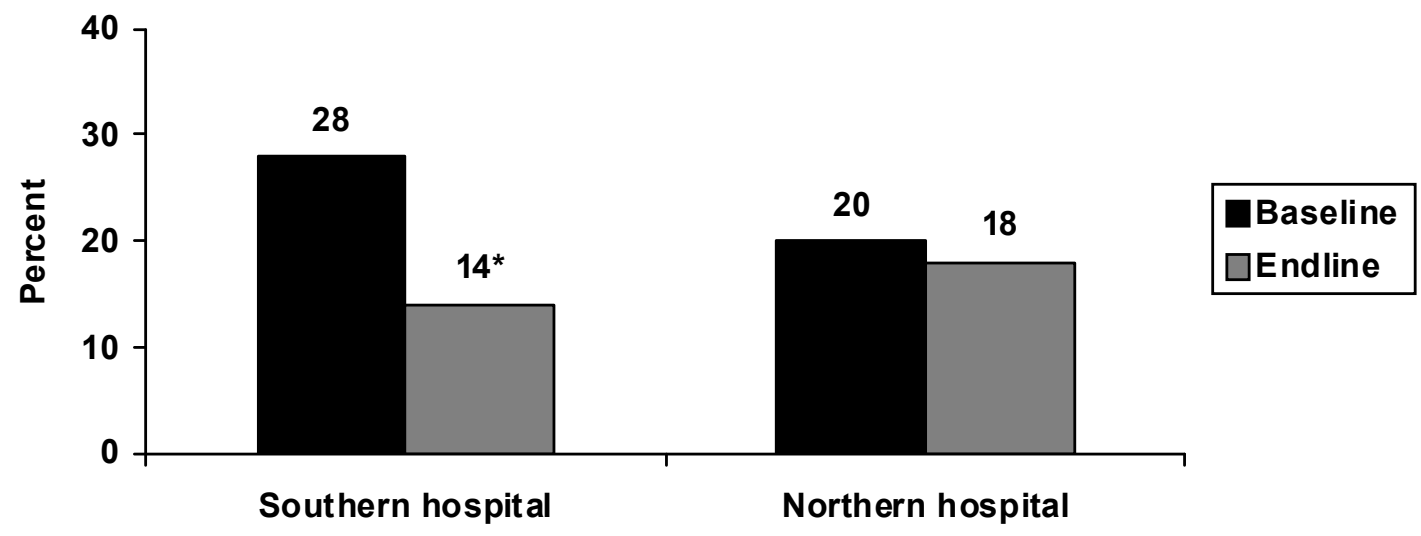

${ }^{*} p<.001$

Patient-provider interactions in Arm 2 hospitals

The reverse was true in the Arm 2 hospitals, where hospitals workers in the north reported significant reductions in observations of enacted stigma in patient-provider interactions $(\mathrm{p}<.001)$ (see Figure 6$)$. The most often reported cases of observed stigma involved a health provider disclosing a patient's status to their family without the patient's consent and health providers gossiping about a patient's HIV status, both of which were reported significantly less frequently after the intervention in the Arm 2 hospitals.

Among those observations most frequently cited post-intervention were a senior health provider passing a patient to a junior provider because the patient is HIV-positive and a health provider disclosing a patient's status to their family without the patient's consent.

Figure 6 Changes in percentage of hospital workers in Arm 2 hospitals who observed at least one of three situations of discrimination

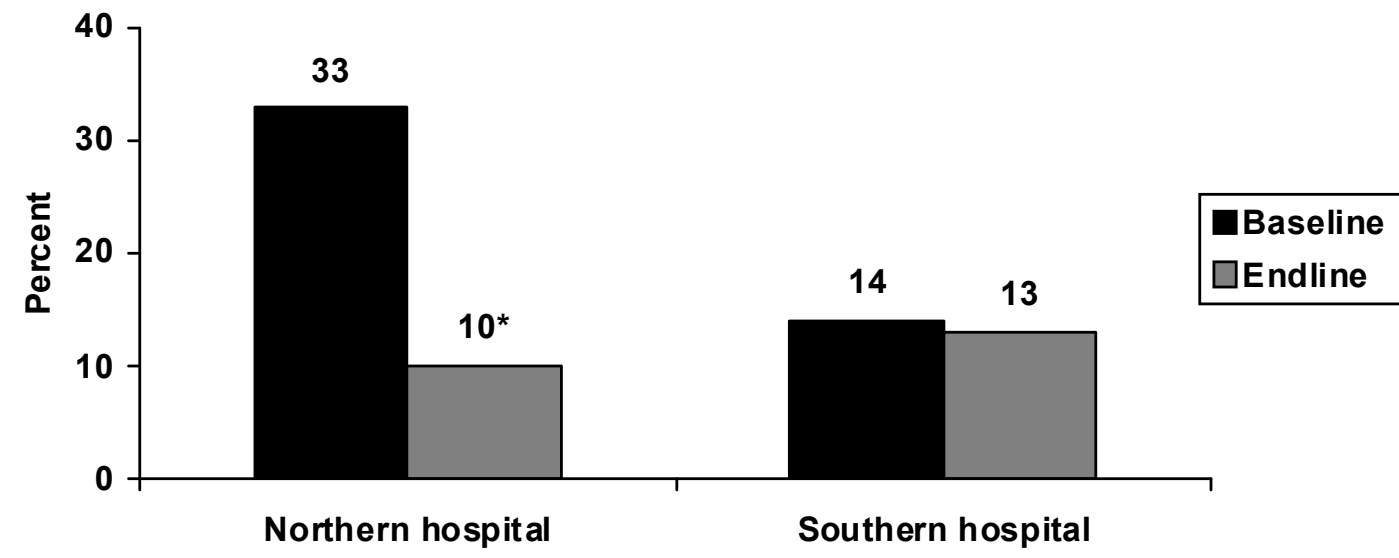

${ }^{*} \mathrm{p}<.001$ 
Significant declines in observed enacted stigma were only reported in the Arm 2 hospital in the north (33 percent to 10 percent; $\mathrm{p}<.001)$. The most significant reduction in observations in the Arm 2 hospitals was workers who reported seeing a health provider disclosing a patient's status to their family without the patient's consent $(\mathrm{p}<.001)$.

\section{HIV testing policy awareness}

After the intervention, awareness of hospital policy regarding HIV testing rose significantly among hospital workers. In the Arm 2 hospitals, the proportion of hospital workers who were aware of this policy rose from 10 percent to 65 percent $(\mathrm{p}<.001)$ after the intervention, and in the Arm 1 hospitals awareness rose from 9 percent to 51 percent $(\mathrm{p}<.001)$.

\section{Hospital-wide practices in Arm 1 hospitals}

In the Arm 1 hospitals, frequency of hospital workers reporting labels on files of HIV-positive patients declined from 56 percent to 31 percent $(\mathrm{p}<.001)$ in the south and from 68 percent to 41 percent $(\mathrm{p}<$ .001 ) in the north. Reported observations of signs on beds fell significantly in both hospitals in the Arm 1 intervention sites. At baseline in the north, 46 percent of hospital workers reported signs on beds, decreasing to 22 percent $(\mathrm{p}<.001)$ at endline. In the south, this change was from 38 percent to 20 percent $(\mathrm{p}<.001)$ (see Figure 7).

\section{Figure 7 Changes in percentage of hospital workers in Arm 1 hospitals reporting hospital-wide discriminatory practices}

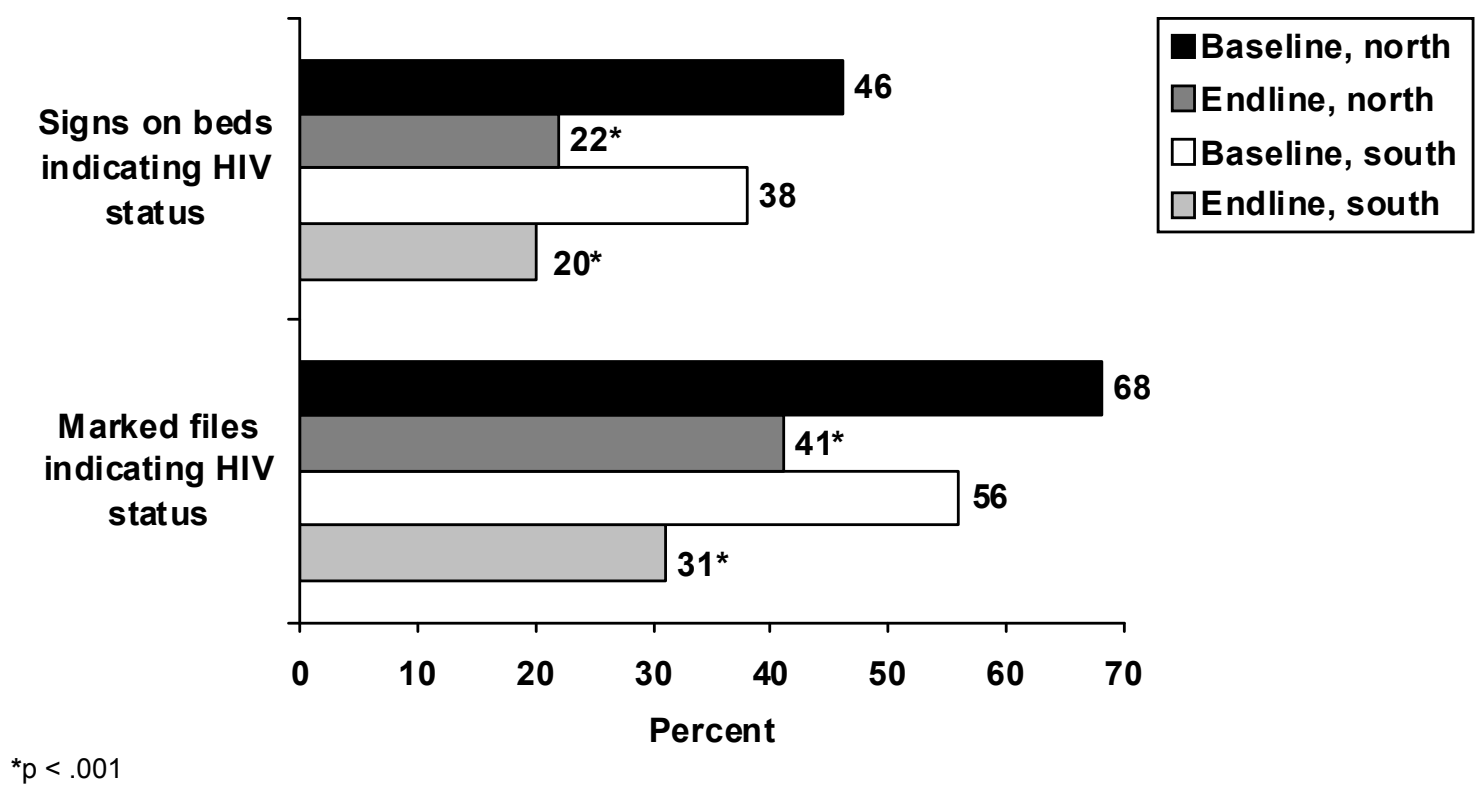




\section{Hgrizons}

Hospital-wide practices in Arm 2 hospitals

Labels on files of HIV-positive patients decreased significantly, from 46 percent to 12 percent $(\mathrm{p}<.001)$ in the Arm 2 hospital in the north, and from to 31 percent to 17 percent $(p<.002)$ in the Arm 2 hospital in the south. Reports of signs on beds also declined, from 12 percent to 8 percent (not significant) in the hospital in the north. Significantly fewer hospital workers in the Arm 2 hospital in the south reported signs on beds (19 percent to 5 percent; $p<.001$ ) (see Figure 8).

Figure 8 Changes in percentages of hospital workers in Arm 2 hospitals reporting hospital-wide discriminatory practices in Arm 2 hospitals

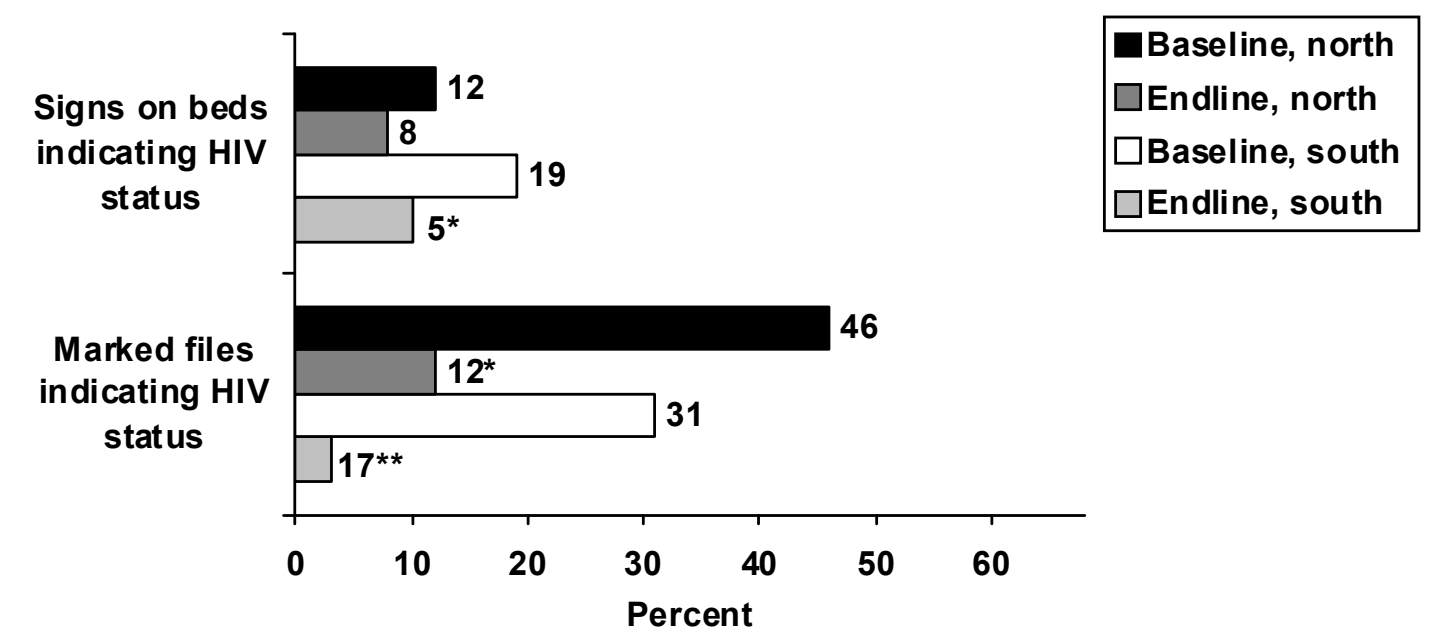

${ }^{*} p<.001 ;{ }^{* *} p<.01$

Fears affecting interactions

Nearly half (48 percent) of all hospital workers across all four hospitals reported having some fear of getting infected with HIV while at work and that these fears affected their interactions with patients. Significantly fewer hospital workers said this after the intervention, ranging from 28 percent to 11 percent of hospital workers at endline (see Figure 9). These changes were significant in all hospitals $(\mathrm{p}<.001)$. 
Figure 9 Changes in percentage of hospitals workers reporting that fear affects their interactions with patients, by hospital and study arm

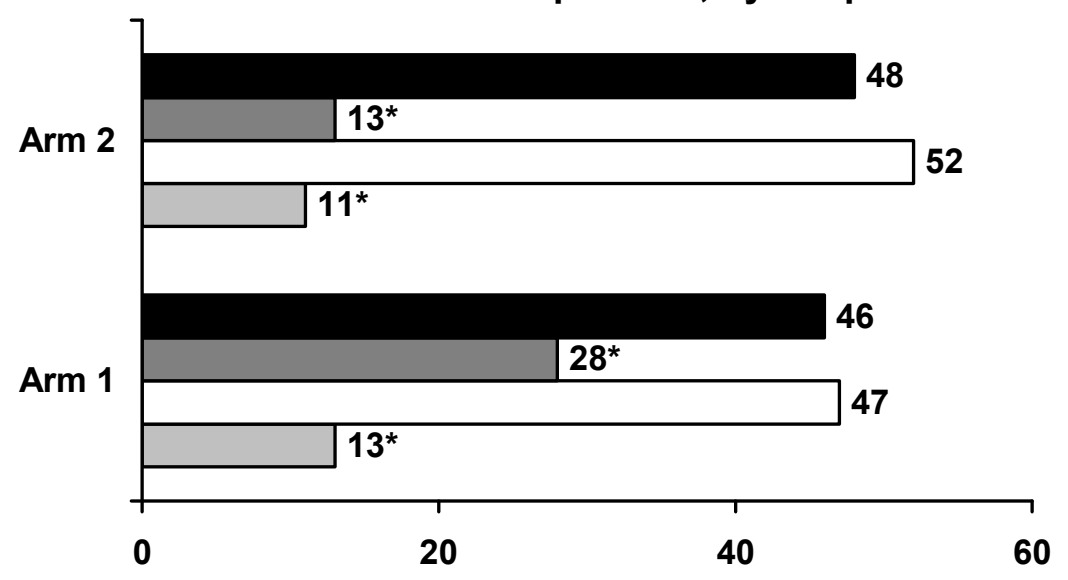

${ }^{*} \mathrm{p}<.001$

Use of barrier protections in Arm 1 hospitals

Among those reporting fears, overuse of barrier protections decreased significantly from 42 percent to 17 percent $(\mathrm{p}<.001)$ in the Arm 1 hospitals overall. Figure 10 displays changes in overuse of barrier intervention-auxiliary nurses and ward staff, clinical and administrative nurses, and managers and other administrative staff.

Figure 10 Changes in percentage of hospital workers in Arm 1 hospitals overusing any form of barrier protection

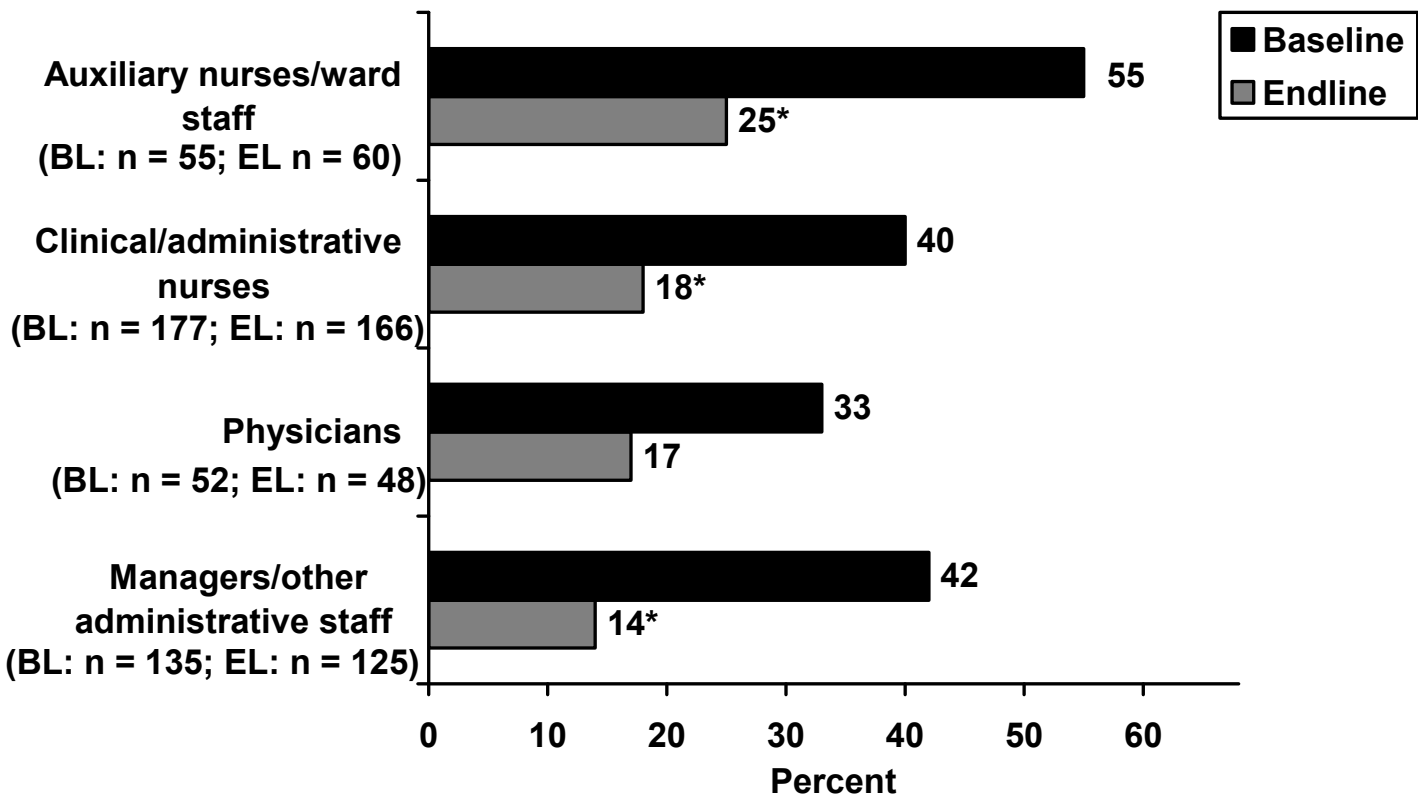

${ }^{*} \mathrm{p}<.001$ 


\section{Hgrizons}

Use of barrier protections in Arm 2 hospitals

Similarly, in the Arm 2 hospitals significant declines were reported in overuse of barrier protections, from 43 percent to 11 percent $(\mathrm{p}<.001)$. Significant reductions were observed among all positions $(\mathrm{p}<.001)$ (see Figure 11).

Figure 11 Changes in percentage of hospital workers in Arm 2 hospitals overusing any form of barrier protection

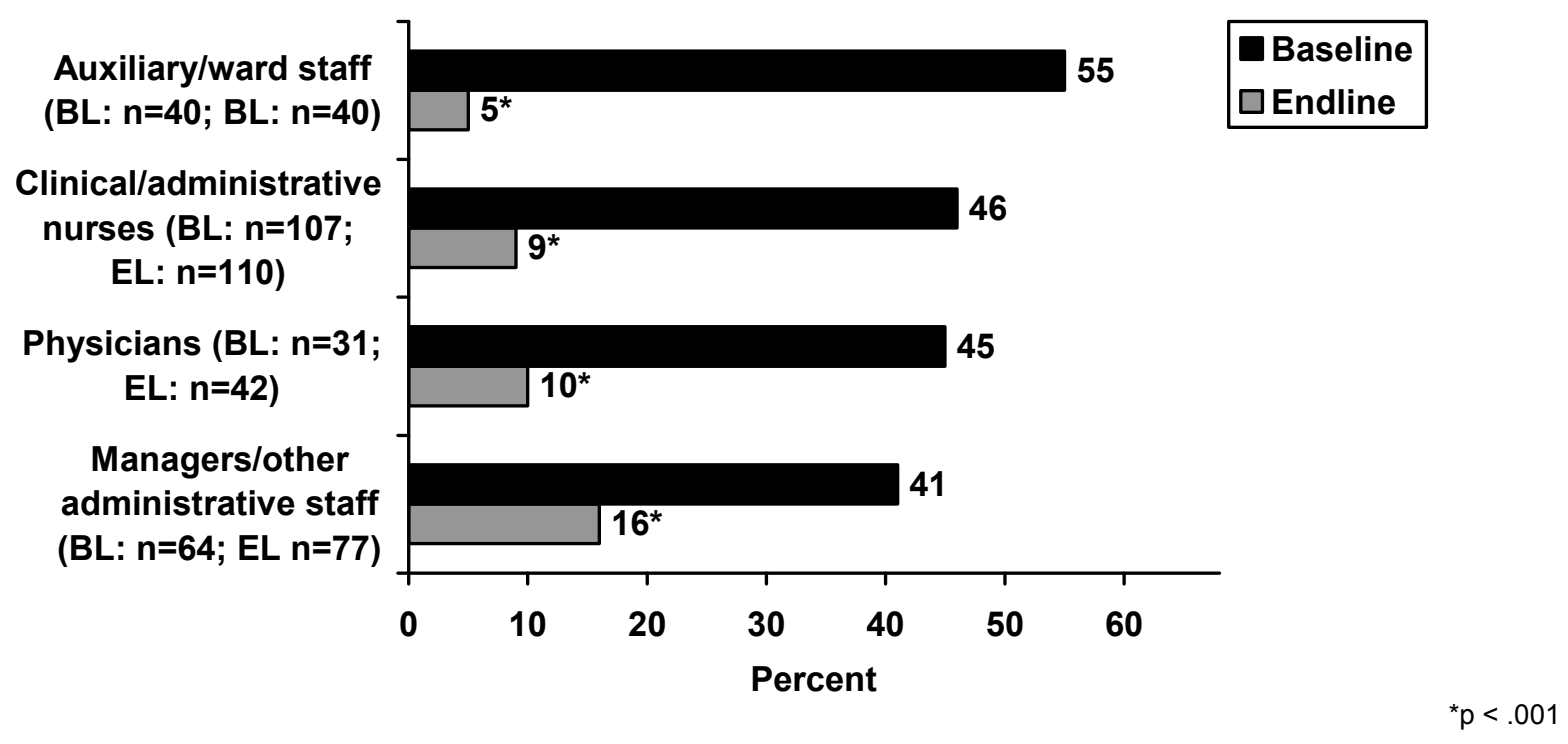

\section{Changes in in-depth HIV knowledge in Arm 1 hospitals}

Changes in in-depth knowledge were observed in correctly identifying whether the following bodily fluids could transmit HIV: saliva (correct knowledge: 79 percent at baseline to 91 percent at endline; $\mathrm{p}<$ .000 ), sweat (correct knowledge: 89 percent at baseline to 97 percent at endline; $p<.000$ ), and urine (correct knowledge: 79 percent at baseline to 93 percent at endline; $\mathrm{p}<.000$ ). Significant increases in correct knowledge about breast milk were only found in the hospital in the north (correct knowledge: 49 percent at baseline to 80 percent at endline; $\mathrm{p}<.000)$. Looking at the composite scores on the knowledge index, mean scores rose from 7.56 to $8.49(\mathrm{p}<.001)$ in the north and from 7.61 to 8.14 in the south $(\mathrm{p}<$ $.001)$.

\section{Changes in in-depth HIV knowledge in Arm 2 hospitals}

Similar changes were observed in the Arm 2 hospitals, with increased correct knowledge about saliva, (72 percent at baseline to 92 percent at endline; $p<.000)$, sweat $(86$ percent at baseline to 96 percent at endline), and urine (77 percent at baseline to 93 percent at endline; $\mathrm{p}<.000)$. Mean scores increased from 7.71 to $8.61(p<.001)$ in the Arm 2 hospital in the north and from 7.63 to $8.12(p<.001)$ in the south. 


\section{Differential Impacts of Arm 1 and Arm 2 Interventions}

A series of multivariate models, controlling for hospital type and key sociodemographic variables of health workers, were created to explore whether the Arm 2 intervention, which included a greater emphasis on value-based stigma, was more effective than the Arm 1 intervention in reducing stigma and discrimination in the hospital setting. Results of these ordinary least squares and/or logistic regression models are described in detail here.

\section{Fear-based, value-based, and compounded stigma}

A model was created to explore the relationship between the interventions and fear-based stigma. Results of this model showed that the average scores on fear-based stigma at endline were lower among hospital workers who received the Arm 2 intervention as compared to the Arm 1 intervention $(p<.001)$ (see Table $3)$.

\section{Table 3 Results of ordinary least squares regression of impact of the two interventions on fear-based stigma, controlling for type of hospital, age, and education}

\begin{tabular}{lc}
\hline & $\begin{array}{c}\text { Fear-based stigma mean score } \\
(\mathbf{n}=\mathbf{7 9 6})\end{array}$ \\
\hline Arm 2 intervention & $-0.339^{*}$ \\
& $(-3.261)$ \\
Arm 2, north & -0.242 \\
& $(-1.916)$ \\
Arm 1, north & -0.207 \\
& $(-0.081)$ \\
Age & 0.000 \\
Education (years) & $(0.114)$ \\
& $0.059^{* *}$ \\
\end{tabular}

t-statistics in parentheses

${ }^{*} p<.001 ;{ }^{* *} p<.05$

Similar results were found when modeling the relationship between the interventions and value-based stigma. Hospital workers who had been exposed to the Arm 2 intervention had significantly lower mean scores on the value-based stigma measure as compared to the Arm 1 intervention $(p<.005)$ (see Table 4$)$. 


\section{Hgrizons}

Table 4 Results of ordinary least squares regression of impact of the two interventions on value-based stigma, controlling for type of hospital, age, and education

\begin{tabular}{lc}
\hline & $\begin{array}{c}\text { Value-based stigma mean score } \\
(\mathbf{n}=\mathbf{7 9 6})\end{array}$ \\
\hline Arm 2 intervention & $-0.708^{* *}$ \\
& $(-2.835)$ \\
Arm 2, north & $-0.711^{* * *}$ \\
& $(-2.341)$ \\
Arm 1, north & -0.285 \\
Age & $(-1.130)$ \\
& 0.007 \\
Education (years) & $(3.472)$ \\
& 0.239 \\
\hline
\end{tabular}

t-statistics in parentheses

${ }^{*} p<.001 ;{ }^{* *} p<.01 ;{ }^{* * *} p<.05$

Hospital workers participating in the Arm 2 intervention also had lower average scores on attitudes related to compounded stigma versus Arm 1 participants $(\mathrm{p}<.001)$ (see Table 5).

Table 5 Results of ordinary least squares regression of impact on the two interventions on compounded stigma, controlling for hospital type, age, and education

\begin{tabular}{lc}
\hline & $\begin{array}{c}\text { Compounded stigma mean score } \\
(\mathbf{n}=\mathbf{7 9 6})\end{array}$ \\
\hline Arm 2 intervention & $-0.328^{*}$ \\
& $(-3.582)$ \\
Arm 2, north & $0.265^{\star *}$ \\
Arm 1, north & $(2.376)$ \\
Age & -0.121 \\
& $(-1.301)$ \\
Education (years) & -0.003 \\
& $(-0.703)$ \\
\hline
\end{tabular}

t-statistics in parentheses

${ }^{*} p<.001 ;{ }^{* *} p<.05$ 


\section{Discrimination or enacted stigma}

Logistic regression models were created that predicted discriminatory hospital-wide practices and specific patient-provider interactions, while controlling for hospital facility and key sociodemographic characteristics. The first model predicted signs on the outside of patient's beds indicating patients' status. In the second model, the relationship between the intervention and labels on patients' files indicating patients' status were examined. Results of these two models show hospital workers in the Arm 2 intervention were significantly less likely at endline to report signs on the outside of patients' beds ( $\mathrm{p}<$ .001 ) (see Table 6 ) and labels on patient files $(\mathrm{p}<.001)$ (see Table 7) compared to participants in the Arm 1 intervention.

Table 6 Results of logistic regression of observing signs on beds indicating HIV patients' HIV status, controlling for age and education

\begin{tabular}{lc}
\hline & $\begin{array}{c}\text { Observing signs on beds } \\
(\mathbf{n}=\mathbf{7 9 7}) \\
\text { OR } \mathbf{C l}^{\S}\end{array}$ \\
\hline Arm 2 intervention & $4.71^{*}(2.32,9.56)$ \\
Arm 2, north & $1.52(0.61,3.79)$ \\
Arm 1, north & $1.09(0.68,1.75)$ \\
Age & $1.00(0.98,1.02)$ \\
Education (years) & $1.29^{*}(1.10,1.51)$ \\
\hline${ }^{*} \mathrm{p}<.001 \cdot{ }^{\S} \mathrm{OR}=$ Odds ratio and $\mathrm{Cl}=$ Confidence interval &
\end{tabular}

${ }^{*} \mathrm{p}<.001 ;{ }^{\S} \mathrm{OR}=$ Odds ratio and $\mathrm{Cl}=$ Confidence interval

Table 7 Results of logistic regression of observing marked files indicating HIV patients' HIV status, controlling for age and education

\begin{tabular}{lc}
\hline & $\begin{array}{c}\text { Observing marked files } \\
(\mathbf{n}=\mathbf{7 9 7}) \\
\text { OR CI}^{\S}\end{array}$ \\
\hline Arm 2 intervention & $2.33^{*}(1.46,3.72)$ \\
Arm 2, north & $0.74(0.38,1.44)$ \\
Arm 1, north & $1.61^{* * *}(1.08,2.40)$ \\
Age & $0.99(0.97,1.01)$ \\
Education (years) & $1.21^{* *}(1.07,1.38)$ \\
\hline
\end{tabular}

${ }^{*} \mathrm{p}<.001 ;{ }^{* \star} \mathrm{p}<.01 ;{ }^{* * *} \mathrm{p}<.05 ;{ }^{\S} \mathrm{OR}=$ Odds ratio and $\mathrm{Cl}=$ Confidence interval

A third model tested the relationship between the intervention and awareness of hospital policy on HIV testing of patients, while controlling for hospital facility. In this last model, no significant relationship was found for the intervention. 


\section{Hgrizons}

Two logistic regression models were created to examine the relationship of the interventions and practices with HIV-positive patients among hospital workers post-intervention. The first model predicted the likelihood of hospital workers reporting having fears related to HIV that affected their behaviors toward HIV-positive patients (see Table 8). Hospital workers in the Arm 2 intervention groups were less likely to report fears affecting their interactions with patients with HIV $(\mathrm{p}<.001)$. In the second model, the outcome was hospital workers reporting an overuse of barrier protections with HIV-positive patientsthat is, workers using gloves, goggles, and masks at all times when attending a patient with HIV, even during casual contact (see Table 9). Hospital workers who participated in the Arm 2 intervention, as opposed to the Arm 1 intervention, were less likely to report overuse of gloves, masks, and goggles ( $\mathrm{p}<$ $.008)$.

Table 8 Results of logistic regression of fear affecting interaction with patients, controlling for hospital facility, age, and education

\section{Fear affecting interaction with patients}

$(n=797)$

OR Cl $\$$

\begin{tabular}{ll}
\hline Arm 2 intervention & $0.36^{*}(0.22,0.60)$ \\
Arm 2, north & $0.73(0.36,1.48)$ \\
Arm 1, north & $0.28^{*}(0.17,0.48)$ \\
Age & $1.03^{*}(1.01,1.06)$ \\
Education (years) & $1.16^{* *}(1.01,1.34)$ \\
\hline
\end{tabular}

${ }^{*} \mathrm{p}<.001 ;{ }^{* *} \mathrm{p}<.05 ;{ }^{\S} \mathrm{OR}=$ Odds ratio and $\mathrm{Cl}=$ Confidence interval

Table 9 Results of logistic regression of reporting over use of barrier protections, controlling for hospital facility, age, and education

\begin{tabular}{lc}
\hline & $\begin{array}{c}\text { Overuse of barrier protections } \\
(\mathbf{n}=\mathbf{7 9 7}) \\
\mathbf{O R ~ C l}^{\S}\end{array}$ \\
\hline Arm 2 intervention & $0.48^{* *}(0.28,0.82)$ \\
Arm 2, north & $0.55(0.25,1.22)$ \\
Arm 1, north & $0.34^{*}(0.19,0.59)$ \\
Age & $1.03^{* *}(1.01,1.05)$ \\
Education (years) & $1.10(0.95,1.27)$ \\
\hline${ }^{*} \mathrm{p}<.001 ;{ }^{* *} \mathrm{p}<.01 ;{ }^{\S} \mathrm{OR}=$ Odds ratio and $\mathrm{Cl}=$ Confidence interval
\end{tabular}

Logistic regression was also used to examine the relationship between the interventions and observing one of the three acts of discrimination in the hospital setting (discussed above). No statistically significant relationships were found between the interventions and the likelihood of observing discriminatory behaviors in patient-provider interactions. 


\section{Additional Findings and Insights}

\section{Monthly monitoring}

At each monthly monitoring visit, data were gathered using the structured checklist. The checklist included 29 items in four major areas of interest which were observed in five randomly selected patients, five randomly selected workers, and five randomly selected locations in the hospital. At the end of the monitoring visit, the team discussed and gave each item a score. Each item was scored from 1 to 5 on the level of implementation. The total possible score ranged from 29 to 145. Major topic areas included admissions and care of HIV-positive patients, HIV voluntary counseling and testing, protecting the confidentiality of patients with HIV, and the practice of universal precautions. After the data were gathered, an interview was conducted with the relevant hospital administrators and staff to discuss progress thus far, challenges, and potential ways to improve certain areas of implementation of the intervention. These meetings proved to be critical elements in the process of implementation for strengthening and supporting change throughout the duration of the project. Findings from monitoring data reveal a steady, consistent increase in improvement in all areas of hospital practices over the course of the study (see Figure 12). Of particular note during the monitoring visits were increased hand washing and use of sharps boxes.

\section{Figure 12 Changes in total scores}

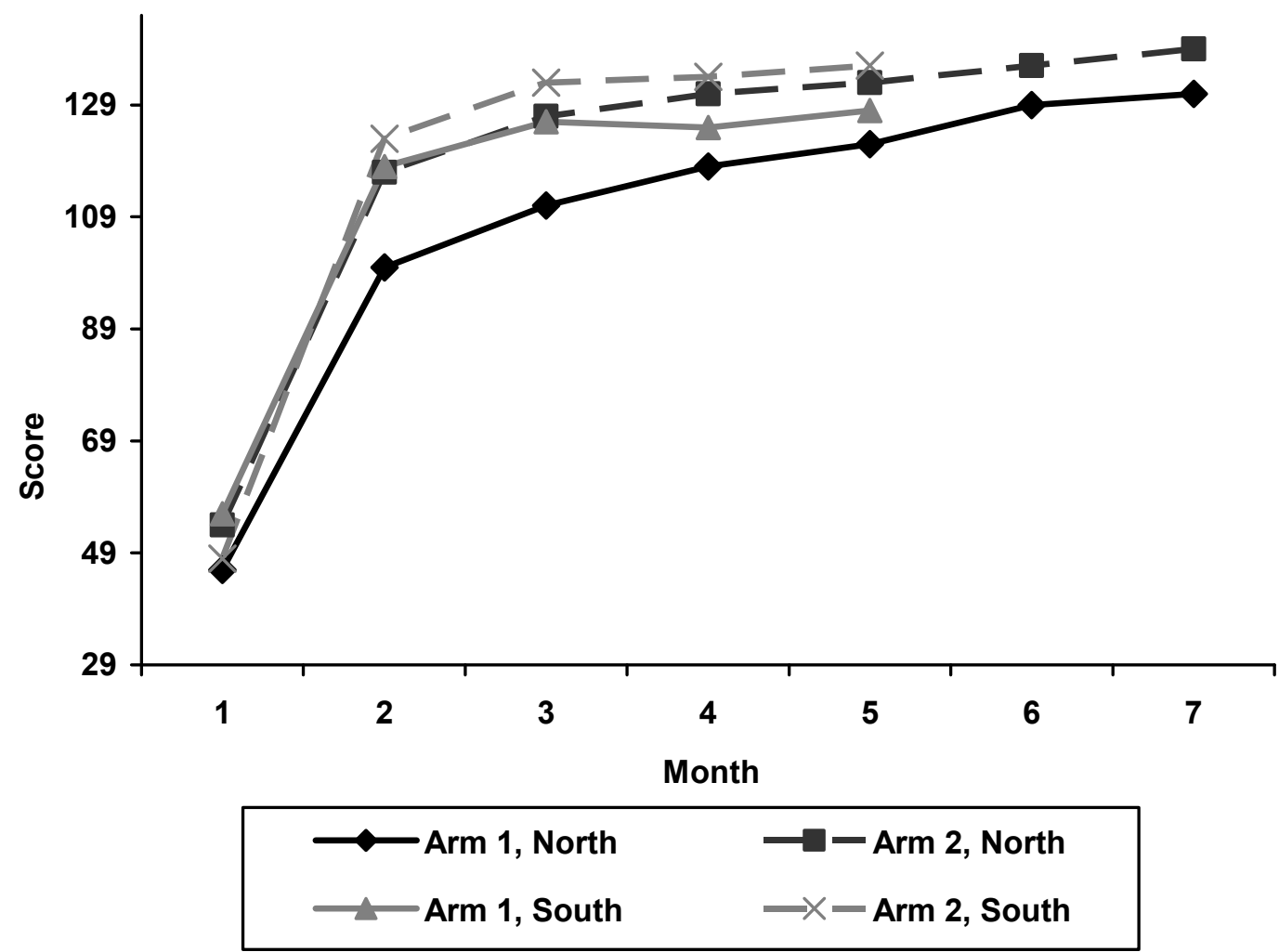




\section{Hgrizons}

\section{Conclusions}

Relatively high levels of fear-based stigma were evident among hospital workers at baseline. Hospital workers expressed great fear of contagion, and these fears affected their interactions with HIV-positive patients. These fears caused differential treatment of patients in an effort for workers to "protect" themselves from becoming infected with HIV. The protection of HIV-positive patients from potential risk of infection from others was generally not taken into consideration by most hospital workers.

Similarly, hospital workers also expressed high levels of value-based stigma, as noted by the shame associated with having HIV and the blame extended to sex workers, IDUs, and promiscuous men. The lack of policies in the provision of patient care, including voluntary HIV testing and counseling, created an environment of uncertainty regarding relative risks of HIV transmission as well as value-laden assumptions about the behaviors of certain patients who were presumed to have HIV.

Despite these fears and attitudes, hospital workers and administrators also demonstrated sympathy for patients with HIV. There was general agreement that HIV-positive patients should be treated the same as others, yet the extensive efforts to be "protected" from HIV overwhelmed these sympathies. Hospital workers often felt bad about their extra precautions when treating HIV patients and tried to hide discriminatory behavior from patients. Hospital workers recognized that their differential treatment could negatively impact their patients, and workers often expressed regret about their discriminatory practices.

These fears and judgments were manifested in a variety of ways, such as the extensive and unnecessary use of barrier protections while interacting with patients with HIV, even via casual contact, and in hospital-wide practices such as specially marked clothing and linens for HIV patients and marked files indicating a patient's HIV status. The fear of casual transmission was not only evident in the high rates of reported overuse of barrier protections generally, but was also extensively illuminated in interviews where detailed descriptions were given of the precautions hospital workers take while attending patients with HIV, such as the use of lab coats, long or extra gloves, goggles, and masks. These behaviors largely declined by the end of the intervention, often more so in the Arm 2 intervention that addressed both fear and social stigma reduction.

Another key finding was that in the absence of a hospital policy, hospital practices reinforced stigma and led to discrimination through individual behaviors and through hospital-wide practices. The absence of clear policies on HIV testing and counseling led to subjective identification and testing of patients who fit a predetermined profile or appearance of someone who may have HIV, and the separation or identification of HIV-positive patients through specially marked clothing and linens, among other practices. These practices were either eliminated or declined significantly after the intervention.

Both interventions were successful in reducing the fear- and value-based stigma reported by hospital workers and discriminatory hospital-wide practices. The interventions had significant effects on various practices such as marking files and putting signs on beds to indicate a patient's HIV status, as well as workers reporting that they treated HIV-positive patients differently.

Observations during monitoring visits also support the findings from the survey and qualitative data. Improved hospital-wide practices in Universal Precautions, patient confidentiality, and provision of voluntary counseling and testing were sustained over time. Infrastructural improvements enabled workers to practice more frequent hand washing, and opportunities to receive training in pre- and post-test 
counseling enabled hospital workers to begin to implement the standards of care stipulated by law. Informal interviews with staff during monitoring visits also highlighted the critical importance of including representatives from each hospital to provide feedback and input into the design of the intervention; that involving all categories of hospital staff (e.g., doctors, guards) in training and in policy development assisted in creating a stigma-free environment at all levels; and that including people living with HIV in the education sessions was a key component of the intervention.

Several limitations in this study should be noted. Data were collected from all hospital staff (i.e., census data) although the participants were not matched from baseline to endline data collection. In essence, we have cross-sectional data, which limits our ability to attribute individual-level change to specific intervention activities. Further, in the multivariate models, we assume that the hospital workers in hospitals who received the Arm 2 intervention were not different in any way that would affect either outcomes measures or the probability of being exposed to the intervention, from those who worked in hospitals that received the Arm 1 intervention, and that the differences in outcomes observed at endline were due to the interventions.

Both intervention strategies - which focused on addressing the entire hospital environment in addition to training hospital workers - successfully reduced stigma and discrimination and improved quality of care in the healthcare setting. In addition, the Arm 2 intervention, which included greater involvement of people living with HIV and more intense staff training on stigma and discrimination, often was more effective than the Arm 1 intervention. These findings show that addressing stigma and discrimination in the healthcare setting is an effective intervention strategy for improving quality of care and preventing occupational transmission of HIV. These changes are demonstrated in the adoption of policies and practices related to improvements in HIV testing and counseling, reductions in the labeling of beds and files indicating patients' HIV status, as well as decreased overuse of barrier protections. Therefore, effective interventions to reduce stigma and discrimination in healthcare settings need to address the full environment of the hospital and reach all hospital workers.

\section{Program Implications}

Change in hospital-based stigma and discrimination is possible using participatory methods and addressing stigma on multiple levels. The full intervention package that addressed both fear reduction and social stigma reduction should be considered for adoption by healthcare institutions concerned about reducing stigma. Programs to provide stigma training more widely to hospital workers in all government hospitals could have a positive impact on the quality of care nationwide. Integrating stigma training into the medical school training curriculum could also provide a foundation for new physicians.

\section{Policy Implications}

Critical to reducing the spread of HIV is providing prevention interventions in an effective and ethical manner. Stigma and discrimination create barriers to accessing HIV testing, requesting or adhering to treatment, and receiving medical care. Providing financial and policy support for HIV stigma reduction programs in healthcare settings is a critical step to reduce barriers to accessing prevention, care, and treatment. Access to these services will contribute to the normalization of HIV and minimize the devastating effects of the consequences of HIV on families and communities. Development and implementation of AIDS Laws similar to the one in Vietnam builds the legal framework from which to 


\section{Hgrizons}

support hospital workers to implement the programs and resources necessary to fulfill this legal obligation. These policies will have tremendous effects on the type and quality of care hospital workers in all health sectors are able to provide.

\section{Research Implications}

Results from this report contribute to the limited body of literature on successful HIV stigma reduction interventions, and additional evaluations are needed in varied types of settings (e.g., schools, workplaces). Results also contribute to the development of quantitative measures of stigma. Continued work testing quantitative measures in different contexts is needed to continue to develop reliable and valid scales for stigma, and sub-scales for the many dimensions that could be conceptualized under the construct of stigma. 


\section{References}

Adebajo, S.B., A.O. Bamgbala, and M.A. Oyediran. 2003. "Attitudes of health care providers to persons living with HIV/AIDS in Lagos State, Nigeria," African Journal of Reproductive Health 7(1): 103-112.

Banteyerga, H. et al. 2004. Yichalaliko! Exploring HIV and AIDS Stigma and Related Discrimination in Ethiopia: Causes, Manifestations, Consequences, and Coping Mechanisms. Addis Ababa: Miz-Hasab Research Center.

Campbell, C. et al. 2005. Understanding and Challenging HIV/AIDS Stigma. HIVAN Community Booklet Series (HIVAN), CfHAN. Durban: University of KwaZulu Natal.

Decree 45/CP, dated April 6, 2005, Stipulations on Punishments for Administrative Violations in Health.

Goffman, E. 1963. Stigma: Notes on the Management of Spoiled Identity. New York: Simon \& Schuster Inc.

Hong, K.T., N.T. Van Anh, and J. Ogden. 2004. "'Because this is the disease of the century':

Understanding HIV and AIDS-related dtigma and discrimination in Vietnam." Washington, DC:

International Center for Research on Women.

Horizons Program. 2002. "Addressing HIV/AIDS stigma and discrimination in a workplace program: Emerging findings," Horizons Research Update. Washington, DC: Population Council.

JVnet. 2004. Gender norms, gender roles and HIV/AIDS in Vietnam.

Kalichman, S. C. et al. 2005. "Development of a brief scale to measure AIDS-related stigma in South Africa," AIDS and Behavior 9(2): 135-43.

Kidd, R. et al. 2007. Understanding and Challenging HIV Stigma: Toolkit for Action. Brighton, UK: International HIV/AIDS Alliance, AED, and ICRW.

Kohi, T.W. and M.J. Horrocks. 1994. "The knowledge, attitudes and perceived support of Tanzanian nurses when caring for patients with AIDS," International Journal of Nursing Studies 31(1): 77-86.

Link, B. and J. Phelan. 2001. On Stigma and Its Public Health Implications in Stigma and Global Health: Developing a Research Agenda. Washington, DC: National Institutes of Health.

Liu, H. et al. 2006. "Understanding interrelationships among HIV-related stigma, concern about HIV infection, and intent to disclose HIV serostatus: a pretest-posttest study in a rural area of eastern China," AIDS Patient Care and STDs 20 (2): 133-42.

Madan, Y. et al. 2006. "Active involvement of PLAs to design and develop mass media campaign to address stigma and discrimination related to HIV and AIDS," poster abstract 287 for PEPFAR Annual Meeting. Durban, South Africa. 


\section{Hgrizons}

Mahendra, V. S. et al. 2006. "Reducing AIDS-related stigma and discrimination in Indian hospitals," Horizons Final Report. New Delhi: Population Council.

Mbwambo, J. et al. 2004. Understanding HIV-Related Stigma in Tanzania. Dar es Salaam: MUCHS.

Mills, E. A. 2006. "Briefing-From the physical self to the social body: Expressions and effects of HIVrelated stigma in South Africa," Journal of Community and Applied Social Psychology 16: 498-503.

Ministry of Health Viet Nam. 2004. "HIV/AIDS Estimation and Projection 2003-2005," paper presented at the Workshop: HIV/AIDS Estimation and Projection in Vietnam, Hanoi, Vietnam.

2005. HIV/AIDS estimates and projections 2005-2010. Hanoi: General Department of

Preventive Medicine and HIV/AIDS Control, Ministry of Health.

2006. Results from the HIV/STI integrated biological and behavioural surveillance (IBBS) in VietNam, 2005-2006. Hanoi: Ministry of Health.

National Assembly of the Socialist Republic of Viet Nam. 2006. "Law on HIV/AIDS prevention and control, No. 64/2006/QH11," passed on 29 June.

National Committee for AIDS, Drug and Prostitution Prevention and Control (NCADP). 2004. The National Strategy on HIV/AIDS Prevention and Control in Vietnam until 2010 with a Vision to 2020. Hanoi.

National Institute of Public Health of Mexico (INSP). L.M. Anuar Luna and Ken Morrison, eds. 2004. Mo Kexteya: Reduction of Stigma and Discrimination Related to HIV/AIDS in Mexico. Mexico: National Institute of Public Health (INSP) of Mexico.

Quach, L. et al. 2005. "Knowledge, attitudes, and practices among physicians on HIV/AIDS in Quang Ninh, Vietnam," AIDS Patient CARE and STDs 19(5): 335-346.

Tanzania Stigma Indicators Field Testing Group 2005. "Working report, measuring HIV stigma: Results of a field test in Tanzania." Washington, DC: The Synergy Project.

The Socialist Republic of Vietnam. 2008. "The third country report on following up the implementation to the declaration of commitment on HIV and AIDS." Hanoi: Socialist Republic of Vietnam.

UNAIDS. 2001. "India: HIV and AIDS-related discrimination, stigmatization and denial," Best Practice Collection." Geneva: UNAIDS. 


\section{Appendix 1}

\section{Horizons/Population Council, ISDS, and ICRW Project "Safe and Friendly Hospital"}

\section{In-depth Interview Protocol for Hospital Patient (Baseline)}

1. Please tell me some information about your self?

- Age

- Education

- Occupation, work, income

- Marital status, children

2. Why did you go to this hospital?

- Referred? Who referred?

- Since when and how often do you come to the hospital?

- Who accompanies you?

3. What sort of medical services/care are you receiving here?

- In-patients

- Out-patient

- Surgical

- Counselling

\section{Admission}

4. What procedures have you been asked to follow as inpatient or outpatient in this hospital?

- Procedures

- Undue delays in admission or referred out often

- Asked for any tests or records?

- Payment (for registration/admission fee) 


\section{Hgrizons}

\section{Treatment (opinion on quality of care)}

5. In general, what has been your experience in getting the needed care in this hospital?

- Quality and timeliness of the care

- Experiences with doctors

- Experiences with nurses

- Experience with ward boys/ayahs/sweepers

- Hygiene/cleanliness

- Comfort of the facilities/wards

- Getting needed medications

- Meals

- Nursing care

- How is care provided to you (contact, gloves, etc)?

- How information about your health status, files etc have been handled?

- What has been the experience of your family/friends in this hospital?

- (For HIV+) Isolated or roomed-in

- (For HIV+) Any other examples

- (For HIV+) Why do you think this is?

- (For HIV+) Were/are you treated differently from other patients? How? Why do you feel that you are treated differently? How do you feel about it?

(For HIV+ patients) If there is any change, why do you think there is this change in care you receive?

- Hospital system in general

- Attitude of medical staff

- Fear, ignorance, over-cautious

- Can anything be done to change this

- Have you ever complained?

- If yes, to whom and where/ was anything done?

- If not, would you complain and bring this to the notice of higher authorities (or if there was a grievance cell)?

6. Were there any services that this hospital was unable to provide you?

- What services?

- What reasons were you given for not giving you services?

- What were you asked to do? 


\section{Testing \& Counseling}

7. Were you asked to get any diagnostic tests done?

- What were these tests?

- From the hospital

- Outside this hospital

- Were you explained why the tests were required and what would be the outcome of these?

- Did you undergo these tests and what happened after that?

8. Were you ever tested for HIV while seeking care at this hospital?

- Were you aware at the time that an HIV test was performed? What reasons were given to you for testing HIV?

- Had you ever been tested before elsewhere for HIV?

- Were those results accepted by this hospital, or were you asked to be tested again?

9. When you were tested for HIV in this hospital were you given any counselling before that?

- Who counselled you?

- Where were you counselled?

- Was there anybody else/ all alone/ with accompanying members? Who?

- What did they discuss?

- Do you need to know anything more?

10. Were you asked to give consent specifically for the HIV test?

- Who asked?

- In writing or verbal?

- Did you feel you could choose not to test? Why (not)?

\section{Where was the blood drawn for HIV test?}

- In the laboratory of the hospital

- Lab outside the hospital

- Bedside

- Any other..?

\section{How was the result shared with you?}

- How long did you have to wait before learning the results?

- Who told you?

- Where were you? Was there anyone else with you - family, friends etc.?

- Who else was told? Who was told first? How did you feel about that?

- What kind of information

- What support were you given?

- Have you yourself told anyone else about the results of your test?

- Have you been encouraged to inform anyone else about your status? Who has encouraged and to whom?

- Were you informed of any future care services that you need to avail, either services here at the hospital or elsewhere? 


\section{Hgrizons}

13. In this hospital, who all know of your HIV status?

- Who knows? How can you tell?

- Who do you feel should not know of your HIV status in this hospital? Why?

- Is confidentiality about this important to you?

- How do you think that they got to know?

14. In general, how do you feel about the way testing was handled?

\section{Care}

15. What things have you had to pay for in connection to seeking care at this hospital? (What was the approximate cost? You may even include things that will be covered by insurance).

For both non-HIV and HIV patients

- Medicines (For OB/GYN Patients: Medication for Prevention of Mother to Child Transmission? Breast Milk Substitutes?)

- Tests

- Surgical procedures/deliveries etc.

\section{For HIV patients}

- $\quad$ HIV test

- Actual services and procedures

- "AIDS Kit" for surgery or delivery

- Other supplies for "barrier nursing" etc, e.g. gloves.

16. Have you been referred to/told about any other services for HIV? Where have you been referred?

- NGOs

- Other hospitals

17. Will you come back here in the future if you need care?

- Why/Why not?

- Does the client have access to any other sources of care? 


\section{Appendix 2 \\ Horizons/Population Council, ISDS, and ICRW Project "Safe and Friendly hospital"}

\section{In-depth Interview Protocol for Hospital Patient (Endline)}

\section{Information background}

- Age

- Where do you live

- Education level

- Occupation, income sources

- Marital status

- HIV positive status: why testing? Where? When? Voluntary testing or not, your testing result kept secret or not? How did you feel when know your testing result? How does family/neighbour/medical worker treat with patients when they know this patient got HIV? Stigma and discrimination against PLWHA.

2. Why did you go to this hospital?

- Referred? Who referred?

- Since when and how often do you come to the hospital?

- Who accompanies you?

\section{Experience this time at the hospital}

Recode the story from be introduced to this hospital to the interview time (if patient still at stay at the hospital) or at the time when the patient came out of hospital (if patient already out of the hospital.

- Do health workers know patients HIV status? Who knows? Why they know?

- If patient tested HIV at this hospital:

- How the testing took place (voluntary or mandatory, counsel before and after testing)

- The confidentiality, who know testing result? Who informed? How did it take place?

- How was medical health worker's attitude with patients and their family (doctors, nurses, ward staffs, staffs at canteen, security wards, technicians, cashiers ...)-compare with non- HIV patients.

- What are other patient's attitude and their families' attitude?

- Did you must wait for long time to get the services? Compare with non- HIV patients.

- Have the patients ever refused received services? What kind of services? How did it take place? Did the medical worker explain to the patients?

- Precaution (gloves, mass,....) that medical workers use when take care patients- compare with non-HIV patients

- All tests be required patients to do-compare with non- HIV patients

- Money to pay - compare with non- HIV patients

- The quality of services - compare with non- HIV patients

- Discrimination signs: clothes, bed, mark patient's file, mark patient's bed... 


\section{Hgrizons}

- Who/What services /What did you feel most comfortable in this hospital? Most uncomfortable? Why?

- How do the way medical workers and other patient treated affect to the patients? How do its affect to patient's family?

- Is there any right or wrong of the ways medical workers or other patients treat patients and their family? Why?

\section{Reduce stigma strategy}

- What did patients and their family do to reduce stigma and discrimination in hospital? Or to feel more comfortable? (give money, reaction, comment ...) Have patients and their family ever commented with hospital when feel unfair? What did it take place?

\section{The endeavours of hospital to reduce HIV transmission in the hospital?}

Through patient's observation:

- Hospital provides information related to HIV for patients come to the hospital?

- What did hospital do to reduce HIV transmission in the hospital?

5. The endeavours of hospital to reduce stigma and discrimination against HIV + patients in the hospital?

Through patient's observation:

- What did hospital do to reduce stigma and discrimination against HIV + patients from medical workers in the hospital?

- What did hospital do to reduce stigma and discrimination against HIV + patients from other patients?

\section{Comments of patients about the services at this hospital}

- Evaluations of patients about the services at this hospital (attitudes, quality of services...). Why do you have these evaluations?

- In the future, if you get the same disease, would you come back to this facility? Why? 


\section{Appendix 3 \\ Horizons, ISDS, and ICRW \\ Improving the Hospital Environment for PLHA in Vietnam DRAFT In-depth Interview protocol}

Gender: M/F

Education (exact):

Total number of years in service:

Years of employment in this hospital:

Department/ward:

Tenure in current department/ward:

Designation:

Date of Interview:

Time of Interview:

Name of Contact Person \& Designation:

Name of Interviewer:

Name of Recorder:

Transcription done on:

Checked on: 


\section{Hgrizons}

1. What activities do you perform as a part of daily work routine?

\section{Risk Perception}

2. Do you think that health care workers are at risk of infection during service delivery?

- $\mathrm{Yes} / \mathrm{No}$

- Why do you think so?

3. How do you feel while caring for patients with infectious diseases?

- Is the threat the same for Hep B as for HIV?

- Given a choice would you like to refuse to care or change duties for HIV positive because of this fear?

4. How could HIV be spread in the hospital setting?

- $\quad$ From patient to patient?

- $\quad$ From HCW to patient?

After the nurse answers, probe specifically with regard to:

- $\quad$ blood splash/spill

- $\quad$ body fluid on intact skin? If yes, ask which body fluids?

- $\quad$ Respiratory transmission?

\section{General Background}

5. How many HIV patients, on average, are treated in this hospital/department in a month?

- out-patients

- in-patients

6. Do you personally care for patients with HIV/AIDS?

IF YES,

- $\quad$ how many in the last one month?

- $\quad$ What kind of care do you provide? (Bathing, bedpan, IV, injections, feeding, bandaging, etc)

7. What is the department's practice in admitting patients who are HIV positive?

8. Can you tell us something about any hospital (or department-specific) written policy (regulations, guidelines) with regard to admission of HIV patients?

IF YES,

- $\quad$ Do you think such a policy is required and is appropriate?

- $\quad$ Any constraints in following this policy? 


\section{Infection Control}

9. What precautions do you generally take to protect yourself against infectious disease?

- Do you take any precautions for patients with no known communicable diseases?

- What precautions do you take for Hep B \& other blood-borne diseases?

- Do you do anything different if you know the patient is HIV positive?

10. Do you feel that the precautions you take are adequate to protect you from infection?

- Why/why not?

- What are your concerns/doubts?

\section{Could you tell us something about UP?}

- Are you able to follow them?

12. Do you know of any written policy (guidelines) on universal precautions in this hospital/department?

- How did you come to know of it?

- Any manual on UP provided to you?

- Are there are some aspects of this policy that are not easy to implement/follow? Elaborate.

13. Would you like to a general hospital policy on universal precautions for all patients or specific precautions for HIV positive patients only?

14. Do you know of any colleague/HCW who has had a needle stick injury?

- $\mathrm{Yes} / \mathrm{No}$

If it happens to you

If yes, elaborate

- Are you at risk of contracting any infection

- from general patient?

- from infectious patient?

- from HIV positive patient?

- What steps would you take after the accident?

- Are you able to get timely assistance in the event of such an accident? From where? Any constraints in accessing it?

15. Could you tell us if there is a written policy (guidelines) for post-exposure prophylaxis for HIV in the hospital? 


\section{Hgrizons}

\section{Testing \& Diagnosis}

16. On what basis do you recommend a patient to go for an HIV Test?

-Where is the test conducted

-Where is the blood drawn

17. What do you do if a patient produces test results from another hospital or lab?

-If the test is positive

- If it is negative

18. Do you necessarily inform patients about their blood being tested for HIV?

-Is consent taken, written/verbal

-Under what circumstances (if any) would an HIV test be conducted without the patient's knowledge?

19. What is the general procedure followed when a patient refuses to get tested for HIV?

20. Are you aware of any hospital/department written policy (guidelines) with respect to HIV testing?

IF YES:

- What are the elements of the policy - mandatory/routine/selective/voluntary testing?

- Do you agree with the policy? If no, why not? What would you suggest to change/improve it?

- Do you face any constraints in implementing this policy? What are those?

IF NO:

- Do you think there should be a formal policy?

- If yes, what are some of the elements that should be included?

\section{Counseling}

21. Are all patients who are tested for HIV also given pre-test counseling?

- What information given to patient?

- By whom?

- Have you ever provided any pre-test counseling?

- IF YES, what are the elements of the counseling you provide? 
22. In general, how are test results handled?

- Who is the first person to receive the result (among the hospital staff) and from whom?

- Are the patients informed of the result? Always? By whom?

- Are there circumstances under which the patient would not be informed of the results? Elaborate.

23. If the test comes back negative, what are the next steps?

- Inform patient of negative result?

- Test again?

- Counseling? Who provides it?

24. If the HIV test comes back positive, what are the next steps?

- Who is informed first?

- Who tells the family or caretaker? Is family informed only after patient's permission?

- Is any counseling provided - by whom, when?

- Is any treatment recommended - where and by whom?

- Referrals to other departments, hospitals, community clinics, NGOs?

\section{Records and Confidentiality}

25. How is the patient's positive test result recorded/maintained?

- Where is it recorded?

- Who is responsible for recording it and maintaining the records/files?

23. In the hospital, who all knows that the patient is HIV positive?

- Why is it essential for all of these staff to know the status? Is it appropriate?

- Do other patients know the patient's status?

- How is this information communicated - written, verbal, cues, etc

24. Is there a written hospital policy regarding confidentiality of HIV status?

IF YES:

- What are the elements of that policy?

- Do you agree with the policy? If not, what would you suggest to change/improve it?

IF NO:

- In your opinion, should there be a formal policy?

\section{Care of HIV Positive Patients}

25. Do you face any constraints in providing nursing care for HIV positive patients in the way that you would like?

- What constraints? Why? 


\section{Hgrizons}

\section{Attitudes \& Fears}

26. Are you concerned about treating HIV patients?

IF YES:

- Why? What are the concerns?

- How would you explain/justify these concerns?

- What would you suggest to allay these concerns?

27. In your opinion, how do you think care should be provided to HIV positive patients?

- Where? (public/private hospitals, separate wards/clinics, mainstreamed/integrated?)

- By whom? (specially trained doctors, community, family?)

28. Are there any changes you or your colleagues would like to see to improve the care of HIV positive patients in this department/hospital?

\section{Training}

29. Have you received training in any of the following HIV-related areas?

- Universal precautions

- Post-exposure prophylaxis

- $\quad$ Testing and counseling

- Clinical/case management

For each area, list the following:

- Approximate date

- Duration

- Who sponsored the training? (part of nursing school, provided by hospital, outside agency, etc.)

- Satisfaction with quality or extent

30. What areas would you like to receive more training in?

31. Is there anything you would like to add on the subjects we have discussed? 


\section{Appendix 4 \\ Improving the Hospital Environment in Vietnam HEALTH WORKER SURVEY 2006}

Thank you for completing this survey. The information obtained in this study will be used to offer practical guidelines to hospitals and hospital staff who provide care for people living with HIV/AIDS, so that needs of both hospital staff and patients are met. Your name will not be on the survey, so please answer honestly.

Please circle the answer that best represents what you think or feel or write in the answer.

Please choose only one answer for each question, unless there is a note that multiple answers are possible.

Example 1: $\quad$ Is smoking bad for your health?
1) Yes
3) Don't know

Example 2: $\quad$ How old are you?

[26] years old

First we will ask about your background.

\section{Are you female or male?}
1) Female
2) Male

2. How old are you?

[__ ] years old

\section{What is your educational level?}
1) Post-Graduate
2) University graduate
3) College
4) Post-high school
5) Completed high school
6) Not yet completed high school 


\section{Hgrizons}

4. What is your trained occupation?

1) Doctor

2) Nurse

3) Pharmacist

4) Medical Technician

5) Other technician

6) Auxiliary nurse (ward staff)

7) Accountant, cashier...

9) Other (specify)......

10) Have never been trained for any occupation

\section{What is your current title/position?}

Choose one most appropriate answer.
1) Manager (hospital, department)
2) Physician
3) Clinical nurse
4) Administrative nurse (in the clinical department or laboratory)
5) Pharmacist
6) Technician/lab staff
7) Auxiliary nurse/ward staff
8) Other admin staff
9) Other (specify)

6. How many years have you been working at this facility?

[__ ] years

\section{What department/ward do you currently work in?}
1) AIDS Department
2) Clinical department
3) Intensive care department
4) Screening/outpatient department
5) Nursing department
6) Infection control
7) Nutrition
8) Pharmacy
9) $\mathrm{Lab}$

10) Imaginary diagnosis department

11) Planning

12) Admin - Human resource

13) Accounting

14) Special department

15) Other (specify).... 
Now we will ask about some of your opinions related to HIV and TB.

8. Which of the following bodily fluids have a high enough concentration of HIV to transmit the virus?
A. Semen
1) Yes
2) No
3) Don't Know
B. Blood
1) Yes
2) No
3) Don't Know
C. Vaginal fluid
1) Yes
2) $\mathrm{No}$
3) Don't Know
D. Breast milk
1) Yes
2) $\mathrm{No}$
3) Don't Know
E. Saliva
1) Yes
2) No
3) Don't Know

F. Sweat

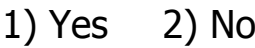

3) Don't Know

G. Tears

1) Yes

2) $\mathrm{No}$

3) Don't Know

$\mathrm{H}$. Urine

1) Yes

2) $\mathrm{No}$

3) Don't Know

I. Other bodily fluids containing blood
1) Yes
2) No
3) Don't Know

9. In comparison to HIV, which of the following infections is more difficult or easier to be transmitted from patient to hospital worker?
A. Hep B
1) Easier
2) More difficult
3) The same
4) Don't know
B. Hep C
1) Easier
2) More difficult
3) The same
4) Don't know
C. TB
1) Easier
2) More difficult
3) The same
4) Don't know

10. Is it required to wear latex gloves whenever performing ANY task related to taking care of a patient who might be HIV positive?
1) Yes
2) No
3) Don't know

11. Is there a risk of getting HIV from handling soiled linens?
1) Yes
2) No
3) Don't know
4) Other (specify) ..........

12. Is there a risk of getting HIV from a needle prick?
1) Yes
2) $\mathrm{No}$
3) Don't know
4) Other (specify) 
13. Is there a risk of getting HIV from touching the skin of a person with HIV?
1) Yes
2) No
3) Don't know
4) Other (specify).............

14. Can HIV be transmitted from a mother to her baby?
1) Yes
2) No
3) Don't know
4) Other (specify)

15. Can HIV be transmitted through sex without a condom?
1) Yes
2) No
3) Don't know
4) Other (specify).............

16. Can HIV be transmitted through a mosquito bite?
1) Yes
2) No
3) Don't know
4) Other (specify)

17. Can HIV be cured?
1) Yes
2) No
3) Don't know
4) Other (specify)..........

19. Can AIDS be treated?
1) Yes
2) No
3) Don't know
4) Other (specify)........... 
19. In response to the following situations, please tell me if you have a lot fear of HIV transmission, a little fear of HIV transmission, or no fear of HIV transmission. Answer the question thinking about when you are NOT wearing gloves or other protection.

A. Touching the saliva of a person with HIV or AIDS
1) A lot of fear
2) A little fear
3) No fear

B. Touching the sweat of a person with HIV or AIDS
1) A lot of fear
2) A little fear
3) No fear

C. Taking blood samples from a person with HIV or AIDS
1) A lot of fear
2) A little fear
3) No fear
4) Not relating to my work

D. Removing the used needle from a syringe after attending a person with HIV or AIDS
1) A lot of fear
2) A little fear
3) No fear
4) Not relating to my work

E. Conducting an invasive procedure on a person with HIV or AIDS
1) A lot of fear
2) A little fear
3) No fear
4) Not relating to my work

F. Sharing eating utensils with a person with HIV or AIDS
1) A lot of fear
2) A little fear
3) No fear
4) Not relating to my work

G. Putting an IV drip in a person with HIV or AIDS
1) A lot of fear
2) A little fear
3) No fear
4) Not relating to my work 
H. Taking the blood pressure of a person with HIV or AIDS
1) A lot of fear
2) A little fear
3) No fear
4) Not relating to my work

I. Changing the bed pan of a person with HIV or AIDS
1) A lot of fear
2) A little fear
3) No fear
4) Not relating to my work

J. Changing the clothes of a person with HIV or AIDS
1) A lot of fear
2) A little fear
3) No fear

K. Serving food to a person with HIV
1) A lot of fear
2) A little fear
3) No fear

\section{Touch skin of a person with HIV (alive or dead)}
1) A lot of fear
2) A little fear
3) No fear
4) Not relating to my work

20. If you have any fears, do these fears affect your interaction with patients with HIV or AIDS?

1) Yes

2) No (skip question 21, continue to question 22)

21. If yes, do these fears affect your interaction with patients with HIV or AIDS in any of the following ways?

You may circle multiple answers

1) You avoid contact completely with HIV-positive patients

2) You do not touch patients with HIV

3) You wear gloves at all time with HIV+ patients

4) You wear mask at all times with HIV-positive patients

5) You wear goggles' at all times with HIV-positive patients

6) Other (please specify) 
22. Do you know about what percent (\%) of patients come to this hospital were HIV positive last year?

1) [_ ] percent (\%)

2) Don't know

23. Do you know of any HIV positive patients among those you come in contact every day?
1) Yes
2) No

Next these questions are about TB.

24. Can TB be transmitted through sex without a condom?
1) Yes
2) No
3) Don't know

25. Can TB be cured?
1) Yes
2) No
3) Don't know

26. Can TB be transmitted from a mother to her baby?
1) Yes
2) No
3) Don't know

27. Can TB be transmitted by sharing eating utensils with a person with TB?
1) Yes
2) No
3) Don't know

28. Is TB a genetic disease that runs in families?
1) Yes
2) No
3) Don't know

Now we will ask about opinions related to people with HIV or AIDS. 
29. Society reacts and behaves in various ways towards people with HIV or AIDS or people suspected of having HIV. Please state whether you find the following reactions/ behavior towards people with HIV or AIDS reasonable, you're not sure, or unreasonable.

A. Divorce/leave a husband/partner because has HIV or AIDS
1) Reasonable
2) Unreasonable
3) Not sure

B. On learning that someone is HIV positive, asking the person, or someone close to them how the person got infected
1) Reasonable
2) Unreasonable
3) Not sure

C. Discussing how a person got HIV or AIDS with others in the absence of the person
1) Reasonable
2) Unreasonable
3) Not sure

D. No longer inviting a person with HIV or AIDS to social events, like weddings
1) Reasonable
2) Unreasonable
3) Not sure

E. Limiting participation of people with HIV or AIDS in community activities
1) Reasonable
2) Unreasonable
3) Not sure

F. Not allowing a child to play with another child who has HIV or AIDS
1) Reasonable
2) Unreasonable
3) Not sure

G. Assigning specific utensils for a person with HIV or AIDS
1) Reasonable
2) Unreasonable
3) Not sure

H. Avoiding using something touched by a person with HIV or AIDS
1) Reasonable
2) Unreasonable
3) Not sure 
I. Refusing to share a toilet with a person with HIV or AIDS
1) Reasonable
2) Unreasonable
3) Not sure

J. Divorce/leave a wife/partner because has HIV or AIDS
1) Reasonable
2) Unreasonable
3) Not sure

K. Refusing to rent a room to a person with HIV or AIDS
1) Reasonable
2) Unreasonable
3) Not sure

30. If a hospital worker learns that he/she is HIV positive, but is not showing symptoms of AIDS, would you want:

1) It remains the person's secret

2) It remains a family secret

3) Other staff in the hospital know

4) Patients know

5) Not sure

6) Don't know

31. What is the reason(s) for your response? Please write your answer below.

32. If a member of your family got infected with HIV, but is not showing any symptoms of AIDS, would you want:
1) It remains the person's secret
2) It remains a family secret
3) Other people know
4) Not sure
5) Don't know 
33. What is the reason(s) for your response? Please write your answer below.

34. Do you agree or disagree with the following statements:

A. It is the women prostitutes that spread HIV

1) Agree

2) Disagree

3) Do not agree or disagree

B. It is the drug users that spread HIV
1) Agree
2) Disagree
3) Do not agree or disagree

C. It is promiscuous men that spread HIV in our community
1) Agree
2) Disagree
3) Do not agree or disagree

D. People with HIV or AIDS deserve sympathy
1) Agree
2) Disagree
3) Do not agree or disagree

E. HIV/AIDS is a punishment for bad behavior
1) Agree
2) Disagree
3) Do not agree or disagree

F. People with HIV or AIDS should be ashamed of themselves
1) Agree
2) Disagree
3) Do not agree or disagree 
G. I would attend a social event (wedding, festival...) even if I know someone with HIV or AIDS will attend
1) Agree
2) Disagree
3) Do not agree or disagree

I. People with HIV or AIDS should be treated the same as people without HIV or AIDS
1) Agree
2) Disagree
3) Do not agree or disagree

J. I would be ashamed if someone in my family had HIV or AIDS
1) Agree
2) Disagree
3) Do not agree or disagree

K. People with HIV or AIDS should be allowed to fully participate in social events
1) Agree
2) Disagree
3) Do not agree or disagree

L. People with HIV or AIDS are promiscuous
1) Agree
2) Disagree
3) Do not agree or disagree

M. It is someone's fate to have HIV
1) Agree
2) Disagree
3) Do not agree or disagree

N. I would feel ashamed if I was infected with HIV
1) Agree
2) Disagree
3) Do not agree or disagree

0. Women with HIV should be allowed to have children if they wish
1) Agree
2) Disagree
3) Do not agree or disagree

P. People with HIV should not be allowed to get married
1) Agree
2) Disagree
3) Do not agree or disagree 
Q. People with HIV have the right to tell no-one, except their doctor, about their HIV status

1) Agree

2) Disagree

3) Do not agree or disagree

R. Children with HIV should not be allowed to study with non-infected children
1) Agree
2) Disagree
3) Do not agree or disagree

S. I would be afraid to tell anyone if I had HIV
1) Agree
2) Disagree
3) Do not agree or disagree

Now we will ask you questions about typical practices at this hospital.

35. In this hospital, which kinds of patients are generally tested for HIV?

You may circle multiple answers
A. Injecting Drug Users
B. Medical IV Drug/blood user
C. Pregnant women
D. Sex workers
E. Homosexuals
F. Truck drivers
G. Spouse Positive
H. STD patients
I. People living in urban areas
J. Young and middle age people
K. Voluntary clients
L. Other (please specify)
M. I don't know 
36. In your hospital, is HIV testing routinely required for any of the following procedures?
A. Major surgery
1) Yes
2) No
3) Don't know

B. Minor surgery (such as those that require suturing skin incision)
1) Yes
2) No
3) Don't know

C. Other invasive procedures (such as: Drain liquid from the spinal column; Biopsy)
1) Yes
2) No
3) Don't know

D. Bronchoscopy
1) Yes
2) No
3) Don't know

E. General exam
1) Yes
2) No
3) Don't know

37. How many cases have you done and/or assisted with in the last four weeks that involve conducting invasive procedures?
1) [__ Cases
2) Don't know
3) I have never done this (skip question 38, continue with question 39)

38. How many of these cases were tested for HIV?
1) None
2) All
3) Most
4) Some
5) Don't know 
39. In your hospital, are invasive procedures deferred until sero-status is determined through testing?
1) Yes, always deferred
2) Yes, if patient is in a "high risk" group
3) Yes, if patient has symptoms of HIV/AIDS
4) No
5) Don't know

40. In your own opinion, is it necessary to test all patients at the hospital for HIV?
1) Yes
2) $\mathrm{No}$
3) No opinion

41. Do you know of any policies in your hospital in regards to HIV testing?
1) Yes
2) No
3) Don't know

If you do know, please briefly summarize the policy

42. In your hospital, does a patient's HIV status get known to hospital staff in any of the following ways?

A. From general rumors/gossip
1) Yes
2) No
3) Don't know

B. From the HIV+ person's family
1) Yes
2) No
3) Don't know

C. From the HIV+ person's employer
1) Yes
2) No
3) Don't know

D. From the HIV+ person's friends/neighbors
1) Yes
2) No
3) Don't know 
E. From the facility where the person got tested

1) Yes

2) No

3) Don't know

F. From the patient's file, which includes HIV test results

1) Yes

2) No

3) Don't know

G. From patient's file because it is marked
1) Yes
2) No
3) Don't know

H. From the ward that patient stays as they are in the separate places

1) Yes

2) No

3) Don't know

I. Responsible nurse/doctor informs involved staff
1) Yes
2) No
3) Don't know

J. Head of the department informs all staff in the department

1) Yes

2) No

3) Don't know

K. The person with HIV person discloses his/her status
1) Yes
2) No
3) Don't know

L. From the referral documents by the referring facility
1) Yes
2) No
3) Don't know 


\section{Hgrizons}

43. Have you ever come in contact with a person that you know for sure as having HIV?

Multiple answers are possible:

A. Yes, in the hospital

B. Yes, in the community

C. No, not to my knowledge

D. Don't know

44. Which are common ways for you to find out that there is an HIV/AIDS patient in the ward?

You may circle multiple answers
A. Doctors tell us
B. Counselors tell us
C. Nurses tell us
D. Staff of the clinical management office inform us
E. By marking on files
F. By test result in the files
G. By locations of beds
H. Bed signs
I. As patient's stuff have special signs
J. Other (please specify)

45. When a patient is tested for HIV, who among the following staff regularly become informed of the results?

You may circle multiple answers
A. Head of Department
B. Treating Doctor
C. Ward nurse
D. Head of the clinical management office
E. Counselor
F. Sister nurse
G. All hospital staff
H. Auxiliary nurse (ward staff)
I. Guard
J. Other (please specify)
K. Don't know 
46. When you yourself find out that a given patient is HIV positive, do you inform other staff always, sometimes, or never?

1) Always inform

2) Sometimes inform

3) Never inform (skip question 47, continue with question 48)

4) I have never found this out (skip question 47, continue with question 48)

47. Which staff do you generally inform?
A. All staff in the department
B. Head of Department
C. Treating Doctor
D. Ward nurse
E. Head of the clinical management office
F. Sister nurse
G. All hospital staff
H. Auxiliary nurse (ward staff)
I. Guard
J. Other (please specify)

48. How often do you inform relatives about the HIV status of an HIV positive patient?
1) Always inform
2) Sometimes inform
3) Never inform
4) Don't know

49. Do hospital workers have a right to know the HIV status of all patients?
1) Yes
2) No
3) Don't Know

50. In this hospital, are HIV positive patients separated from other patients?
1) Yes, always
2) Yes, sometimes
3) No
4) Don't know

51. Are any signs put on the beds of patients to indicate that they are HIV positive?
1) Yes
2) $\mathrm{No}$
3) Don't know

52. Are there labels on the outside of files that indicate a patient is HIV positive?

1) Yes

2) No

3) Don't know 
53. With patients whose HIV status you don't know, do you generally wear gloves for the following tasks: always, sometimes, or never?

\section{A. External examination}
1) Always
2) Sometimes
3) Never
4) Not applicable

B. Doing surgery for assisting a surgery
1) Always
2) Sometimes
3) Never
4) Not applicable

C. Doing an invasive procedure (biopsy, draining body liquids...)
1) Always
2) Sometimes
3) Never
4) Not applicable

D. Giving injections
1) Always
2) Sometimes
3) Never
4) Not applicable

\section{E. Giving medicine}
1) Always
2) Sometimes
3) Never
4) Not applicable

\section{F. Dressing wounds}
1) Always
2) Sometimes
3) Never
4) Not applicable

\section{G. Starting an IV}
1) Always
2) Sometimes
3) Never
4) Not applicable 


\section{H. Sponging a patient}
1) Always
2) Sometimes
3) Never
4) Not applicable

\section{K. Drawing blood for a test}
1) Always
2) Sometimes
3) Never
4) Not applicable

L. Handling used and dried linen
1) Always
2) Sometimes
3) Never
4) Not applicable

\section{Cleaning blood stains}
1) Always
2) Sometimes
3) Never
4) Not applicable

\section{N. Transporting patients}
1) Always
2) Sometimes
3) Never
4) Not applicable

O. Handing over food to patient
1) Always
2) Sometimes
3) Never
4) Not applicable

\section{P. Sorting out wastes}
1) Always
2) Sometimes
3) Never
4) Not applicable 
Q. Handling blood-soaked linen
1) Always
2) Sometimes
3) Never
4) Not applicable

\section{R. Transporting samples}
1) Always
2) Sometimes
3) Never
4) Not applicable

54. If you don't always use gloves for procedures like dressing wounds or starting IVs, why is it that you don't always wear gloves?

\section{You may circle multiple answers}
1) Out of stock
2) Uncomfortable
3) Difficult to work with
4) Feel it is not necessary
5) Instructed by hospital staff not to
6) No reason
7) No time to put them on
8) Other (please specify)

55. How often do you wear gloves for the following procedures when you know the patient is HIV positive: always, sometimes or never?

\section{A. External examination}
1) Always
2) Sometimes
3) Never
4) Not applicable

B. Doing surgery for assisting a surgery
1) Always
2) Sometimes
3) Never
4) Not applicable

C. Doing an invasive procedure (biopsy, draining body liquids...)
1) Always
2) Sometimes
3) Never
4) Not applicable 


\section{Giving injections}
1) Always
2) Sometimes
3) Never
4) Not applicable

E. Giving medicine
1) Always
2) Sometimes
3) Never
4) Not applicable

\section{F. Dressing wounds}

1) Always

2) Sometimes

3) Never

4) Not applicable

\section{G. Starting an IV}
1) Always
2) Sometimes
3) Never
4) Not applicable

H. Sponging a patient
1) Always
2) Sometimes
3) Never
4) Not applicable

K. Drawing blood for a test
1) Always
2) Sometimes
3) Never
4) Not applicable

\section{Handling used and dried linen}
1) Always
2) Sometimes
3) Never
4) Not applicable 


\section{Hgrizons}

M. Cleaning blood stains

1) Always

2) Sometimes

3) Never

4) Not applicable

N. Transporting patients
1) Always
2) Sometimes
3) Never
4) Not applicable

O. Handing over food to patient
1) Always
2) Sometimes
3) Never
4) Not applicable

P. Sorting out wastes
1) Always
2) Sometimes
3) Never
4) Not applicable

Q. Handling blood-soaked linen
1) Always
2) Sometimes
3) Never
4) Not applicable

R. Transporting samples
1) Always
2) Sometimes
3) Never
4) Not applicable 
56. Think back to the last time you assisted/performed surgery or an invasive procedure on someone known to be HIV negative, what kind of barrier precautions did you use?

You may circle multiple answers
A. My job does not involve such procedures
B. Single gloves
C. Double gloves
D. Aprons
E. Masks
F. Gowns
G. Boots
H. Goggles
I. Washing hands before the procedure
J. Washing hands after the procedure

57. Think back to the last time you assisted/performed surgery or an invasive procedure on someone known to be HIV positive, what kind of barrier precautions did you use?

You may circle multiple answers
A. My job does not involve such procedures
B. Single gloves
C. Double gloves
D. Aprons
E. Masks
F. Gowns
G. Boots
H. Goggles
I. Washing hands before the procedure
J. Washing hands after the procedure 
58. What steps would you take if you were to get stuck by a needle from a patient if you did not know whether or not the patient was HIV-positive?

You may circle multiple answers
A. Wash with water/soap
B. Clean wound with antiseptic
C. Squeeze/Bleed Wound
D. Dress the wound
E. Report to Head Doctor
F. Fill the reporting form
G. Other (Specify)
H. Don't know what to do

59. Do you have medication to take if exposed to blood at the hospital to reduce the chances that you will become HIV positive (also called Post-Exposure Prophylaxis (PEP))?
1) Yes
2) No
3) Don't know

60. Under what circumstances should a health care worker seek Post-Exposure Prophylaxis (PEP)?

You may circle multiple answers
A. Any needle Stick injury
B. Any cut Blood contact with mucous membrane/non-intact skin
C. Needle Stick Injury from an HIV positive patient
D. Needle stick injury by a large bore needle after using for a HIV+ patient
E. Injury by an instrument after using for a patient who have full-blown AIDS
F. I don't know

61. In the last 12 months, have you been stuck with a needle or splashed with blood on non-intact skin from an HIV positive patient?
1) Yes
2) No (skip question 62, continue with question 63)

\section{2. [If yes] Did you seek PEP?}
1) Yes
2) No, because not needed
3) No, because not available
4) No, because I didn't know that I should seek treatment 
63. What steps do you usually take in disposing a needle after its use?

You may circle multiple answers
A. My job has nothing to do with needle
B. Separate from syringe
C. Recap with one hand only
D. Recap with 2 hands
E. Dispose in PPC
F. Put in needle destroyer
G. Throw away in plastic bag
H. Bend/break on hard surface
I. Other (Specify)

64. In general, in the last 6 months if there is a shortage of gloves, how quickly do new gloves arrive?

1) My work has nothing to do with gloves

2) The next day

3) More than the next day but within a few days

4) Within a week

5) Within a month

6) There have never been enough gloves in last 6 months

7) There have never been out of stock for gloves in last 6 months

65. When you would like to wash your hands, are there always clean running water and soap near the place you work?

1) Yes, always available

2) Sometimes yes, sometimes no

3) I clean my hands by a disinfectant solution

4) No

66. What do you think the likelihood is of a hospital worker being infected with HIV while they are working in this hospital? Would you say...

1) Highly likely

2) Somewhat likely

3) Not likely at all (skip question 67, continue with question 68) 
67. In your opinion, what are the causes for the likelihood of being infected for workers in this hospital?

You can circle multiple answers
A. Because there are many patients with HIV
B. Not enough gloves
C. Not enough other protective equipments/supplies
D. Not enough clean running water to wash hands
E. Hospital workers don't know how to prevent transmission
F. Not enough PEP
G. Patient intentionally transmit the virus
H. Other (specify)...........
I. Don't know

68. In your opinion, what should be done to prevent HIV transmission to workers of this hospital?

You can circle multiple answers
A. Supply enough gloves
B. Test every patient for HIV
C. Wear special protection when contact with HIV patients
D. Have enough clean running water to wash hands
E. Inform all hospital workers about those patients who have HIV
F. Supply enough PEP
G. Do not accept HIV patients
$\mathrm{H}$. Assume that every patient has HIV and always take cautions
I. Other (specify)............
J. Don't know

69. Do people in this hospital behave differently toward or treat people living with HIV or AIDS differently than people without HIV or AIDS?
1) Yes
2) No
3) Don't know

70. In the past 6 months, how many times have you observed any of the following at the hospital:

A. A patient with HIV or AIDS waited longer to be attended to because a provider did not want to treat a person with HIV or AIDS.
1) Yes, many times
2) Yes, few times
3) Yes, once
4) Never 
B. An HIV + patient being unnecessarily referred on to another provider or another facility because the provider did not want to treat a person with HIV.
1) Yes, many times
2) Yes, few times
3) Yes, once
4) Never

C. A patient being denied treatment because they were known or suspected to have HIV.
1) Yes, many times
2) Yes, few times
3) Yes, once
4) Never

D. Testing a patient for HIV without their consent.
1) Yes, many times
2) Yes, few times
3) Yes, once
4) Never

E. A senior health provider passing a patient to a junior provider because the patient is HIV-positive.
1) Yes, many times
2) Yes, few times
3) Yes, once
4) Never

F. A health provider disclosing a patient's HIV status to their family without the patient's consent.
1) Yes, many times
2) Yes, few times
3) Yes, once
4) Never

G. Health providers gossiping about a patient's HIV status.
1) Yes, many times
2) Yes, few times
3) Yes, once
4) Never

H. A provider scolding or blaming a client for having HIV infection.
1) Yes, many times
2) Yes, few times
3) Yes, once
4) Never 
I. A provider not having bed pans or bed clothes changed as often for patients with HIV compared to other patients.

1) Yes, many times

2) Yes, few times

3) Yes, once

4) Never

J. Health worker inform other patients about a patient's HIV status

1) Yes, many times

2) Yes, few times

3) Yes, once

4) Never

71. If yes to any of the examples, did any hospital staff react to this by indicating that they did or did not agree with this behavior?

1) Yes

2) No

3) Don't know

72. If yes, what happened? Please describe what happened below.

Date of the data collection

ID of the questionnaire [

ID of the hospital

A. Quang Ninh TB hospital

B. Hai Phong TB hospital

Field supervisor:

Office supervisor:

Data entry by: 


\section{Appendix 5 \\ STIGMA Vietnam PLHA Survey \\ 2006}

\begin{tabular}{|c|c|c|c|c|}
\hline \multicolumn{5}{|c|}{ SECTION 1; BACKGROUND INFORMATION } \\
\hline \multirow{3}{*}{$\frac{\text { No. }}{101}$} & QUESTIONS AND FILTERS & CODING CATEGORIES & & SKIP \\
\hline & \multirow[t]{2}{*}{ [RECORD TIME INTERVIEW BEGINS] } & HOUR & [___ $]$ & \\
\hline & & MINUTES & [___ $]$ & \\
\hline \multirow[t]{2}{*}{102} & \multirow[t]{2}{*}{ [RECORD SEX OF RESPONDENT] } & Female & 01 & \\
\hline & & Male & 02 & \\
\hline \multirow[t]{2}{*}{103} & \multirow[t]{2}{*}{ [RECORD AGE OF RESPONDENT] } & Age in years & [___ $]$ & \\
\hline & & Don't know & 98 & \\
\hline 104 & $\begin{array}{l}\text { How many years of formal schooling did } \\
\text { you have? }\end{array}$ & [_]__] years & & \\
\hline \multirow[t]{6}{*}{105} & \multirow{4}{*}{$\begin{array}{l}\text { Have you ever gone to school? } \\
\text { If YES, what is the highest level of school } \\
\text { you attended: } \\
\text { Primary, secondary, or higher? }\end{array}$} & Never go to school & 00 & \\
\hline & & Less than primary & 01 & \\
\hline & & Competed primary & 02 & \\
\hline & & Completed secondary & 03 & \\
\hline & \multirow{2}{*}{ [CIRCLE RESPONSE] } & Completed high school & 04 & \\
\hline & & University/post secondary tertiary & 05 & \\
\hline \multirow[t]{4}{*}{106} & \multirow[t]{4}{*}{ What is your marital status? } & Married/cohabiting & 00 & \\
\hline & & Divorced & 01 & \\
\hline & & Widowed & 02 & \\
\hline & & Never married & 03 & \\
\hline \multirow[t]{7}{*}{107} & \multirow[t]{7}{*}{ What is your current employment status? } & Unemployed & 00 & \\
\hline & & Work for hire on irregular basis & 01 & \\
\hline & & Civil servant & 02 & \\
\hline & & Business person & 03 & \\
\hline & & Family-employed & 04 & \\
\hline & & Peasant & 95 & \\
\hline & & Other (specify) & & \\
\hline
\end{tabular}




\section{Hgrizons}

\begin{tabular}{|c|c|c|c|c|}
\hline \multicolumn{5}{|c|}{ SECTION 2: PERCIEVED QUALITY OF CARE } \\
\hline 201 & Is this your first visit to this facility? & $\begin{array}{r}\text { No } \\
\text { Yes } \\
\text { No response }\end{array}$ & $\begin{array}{l}00 \\
01 \\
99\end{array}$ & $\begin{array}{l}->Q 202 \\
->Q 203\end{array}$ \\
\hline 202 & $\begin{array}{l}\text { How many times did you go to this } \\
\text { facility during } 6 \text { months ago? }\end{array}$ & & {[} & \\
\hline 203 & $\begin{array}{l}\text { What were the reasons why you came to } \\
\text { the health center today? }\end{array}$ & & & \\
\hline 204 & $\begin{array}{l}\text { What services did you receive today? } \\
\text { (Multiple responses possible. Explain the } \\
\text { meaning of word "Services" if respondent } \\
\text { don't understand.) }\end{array}$ & $\begin{array}{r}\text { Clinical exam } \\
\text { Blood test(s) } \\
\text { TB test } \\
\text { Biopsy } \\
\text { Xray } \\
\text { Out-patient treatment } \\
\text { In-patient treatment, no surgery } \\
\text { Inpatient with surgery } \\
\text { Other (specify)__t know/Don't remember } \\
\text { No response }\end{array}$ & $\begin{array}{l}01 \\
02 \\
03 \\
04 \\
05 \\
06 \\
07 \\
08 \\
95 \\
98 \\
99\end{array}$ & \\
\hline
\end{tabular}




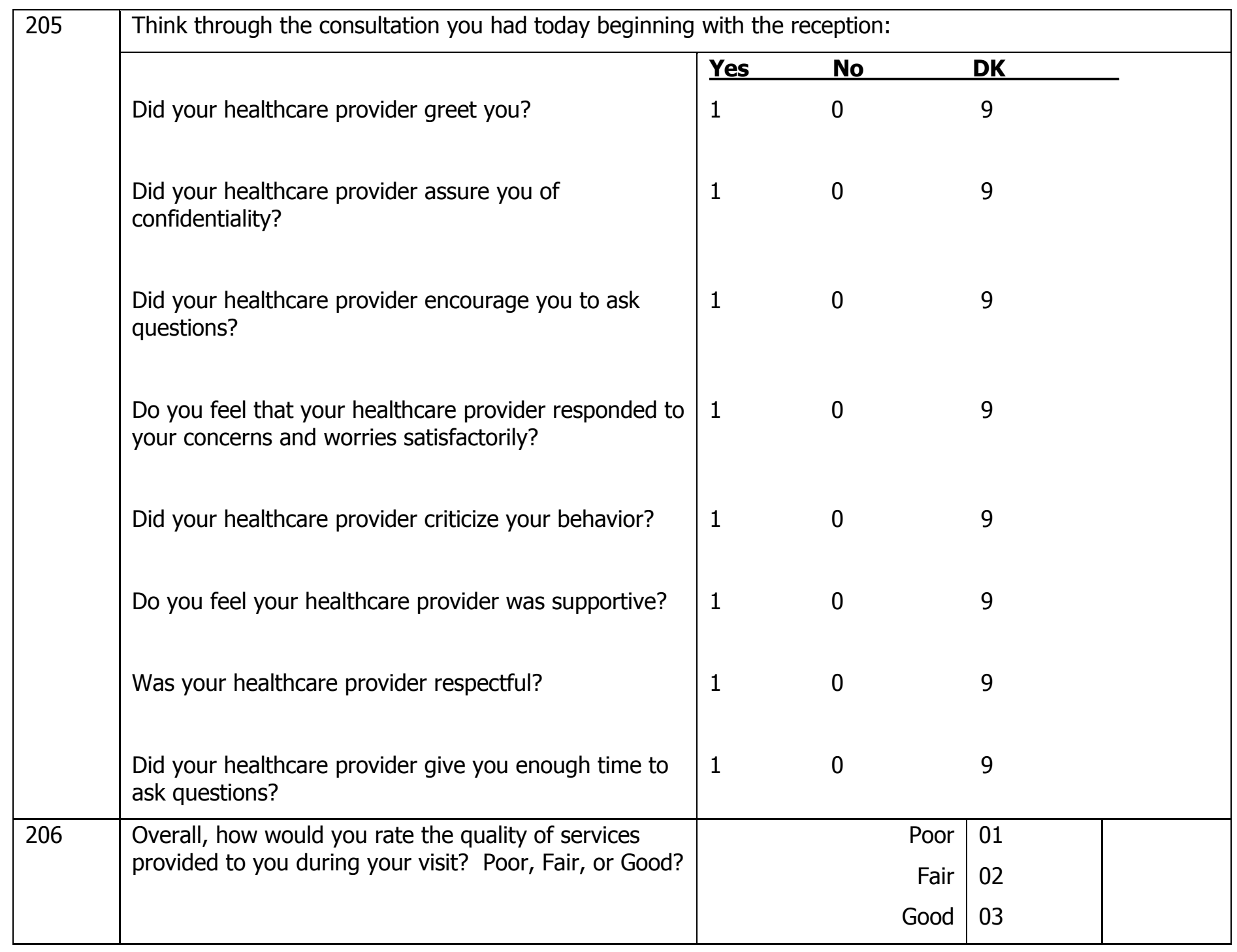




\section{Hgrizons}

\section{SECTION 3: EXPERIENCE IN TB SETTING AS HIV POSITIVE PATIENT}

\begin{tabular}{|c|c|c|c|c|}
\hline 301 & $\begin{array}{l}\text { Did you learn about your HIV } \\
\text { status before visit to this facility? }\end{array}$ & $\begin{array}{r}\text { Before } \\
\text { No } \\
\text { No response }\end{array}$ & $\begin{array}{l}01 \\
02 \\
99\end{array}$ & $\rightarrow$ Q307 \\
\hline 302 & $\begin{array}{l}\text { IF ANSWER "BEFORE" } \\
\text { Did you tell your health provider in } \\
\text { this facility about your status? }\end{array}$ & $\begin{array}{r}\text { No } \\
\text { Yes } \\
\text { No response }\end{array}$ & $\begin{array}{l}00 \\
01 \\
99\end{array}$ & $\rightarrow$ Q304 \\
\hline $302 a$ & $\begin{array}{l}\text { IF ANSWER "NO" } \\
\text { Why didn't you tell them? } \\
\text { Multiple responses possible } \\
\text { Do not read options out loud }\end{array}$ & $\begin{array}{l}\text { Afraid they will refuse to provide ser } \\
\text { Afraid they would tell } \mathrm{s} \\
\text { Afraid I would be gossiped abou } \\
\text { Afraid it would become news around my } \\
\text { Afraid I will } \\
\text { Afraid I wi } \\
\text { Other (specify) }\end{array}$ & $\begin{array}{l}\text { vices for me } \\
\text { omeone else } \\
\text { t/laughed at } \\
\text { living place } \\
\text { be demoted } \\
\text { Il be isolated } \\
\text { Lose respect } \\
\text { ivate matter } \\
\text { Don't know } \\
\text { No response }\end{array}$ & $\begin{array}{l}01 \\
02 \\
03 \\
04 \\
05 \\
06 \\
07 \\
08 \\
09 \\
10 \\
98 \\
99\end{array}$ \\
\hline
\end{tabular}




\begin{tabular}{|c|c|c|c|c|}
\hline 304 & $\begin{array}{l}\text { How long have you known that you } \\
\text { are HIV positive? }\end{array}$ & $\begin{array}{r}\text { Less than } 6 \text { months } \\
6 \text { months to } 1 \text { year } \\
1-5 \text { years } \\
6-10 \text { years } \\
10 \text { or more years } \\
\text { No response }\end{array}$ & $\begin{array}{l}00 \\
01 \\
02 \\
03 \\
04 \\
99\end{array}$ & \\
\hline 305 & $\begin{array}{l}\text { Was the decision to be tested your } \\
\text { own decision, or were you asked by } \\
\text { someone else to be tested? }\end{array}$ & $\begin{array}{r}\text { Went by self/own decision/voluntary } \\
\text { Was asked by someone to get test } \\
\text { Mandatory test } \\
\text { Tested without my knowledge } \\
\text { No response }\end{array}$ & $\begin{array}{l}01 \\
02 \\
03 \\
04 \\
99\end{array}$ & \\
\hline 306 & $\begin{array}{l}\text { Who asked or forced you to be } \\
\text { tested? }\end{array}$ & $\begin{array}{r}\text { Medical professional } \\
\text { Sex partner/wife/husband } \\
\text { Parents } \\
\text { Detox center } \\
\text { Prison } \\
\text { Employer } \\
\text { Other (specify)_Scholarship/school } \\
\text { Visa application }\end{array}$ & $\begin{array}{l}01 \\
02 \\
03 \\
04 \\
05 \\
06 \\
07 \\
08 \\
09 \\
95 \\
99\end{array}$ & \\
\hline 307 & $\begin{array}{l}\text { IF RESPONDENT LEARNED OF } \\
\text { STATUS DURING THIS VISIT: } \\
\text { Was your informed consent taken } \\
\text { before you were tested? }\end{array}$ & $\begin{array}{l}\text { No } \\
\text { Yes }\end{array}$ & $\begin{array}{l}00 \\
01\end{array}$ & \\
\hline 308 & $\begin{array}{l}\text { Did you receive counseling before } \\
\text { or after having your blood taken for } \\
\text { testing? } \\
\text { [PROBE ABOUT PRE- AND POST- } \\
\text { TEST COUNSELING] }\end{array}$ & $\begin{array}{r}\text { No counseling } \\
\text { Pre-test only } \\
\text { Post-test only } \\
\text { Pre-test and Post-test }\end{array}$ & $\begin{array}{l}00 \\
01 \\
02 \\
03\end{array}$ & $\rightarrow$ Q310 \\
\hline 309 & $\begin{array}{l}\text { Did the counselor discuss with you } \\
\text { anything about stigma and } \\
\text { discrimination during any of the pre } \\
\text { or post counseling sessions? }\end{array}$ & $\begin{array}{r}\text { No } \\
\text { Yes }\end{array}$ & $\begin{array}{l}00 \\
01\end{array}$ & \\
\hline
\end{tabular}




\section{Hgrizons}

\begin{tabular}{|c|c|c|c|c|}
\hline 310 & $\begin{array}{l}\text { Were you referred to any group or } \\
\text { place where you could get support? }\end{array}$ & $\begin{array}{l}\text { No } \\
\text { Yes }\end{array}$ & $\begin{array}{l}00 \\
01\end{array}$ & \\
\hline 311 & $\begin{array}{l}\text { Has your HIV status ever been } \\
\text { revealed without your consent from } \\
\text { this TB facility? }\end{array}$ & $\begin{array}{r}\text { No } \\
\text { Yes } \\
\text { Don't know } \\
\text { No response }\end{array}$ & $\begin{array}{l}00 \\
01 \\
98 \\
99\end{array}$ & $\rightarrow$ Q313 \\
\hline 312 & $\begin{array}{l}\text { Who was your status revealed to? } \\
\text { WRITE DOWN ALL EXAMPLES }\end{array}$ & & & \\
\hline 313 & $\begin{array}{l}\text { Did you do anything to other } \\
\text { people don't know your HIV status? }\end{array}$ & $\begin{array}{r}\text { No } \\
\text { Yes } \\
\text { No response }\end{array}$ & $\begin{array}{l}00 \\
01 \\
99\end{array}$ & $\rightarrow Q 315$ \\
\hline 314 & If Yes, what did you do? & & & \\
\hline 315 & During this visit (during 6 months a & pen to you? & & \\
\hline
\end{tabular}




\begin{tabular}{|c|c|c|c|c|c|c|}
\hline & & & Yes & No & DK & NR \\
\hline & 1. Health provider refused to a & tend you & 01 & 00 & 98 & 99 \\
\hline & 2. You were discharged too ea & & 01 & 00 & 98 & 99 \\
\hline & 3. You had to wait longer to be & attended & 01 & 00 & 98 & 99 \\
\hline & $\begin{array}{l}\text { 4. You were being unnecessari } \\
\text { in the same facility or referr }\end{array}$ & $\begin{array}{l}\text { y referred on to another provider } \\
d \text { to another facility }\end{array}$ & 01 & 00 & 98 & 99 \\
\hline & 5. You were told to come back & later & 01 & 00 & 98 & 99 \\
\hline & $\begin{array}{l}\text { 6. You were denied treatment } \\
\text { test/investigations) }\end{array}$ & e.g. drugs, surgery, or relevant & 01 & 00 & 98 & 99 \\
\hline & $\begin{array}{l}\text { 7. You were required to be tes } \\
\text { or surgery was performed }\end{array}$ & ed for HIV before care was given & 01 & 00 & 98 & 99 \\
\hline & $\begin{array}{l}\text { 8. Health provider used latex g } \\
\text { exams or took extra precaut }\end{array}$ & $\begin{array}{l}\text { oves for performing non-invasive } \\
\text { ons }\end{array}$ & 01 & 00 & 98 & 99 \\
\hline & $\begin{array}{l}\text { 9. Health provider disclosed yo } \\
\text { without your consent }\end{array}$ & ur HIV status to your family & 01 & 00 & 98 & 99 \\
\hline & 10. Health provider gossiped ab & ut your HIV status & 01 & 00 & 98 & 99 \\
\hline & $\begin{array}{l}\text { 11. Health provider used deroga } \\
\text { blamed you for having HIV }\end{array}$ & tory language or scolded or & 01 & 00 & 98 & 99 \\
\hline & $\begin{array}{l}\text { 12. Your bed pans or bed clothe } \\
\text { often compared to other pat }\end{array}$ & $\begin{array}{l}\text { were not changed as needed/ as } \\
\text { ents }\end{array}$ & 01 & 00 & 98 & 99 \\
\hline & 13. You received less care/atten & ion than other patients & 01 & 00 & 98 & 99 \\
\hline & 14. Your record was marked & & 01 & 00 & 98 & 99 \\
\hline & 15. Your bed was marked & & 01 & 00 & 98 & 99 \\
\hline & 16. You had to stay in an area $d$ & esignated for HIV+ patients & 01 & 00 & 98 & 99 \\
\hline 316 & $\begin{array}{l}\text { IF YES TO ANY OF ABOVE: } \\
\text { Why do you think you were treated } \\
\text { that way? }\end{array}$ & $\begin{array}{r}\text { Because of my HIV status } \\
\text { Because my condition was } \\
\text { severe } \\
\text { Because I am very poor } \\
\text { Other (specify)_ Don't know } \\
\text { No response }\end{array}$ & $\begin{array}{l}01 \\
02 \\
03 \\
95 \\
98 \\
99\end{array}$ & & $\begin{array}{l}\rightarrow \text { Q318 } \\
\rightarrow \text { Q318 } \\
\rightarrow \text { Q318 } \\
\rightarrow \text { Q318 } \\
\rightarrow \text { Q318 }\end{array}$ & \\
\hline
\end{tabular}




\section{Hgrizons}

\begin{tabular}{|c|c|c|c|c|}
\hline 317 & $\begin{array}{l}\text { IF RESPONDS "BECAUSE OF HIV } \\
\text { STATUS": } \\
\text { How did you know it was because } \\
\text { of your HIV status? } \\
\text { [WRITE DOWN ALL EXAMPLES } \\
\text { GIVEN] }\end{array}$ & & & \\
\hline 318 & $\begin{array}{l}\text { Do you think it is acceptable for } \\
\text { you to be treated this way? }\end{array}$ & $\begin{array}{r}\mathrm{Nc} \\
\mathrm{Yes} \\
\text { No opinior } \\
\text { No response }\end{array}$ & $\begin{array}{l}00 \\
01 \\
98 \\
99\end{array}$ & \\
\hline 319 & $\begin{array}{l}\text { How did you react for you to be } \\
\text { treated this way? } \\
\text { [WRITE DOWN ALL EXAMPLES } \\
\text { GIVEN] }\end{array}$ & & & \\
\hline 320 & $\begin{array}{l}\text { Did you report to anybody in this } \\
\text { facility about the way you were } \\
\text { treated? }\end{array}$ & $\begin{array}{r}\mathrm{Nc} \\
\mathrm{Yes} \\
\text { No response }\end{array}$ & $\begin{array}{l}00 \\
01 \\
99\end{array}$ & $\rightarrow Q 324$ \\
\hline 321 & $\begin{array}{l}\text { Who did you report it to? } \\
\text { [WRITE DOWN ALL EXAMPLES } \\
\text { GIVEN] }\end{array}$ & & & \\
\hline 322 & $\begin{array}{l}\text { What did that person do? } \\
\text { [WRITE DOWN ALL EXAMPLES } \\
\text { GIVEN] }\end{array}$ & & & \\
\hline 323 & $\begin{array}{l}\text { Do you think the response } \\
\text { to/action taken on your report was } \\
\text { satisfactory? }\end{array}$ & $\begin{array}{r}\mathrm{Nc} \\
\mathrm{Yes} \\
\text { Don't knon } \\
\text { No response }\end{array}$ & $\begin{array}{l}00 \\
01 \\
98 \\
99\end{array}$ & \\
\hline 321 & $\begin{array}{l}\text { In the future, if you need TB } \\
\text { services, would you come back to } \\
\text { this facility? }\end{array}$ & $\begin{array}{r}\mathrm{Nc} \\
\mathrm{Yes} \\
\text { Don't knon } \\
\text { No response }\end{array}$ & $\begin{array}{l}00 \\
01 \\
98 \\
99\end{array}$ & \\
\hline
\end{tabular}


SECTION 4: HIV/AIDS and TB KNOWLEDGE

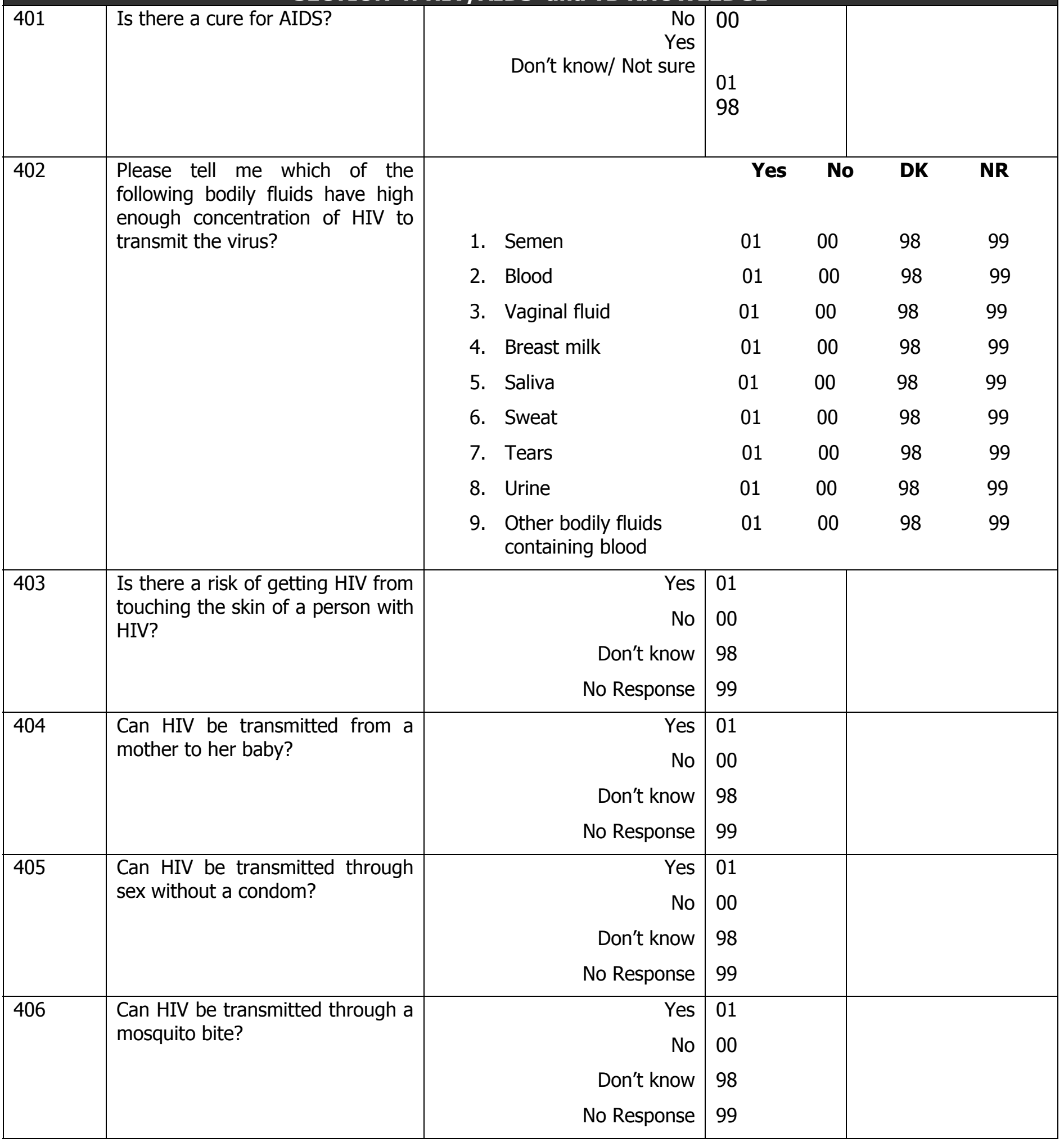




\section{Hgrizons}

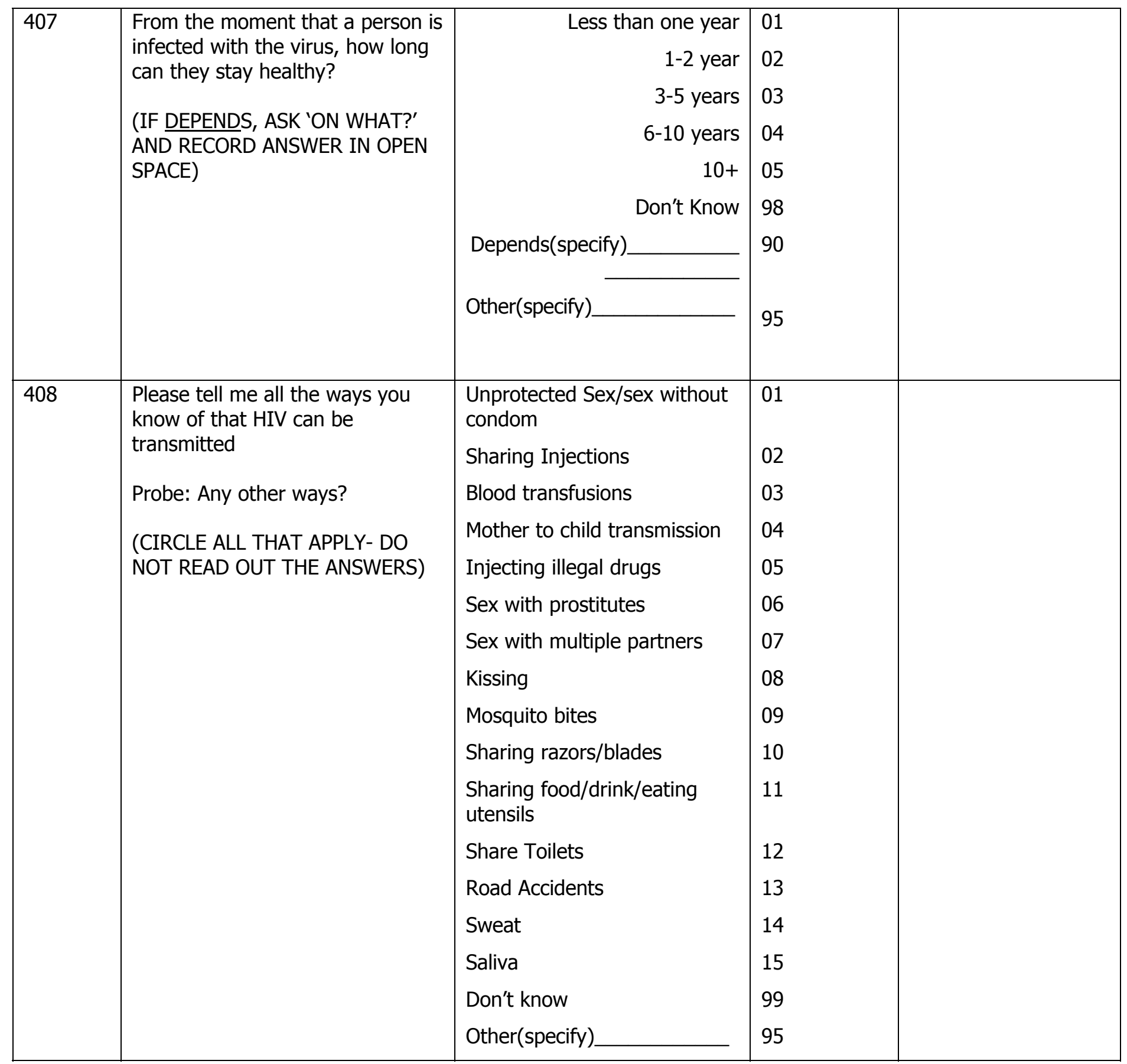




\begin{tabular}{|c|c|c|c|}
\hline 409 & $\begin{array}{l}\text { How can people protect } \\
\text { themselves from getting HIV? } \\
\text { (CIRCLE ALL THAT APPLY-DO } \\
\text { NOT READ OUT THE ANSWERS) }\end{array}$ & $\begin{array}{l}\text { Abstain from sex } \\
\text { Use condoms } \\
\text { Be faithful to one uninfected } \\
\text { partner } \\
\text { Limit number of sexual } \\
\text { partners } \\
\text { Avoid sex with prostitutes } \\
\text { Avoid sex with persons who } \\
\text { have sex with many partners } \\
\text { Avoid sex with homosexuals } \\
\text { Avoid sex with injecting drug } \\
\text { users } \\
\text { Avoid sharing razors/blades } \\
\text { Avoid injections } \\
\text { Avoid kissing } \\
\text { Avoid mosquito bites } \\
\text { Avoid blood transfusions } \\
\text { Sex with younger girls } \\
\text { Protection methods from } \\
\text { traditional Healer } \\
\text { Don't know } \\
\text { Other (specify) }\end{array}$ & $\begin{array}{l}01 \\
02 \\
03 \\
04 \\
05 \\
06 \\
07 \\
08 \\
09 \\
10 \\
11 \\
12 \\
13 \\
14 \\
15 \\
98 \\
95\end{array}$ \\
\hline 410 & $\begin{array}{l}\text { In a married couple, is it possible } \\
\text { for one person to have HIV and } \\
\text { the other one not to have HIV? }\end{array}$ & $\begin{array}{r}\text { No } \\
\text { Yes } \\
\text { Don't know }\end{array}$ & $\begin{array}{l}00 \\
01 \\
98\end{array}$ \\
\hline 411 & $\begin{array}{l}\text { Can TB be transmitted through } \\
\text { sex without a condom? }\end{array}$ & $\begin{array}{r}\text { No } \\
\text { Yes } \\
\text { Don't know }\end{array}$ & $\begin{array}{l}00 \\
01 \\
98\end{array}$ \\
\hline 412 & $\begin{array}{l}\text { Can TB be transmitted from a } \\
\text { mother to her baby? }\end{array}$ & $\begin{array}{r}\text { No } \\
\text { Yes } \\
\text { Don't know }\end{array}$ & $\begin{array}{l}00 \\
01 \\
98\end{array}$ \\
\hline 413 & Can TB be cured? & $\begin{array}{r}\text { No } \\
\text { Yes } \\
\text { Don't know }\end{array}$ & $\begin{array}{l}00 \\
01 \\
98\end{array}$ \\
\hline
\end{tabular}




\section{Hgrizons}

\begin{tabular}{|l|l|r|l|l|}
\hline 414 & $\begin{array}{l}\text { Can TB be transmitted by sharing } \\
\text { eating utensils with a person with } \\
\text { TB? }\end{array}$ & Nes & 00 \\
& & Don't know & 98 & \\
\hline 415 & Is TB a genetic disease that runs & No & 00 & \\
& in families? & Yes & 01 & \\
& & Don't know & 98 & \\
\hline
\end{tabular}




\section{SECTION 5: INTERNALIZED (SELF) STIGMA}

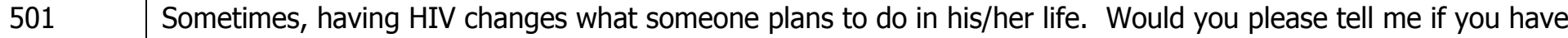
ever done any of the following because of your HIV status?

1. Stopped working

2. Avoided or withdrawn from applying for school, further training, or scholarship?

Yes

No NR

01

00

99

01

00

99

01

00

99

3. Not applied for a job promotion

4. Avoided or isolated yourself from friends or family

5. Decided not to get married or have a sexual partner

6. Decided not to have [more] children

7. Avoided travel to another country or another area in Vietnam

8. Not sought treatment/health care

0

01

00

99

01

00

99

$01 \quad 00$

99

01

00

99

01

00

99

01

00

99

9. Are there any [other] life goals or hopes that you have changed because of your HIV status? Please describe.

10. Others:

[RECORD REPONSE AND WRITE DOWN ALL EXAMPLES GIVEN HERE $\rightarrow$ ]

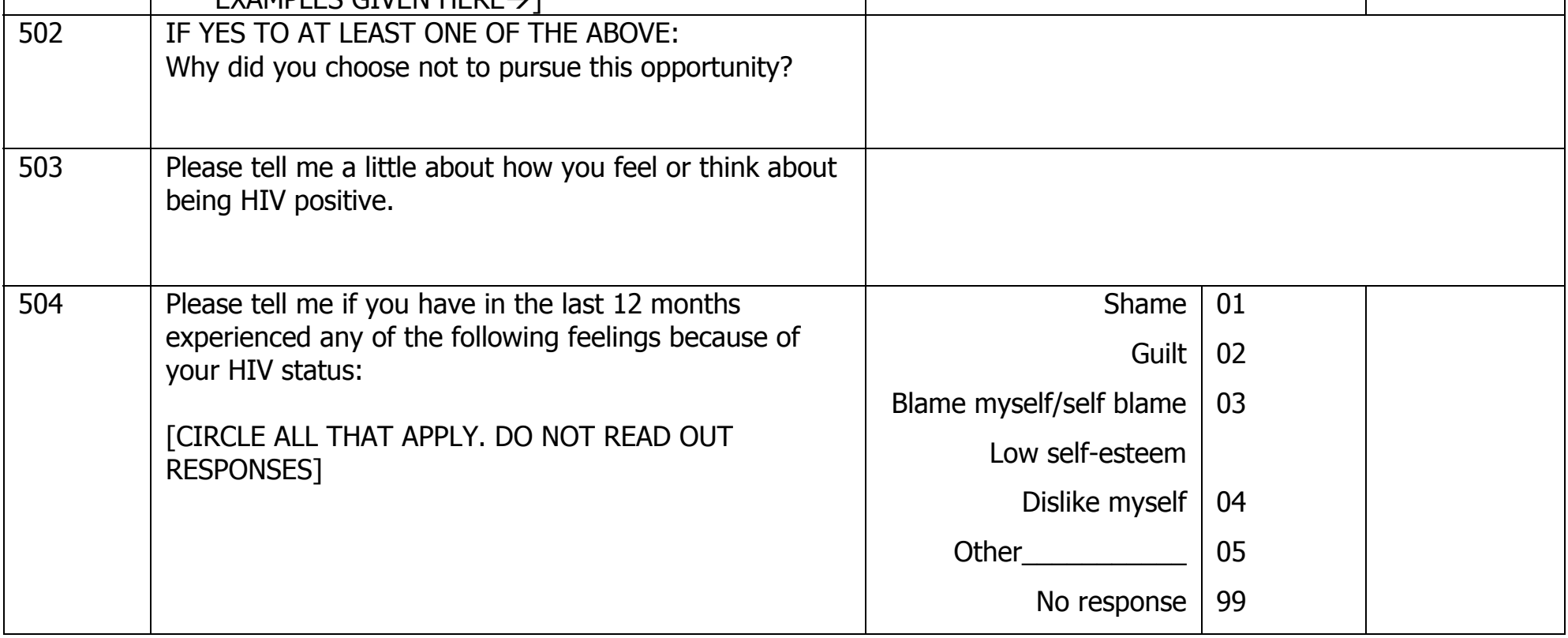




\section{Hgrizons}

\begin{tabular}{|c|c|c|c|c|}
\hline \multicolumn{5}{|c|}{ SECTION 6: KNOWLEDGE OF POLICIES AND LAWS } \\
\hline 601 & $\begin{array}{l}\text { Do you know of any provisions of law or policies against } \\
\text { HIV stigma and discrimination in Vietnam? }\end{array}$ & $\begin{array}{l}\text { No } \\
\text { Yes }\end{array}$ & $\begin{array}{l}00 \\
01\end{array}$ & \\
\hline 602 & What does the policy say? $\quad$ WRITE RESPONSE $\rightarrow$ & & & \\
\hline 603 & $\begin{array}{l}\text { Do you think these provisions are followed in this TB } \\
\text { facility? }\end{array}$ & $\begin{array}{r}\text { No } \\
\text { Yes, but not fully } \\
\text { Yes } \\
\text { Don't know } \\
\text { No response }\end{array}$ & $\begin{array}{l}00 \\
01 \\
02 \\
98 \\
99\end{array}$ & \\
\hline 604 & $\begin{array}{l}\text { Have you seen any regulation/code/policies in this } \\
\text { facility on how to treat HIV+ patient? }\end{array}$ & $\begin{array}{r}\text { No } \\
\text { Yes } \\
\text { Don't know } \\
\text { No response }\end{array}$ & $\begin{array}{l}00 \\
01 \\
98 \\
99\end{array}$ & \\
\hline 605 & What did it say? & & & \\
\hline
\end{tabular}

THANK YOU FOR YOUR TIME AND COOPERATION

Questionnaire ID [ ] ]

Date of interview

Interviewer.

Field supervisor.

Office supervisor.

Data entry by 


\section{Appendix 6 \\ Department Level and Hospital Observation and Documentation Checklist}

\section{A. Observation and monitoring checklists}

DEPARTMENT LEVEL OBSERVATION AND DOCUMENTATION CHECKLIST

1. Skin and STD

2. Obstetrics and Gynecology

3. Medicine

4. Surgery

5. Other (e.g. Pediatrics, "AIDS

Ward," etc.)

\section{DOCUMENTATION}

\section{Basic Department Information}

Name of HOD:-

Professional Qualifications of HOD:

Name of the Nursing Head:

Other Key contacts within department: 1.

2.

3.

Bed Capacity:

Number of inpatients/day:

Number of outpatients/day:

Number of staff:

Staff Strength:

\begin{tabular}{|l|l|l|l|}
\hline Levels & Male & Female & Total \\
\hline Doctors & & & \\
\hline Nurses & & & \\
\hline Class III & & & \\
\hline Class IV & & & \\
\hline Total & & & \\
\hline
\end{tabular}




\section{Hgrizons}

General OPD Hours:

OPD Days:

Population Served:

1. Income Groups:

2. Geographical areas:

Shift hours:

Rotations:

Special Teams within the dept addressing HIV/AIDS related issues: $\quad$ Yes/No

\section{Signs and Labels}

How is this ward labeled? What other prominent signs are there?

\section{Collect all written policies:}

1. Universal Precautions:

2. Admission of and care for PLHA:

3. HIV Testing of Patients:

4. PEP:

5. Hiring Practices re: Staff Who May Be HIV positive: Collected/ Not Available -Recruitment policy for HIV positive staff: -Retention of HIV positive staff:

6. Testing of Staff for TB:

-Testing of Staff for Hep-B:

-Testing of Staff for HIV:

7. Staff Immunization for Hep-A, Hep-B:

8. Confidentiality Regarding HIV Status:

9. Disclosure of HIV Status:

10. Recording of HIV Status:

11. Policy on Surgery:

12. Drug Policy:
Collected/ Not Available

Collected/ Not Available

Collected/ Not Available

Collected/ Not Available
Collected/ Not Available

Collected/ Not Available

Collected/ Not Available

Collected/ Not Available

Collected/ Not Available

Collected/ Not Available

Collected/ Not Available

Collected/ Not Available

Collected/ Not Available

Collected/ Not Available 
13. Waste Management:

14. Training in Clinical Management of HIV:

15. Counseling protocols, guidelines
Collected/ Not Available

Collected/ Not Available

Collected/ Not Available

16. Copies of pamphlets, educational materials, etc. Collected/ Not Available

(Including materials given post-test for HIV positive results)

17. Hospital Management Committee for IC/UP

18.OBS/GYN: Testing of pregnant women

MTCT

Breast feeding
Collected/ Not Available

Collected/ Not Available

Collected/ Not Available

Collected/ Not Available

\section{Pamphlets and Literature}

Collect any literature given out by these departments regarding basic information about RTIs,

STDs, HIV/AIDS, prevention, transmission, condoms and other prevention, living healthily with

AIDS, MTCT.

\section{Posters and Other IEC}

Describe any posters or information displayed on HIV/AIDS, RTIs/STDs, etc.

\section{Facilities}

\section{Add Department Specific Observations re: Equipment and Facilities}

OBS/GYN:

Access to regimens to prevent MTCT:

Access to breast milk substitutes:

Access to ARV:

MEDICINE: Access to any anti retro-virals:

SKIN/STD: What diagnostic tests are available:

SURGERY: Separate facilities and times for PLHA:
$\mathrm{Yes} / \mathrm{No}$

Yes/No

Yes/No

Yes/No

Yes/No

Training: Determine whether there is any training in the following areas.

\begin{tabular}{|c|c|c|c|c|c|c|c|c|}
\hline $\begin{array}{l}\text { Sl. } \\
\text { No. }\end{array}$ & Areas & $\begin{array}{l}\text { Trainee* } \\
\text { (Levels } \\
\text { of Staff) }\end{array}$ & Frequency & $\begin{array}{l}\text { Levels of } \\
\text { Training** }\end{array}$ & Duration & Trainer & $\begin{array}{l}\text { Since } \\
\text { When }\end{array}$ & \begin{tabular}{|l|} 
Modules \\
Collected
\end{tabular} \\
\hline 1. & $\begin{array}{l}\text { Infection } \\
\text { Control }\end{array}$ & & & & & & & \\
\hline 2. & Waste Mgmt. & & & & & & & \\
\hline 3. & $\begin{array}{l}\text { Clinical Mgmt } \\
\text { of HIV }\end{array}$ & & & & & & & \\
\hline 4. & $\begin{array}{l}\text { HIV/AIDS } \\
\text { Info. \& Edn. }\end{array}$ & & & & & & & \\
\hline 5. & HIV Testing & & & & & & & \\
\hline 6. & $\begin{array}{l}\text { Counseling for } \\
\text { HIV }\end{array}$ & & & & & & & \\
\hline 7. & Confidentiality & & & & & & & \\
\hline
\end{tabular}




\section{Hgrizons}

\begin{tabular}{|l|l|l|l|l|l|l|l|l|}
\hline & $\begin{array}{l}\text { \& Informed } \\
\text { Consent }\end{array}$ & & & & & & & \\
\hline 8. & PEP & & & & & & & \\
\hline 9. & Ethics and HIV & & & & & & & \\
\hline 10. & STD Mgmt. & & & & & & & \\
\hline 11. & MTCT & & & & & & & \\
\hline
\end{tabular}

Supplies provided:

Gloves:

$\begin{array}{ll}\text { i) } & \text { Type: } \\ \text { ii) } & \text { Brand } \\ \text { iii) } & \text { Sizes }\end{array}$

\begin{tabular}{|c|c|c|c|c|c|c|c|c|c|c|c|c|}
\hline $\begin{array}{l}\text { Sl. } \\
\text { no }\end{array}$ & Supplies & Users & $\begin{array}{l}\text { Who } \\
\text { controls }\end{array}$ & Storage & Locked & $\begin{array}{l}\text { Who } \\
\text { has } \\
\text { keys }\end{array}$ & $\begin{array}{l}\text { Accessible } \\
\text { (Timing) }\end{array}$ & $\begin{array}{l}\text { Sufficient } \\
\text { Supply }\end{array}$ & $\begin{array}{l}\text { Stock } \\
\text { out }\end{array}$ & $\begin{array}{l}\text { If stock out, } \\
\text { creative } \\
\text { steps by staff }\end{array}$ & Pilferage & $\begin{array}{l}\text { Financial } \\
\text { problem }\end{array}$ \\
\hline 1 & Gloves & & & & & & & & & & & \\
\hline 2 & Masks & & & & & & & & & & & \\
\hline 3 & $\begin{array}{l}\text { Slippers/ } \\
\text { boots }\end{array}$ & & & & & & & & & & & \\
\hline 4 & Aprons & & & & & & & & & & & \\
\hline 5 & Goggles & & & & & & & & & & & \\
\hline 6 & Bleach & & & & & & & & & & & \\
\hline 7 & $\begin{array}{l}\text { Soap \& } \\
\text { water }\end{array}$ & & & & & & & & & & & \\
\hline 8 & $\begin{array}{l}\text { Sterilization } \\
\text { supplies }\end{array}$ & & & & & & & & & & & \\
\hline 9 & $\begin{array}{l}\text { Disposable } \\
\text { Syringes } \\
\end{array}$ & & & & & & & & & & & \\
\hline 10 & $\begin{array}{l}\text { Glass } \\
\text { Syringes }\end{array}$ & & & & & & & & & & & \\
\hline 11 & PEP & & & & & & & & & & & \\
\hline 12 & $\begin{array}{l}\text { Puncture } \\
\text { Proof } \\
\text { Containers }\end{array}$ & & & & & & & & & & & \\
\hline
\end{tabular}

\section{HIV Testing}

Proportion of outpatients sent for HIV tests:

With patients' knowledge:

Yes/No

Proportion of inpatients sent for HIV tests:

With patients' knowledge:

Yes/No 


\section{OBSERVATIONS}

Things to Observe: Where feasible compare HIV + and HIV -

Observe any visible labels or signs indicating HIV positive patients-

Observe the presence of puncture proof containers in wards, halls, departments, operating theatres, and examination rooms. Observe whether any of these are overflowing? Are there any needles disposed of incorrectly.

\section{Location of beds and wards:}

Condition of beds and wards:

Basic amenities provided: linens, pillow, bed etc.

Labeling of beds or wards or files "HIV/AIDS" or "Barrier Nursing", etc.

Frequency of visits by doctors, nurses and ward staff: 


\section{Hgrizons}

Frequency of cleaning the room, changing linens, etc.:

Delivery of meals:

Delivery of medicine-

General manner in which patient is treated-

General manner in which patient's family is treated

Practices of doctors and nurses in terms of examinations, touching, etc

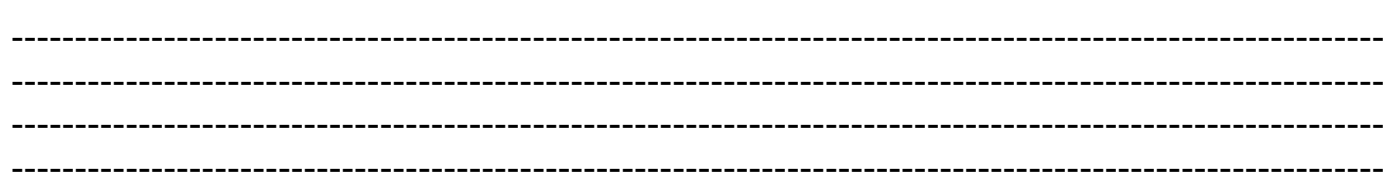

Management and handling of linens-

Management and handling of bodily fluids, e.g. vomit, blood, etc. 
Use of gloves, masks, etc around or with the patient

Remarks, Comments made to patient and family.

Timeliness of care and procedures

De-prioritized for surgery, etc.

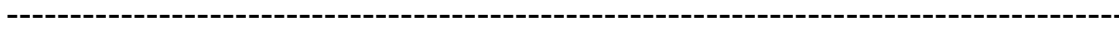

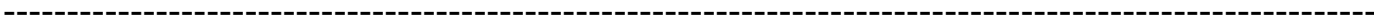

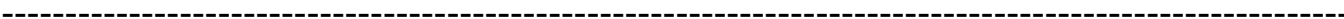

Transport of patient from one area to another - gloves, how treated, etc.

Demeanor of staff around the patient and family generally. 


\section{Hgrizons}

\section{Procedures to Observe: Where feasible compare HIV + and HIV}

Observe: Recapping, Bending, Breaking of Syringes, Needles-

Observe: Disposal of Needles and Sharps, Incl. Transfer to Waste Mgmt-

Observe: Handling of Blood Spills-

Observe: Handling of Linens, Incl. Transfer to laundry or Waste Mgmt-

Observe: Handling of Blood Soaked Cotton, Cloth, etc., incl. Transfer to Waste Mgmt

Observe: Disinfection of Thermometers-

Observe: Procedures for Phlebotomy

Observe: Cleaning and Re-Use of Gloves, Equipment, Etc.

Observe: Hand washing between Patients Observe:

Observe: Handling of Spills or Splashes of Blood, Etc. on Skin or Mucosal Surface.

Separate Equipment or Operating Theatre for PLHA? 
Observe/Ask: What is worn during surgery, delivery for patients known to be HIV positive and/or patients of negative or unknown status?

Are AIDS Kits of any kind used? Are they supplies by the hospital? Does the patient have to obtain and buy these?

OB/GYN: Handling of placenta-

Excessive precautions for patients known to be HIV positive?

Double/ triple gloving?

Extra masks, goggles, aprons, etc.

Fumigation of Rooms Used by PLHA? 


\section{Hgrizons}

\section{HOSPITAL-WIDE OBSERVATION AND DOCUMENTATION CHECKLIST}

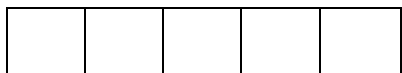

Type of Hospital: $\quad$ Central $\square \quad$ State $\square \quad$ Private $\square$

Name of Superintendent:

Contact Persons:

1.

2.

3.

Name of the Public Relations Officer:

Bed Capacity:

Number of inpatients/day (approx.):

Number of outpatients/day (approx.):

No. of Departments:

Number of Specialties:

Staff Strength:

\begin{tabular}{|l|l|l|l|}
\hline Levels & Male & Female & Total \\
\hline Doctors & & & \\
\hline Nurses & & & \\
\hline Class III & & & \\
\hline Class IV & & & \\
\hline Total & & & \\
\hline
\end{tabular}

General OPD Hours:

OPD Days:

Population Served:

3. Income Groups:

4. Geographical Areas: 
Names of HOD and Nursing Heads in Concerned Departments:

\begin{tabular}{|l|l|l|l|}
\hline Sl. No. & Department & Head of the Dept. & Nursing Head \\
\hline 1. & & & \\
\hline 2. & & & \\
\hline 3. & & & \\
\hline 4. & & & \\
\hline 5. & & & \\
\hline 6. & & & \\
\hline 7. & & & \\
\hline 8. & & & \\
\hline 9. & & & \\
\hline 10. & Public Relations & & \\
\hline
\end{tabular}

Any special Management Teams on:

$\begin{array}{lc}\text { PLHA } & \text { Yes/No } \\ \text { UP } & \text { Yes/No } \\ \text { PEP } & \text { Yes/No } \\ \text { Waste Management } & \text { Yes/No }\end{array}$

Grievance Cell Yes/ No

Any Other (Specify)

\section{Collect all written policies and information on monitoring of policies on}

17. Annual Reports:

18. Universal Precautions:

19. Admission of and care for PLHA:

20. HIV Testing of Patients:

21. Testing of Pregnant Women:

22. Breastfeeding (and HIV/AIDS):

23. PEP:
Collected/ Not Available

Collected/ Not Available

Collected/ Not Available

Collected/ Not Available

Collected/ Not Available

Collected/ Not Available

Collected/ Not Available

24. Hiring Practices re: Staff Who May Be HIV positive: Collected/ Not Available

-Recruitment policy for HIV positive staff:

Collected/ Not Available

-Retention of HIV positive staff:

Collected/ Not Available 


\section{Hgrizons}

25. Testing of Staff for TB:

-Testing of Staff for Hep-B:

-Testing of Staff for HIV:

26. Staff Immunization for Hep-A, Hep-B:

27. Confidentiality Regarding HIV Status:

28. Disclosure of HIV Status:

29. Recording of HIV Status:

30. Policy on Surgery:

31. Testing Policy for Newborns:

32. Drug Policy:

33. Waste Management:

34. Training in Clinical Management of HIV:

35. Counseling protocols, guidelines

36. Copies of pamphlets, educational materials, etc. Collected/ Not Available (including materials given post-test for HIV positive results)

21. Hospital Management Committee for IC/UP
Collected/ Not Available

Collected/ Not Available

Collected/ Not Available

Collected/ Not Available

Collected/ Not Available

Collected/ Not Available

Collected/ Not Available

Collected/ Not Available

Collected/ Not Available

Collected/ Not Available

Collected/ Not Available

Collected/ Not Available

Collected/ Not Available

Collected/ Not Available 


\section{Training}

Determine whether there is any training in the following areas.

\begin{tabular}{|c|c|c|c|c|c|c|c|c|}
\hline $\begin{array}{l}\text { Sl. } \\
\text { No. }\end{array}$ & Areas & $\begin{array}{l}\text { Trainee* } \\
\text { (Levels } \\
\text { of Staff) }\end{array}$ & Frequency & $\begin{array}{l}\text { Levels of } \\
\text { Training** }\end{array}$ & Duration & Trainer & $\begin{array}{l}\text { Since } \\
\text { When }\end{array}$ & $\begin{array}{l}\text { Modules } \\
\text { Collected }\end{array}$ \\
\hline 1. & $\begin{array}{l}\text { Infection } \\
\text { Control } \\
\end{array}$ & & & & & & & \\
\hline 2. & Waste Mgmt. & & & & & & & \\
\hline 3. & $\begin{array}{l}\text { Clinical Mgmt } \\
\text { of HIV }\end{array}$ & & & & & & & \\
\hline 4. & $\begin{array}{l}\text { HIV/AIDS } \\
\text { Info. \& Edn. }\end{array}$ & & & & & & & \\
\hline 5. & HIV Testing & & & & & & & \\
\hline 6. & $\begin{array}{l}\text { Counseling for } \\
\text { HIV }\end{array}$ & & & & & & & \\
\hline 7. & $\begin{array}{l}\text { Confidentiality } \\
\& \text { Informed } \\
\text { Consent }\end{array}$ & & & & & & & \\
\hline 8. & PEP & & & & & & & \\
\hline 9. & Ethics and HIV & & & & & & & \\
\hline 10. & STD Mgmt. & & & & & & & \\
\hline 11. & MTCT & & & & & & & \\
\hline
\end{tabular}

\section{Patient Record Keeping}

Computerized/Manual

Collect a blank Case Sheet.

Collected/ Not Available

Where is HIV status recorded

\section{Lab Facilities}

HIV Testing Facility (where?)

Special Staff for HIV Testing

Techniques used to test for HIV:

ELISA-Rapid/Simple

Confirmatory testing techniques:

W-Blot/ Three kit ELISA method

No. HIV tests/week:

Days for collecting test samples:

Days for HIV Testing:

Reports for HIV available on days:

Proportion Who Test Positive:

Which departments send high volumes of blood for HIV testing?

Where are tests recorded? 


\section{Hgrizons}

What is the practice of communication of HIV status to other hospital staff? Who communicates and how?

Examine record keeping. (names, numbers of patients)

Collect a blank record.

Collected/ Not Available

\section{Waste Management}

Incinerator

Autoclaves Facilities

Micro-waving Facilities On-Site Off-Site

Shredding Facilities

Deep burial
On-site Off-site

On-Site Off-Site

On-Site Off-Site

On-Site Off-Site

Use of municipal Landfills- 
Where/ and how are sharps disposed?

Where/how is hazardous waste disposed?

Volume of waste/day:

Waste segregated (Categories of Waste):

\section{Morgue Facilities}

\begin{tabular}{|l|l|l|l|l|}
\hline Sl.no. & Preparation of body & General & $\begin{array}{l}\text { With infectious } \\
\text { diseases }\end{array}$ & With HIV/AIDS \\
\hline 1 & Wrapped in & & & \\
\hline 2 & Labeled & & & \\
\hline 3 & $\begin{array}{l}\text { Special facility available } \\
\text { (Gloves, goggles etc.) }\end{array}$ & & & \\
\hline 4 & Transportation & & & \\
\hline
\end{tabular}

\section{Basic Clinical Care for PLHA}

Any specialists:

Special wards/facilities:

Special counters:

Special OPD

Special clinic for women

Counseling
Exist/ does not exist

Exist/ does not exist

Exist/ does not exist

Exist/ does not exist

Exist/ does not exist

Exist/ does not exist

Research programme with HIV+ people Exist/ does not exist 


\section{Hgrizons}

Collect case management protocols

Anti-retroviral Therapy

Facilities for opportunistic infections

Access to regimens to prevent MTCT

Access to breast milk alternatives

Any other specialized services:
Collected/ not available

Available/ not available

Available/ not available

Available/ not available

Available/ not available

Exist/ does not exist

\section{Counseling Services}

Designated space/center for counseling on HIV/AIDS Available/ not available

Department in charge of Counseling

Are there designated staffs for the above (specify)

Describe waiting area and counseling rooms, including visual and auditory privacy.

\begin{tabular}{|l|l|l|l|l|l|}
\hline $\begin{array}{l}\text { Sl. } \\
\text { No. }\end{array}$ & Designation & Number of Staff & Male/Female & Qualification & Levels of Training \\
\hline 1 & & & & & \\
\hline 2 & & & & & \\
\hline 3 & & & & & \\
\hline 4 & & & & & \\
\hline 5 & & & & & \\
\hline
\end{tabular}

Days of counseling:

Hours of counseling:

Is counseling conducted on-site (within hospital) or off-site: 
Describe posters or educational materials on HIV:

How is the counseling center labeled, signed:

\section{Referral System}

Does this hospital routinely refer clients to other clinics, hospitals, organizations, private physicians?

$$
\text { Yes/No }
$$

Are patients referred to this hospital from other clinics, hospitals, organizations, private physicians?

$$
\text { Yes/No }
$$

Types of cases are referred (in and out):

Any special referral arrangements for PLHA:

Patients referred from:

Patients referred to:

Collect referral sheets if they exist.

Collected/Not available

\section{Patient Grievance Cell:}

\section{Exists/ does not exist}

How long is it in existence:

What are the hours:

Staff structure

\begin{tabular}{|l|l|l|l|l|}
\hline Sl.no & Designation & Number & Male & Female \\
\hline 1 & & & & \\
\hline 2 & & & & \\
\hline 3 & & & & \\
\hline 4 & & & & \\
\hline
\end{tabular}




\section{Hgrizons}

\begin{tabular}{|l|l|l|l|}
\hline 5 & & & \\
\hline 6 & & & \\
\hline
\end{tabular}

Protocol for handling complaints:

How many complaints / month:

Of these, how many relate to PLHA:

How are patients made aware of this service:

\section{Infection Control and Universal Precautions}

Supplies provided:

Gloves:

iv) Type:

v) Brand

vi) Sizes

\begin{tabular}{|c|c|c|c|c|c|c|c|c|c|c|c|c|}
\hline S.no & Supplies & Users & $\begin{array}{l}\text { Who } \\
\text { controls }\end{array}$ & Storage & Locked & $\begin{array}{l}\text { Who } \\
\text { has } \\
\text { keys }\end{array}$ & $\begin{array}{l}\text { Accessible } \\
\text { (Timing) }\end{array}$ & $\begin{array}{l}\text { Sufficient } \\
\text { Supply }\end{array}$ & $\begin{array}{l}\text { Stock } \\
\text { out }\end{array}$ & $\begin{array}{l}\text { If stock } \\
\text { out, } \\
\text { creative } \\
\text { steps by } \\
\text { staff }\end{array}$ & Pilferage & $\begin{array}{l}\text { Financ } \\
\text { ial } \\
\text { proble } \\
\mathrm{m}\end{array}$ \\
\hline 1 & Gloves & & & & & & & & & & & \\
\hline 2 & Masks & & & & & & & & & & & \\
\hline 3 & $\begin{array}{l}\text { Slippers/ } \\
\text { boots }\end{array}$ & & & & & & & & & & & \\
\hline 4 & Aprons & & & & & & & & & & & \\
\hline 5 & Goggles & & & & & & & & & & & \\
\hline 6 & Bleach & & & & & & & & & & & \\
\hline 7 & $\begin{array}{l}\text { Soap \& } \\
\text { water }\end{array}$ & & & & & & & & & & & \\
\hline 8 & $\begin{array}{l}\text { Sterilization } \\
\text { supplies }\end{array}$ & & & & & & & & & & & \\
\hline 9 & $\begin{array}{l}\text { Disposable } \\
\text { Syringes }\end{array}$ & & & & & & & & & & & \\
\hline 10 & $\begin{array}{l}\text { Glass } \\
\text { Syringes }\end{array}$ & & & & & & & & & & & \\
\hline 11 & PEP & & & & & & & & & & & \\
\hline 12 & $\begin{array}{l}\text { Puncture } \\
\text { Proof } \\
\text { Containers }\end{array}$ & & & & & & & & & & & \\
\hline
\end{tabular}


Is there a hospital committee procedure for supplies?

Yes/No

Explain-

\section{Post-Exposure Prophylaxis}

Is there a hospital management team on occupational exposure

Yes/No

Explain protocol:

Is there a system in place for providing PEP to staff as needed:

Yes/No

If yes, specify-

Which departments and levels of staff are provided PEP

Is there a system for monitoring instances/outcomes of occupational exposure

Yes/No

If yes, explain- 


\title{
Appendix 7 Hospital Policy Guidelines
}

\author{
Convention for a Safe and Friendly Hospital \\ Ninh Kiêu General Hospital \\ $\cos 0303908080$
}

\section{1) Reception, health care and treatment of HIV infected patients}

a) The hospital shall ensure equality in the reception, health care and treatment of HIV infected patients as well as the quality of the services provided for them.

b) HIV infected patients shall not be arranged to stay in a separated ward or department.

c) The hospital shall guarantee to provide contact address of and introduce HIV infected patients to organizations and institutions that offer material and spiritual assistance and services to HIV positive people in their locality.

d) The hospital shall set up a counseling unit and a hot line which operate regularly to deal with patient's inquiry and complaint timely.

e) The Administration Room shall be responsible for monitoring the implementation of these regulations.

\section{2) Consultation and HIV tests}

a) All cases shall be tested for HIV based on patient's willingness (according to patient's request or doctor's assignment and patient's permission). Compulsory cases subject to diagnosis and treatment shall be the cases under Ministry of Health's regulations.

b) Those patients that have had HIV tests with positive results certified by a functional institution shall not need to be tested again.

c) All cases subject to HIV tests shall be counseled before being tested by a professionally trained consultant.

d) HIV test results shall be informed to patients through after-test counseling by a professional trained consultant.

e) The Administration Room shall be responsible for monitoring the implementation of these regulations. 


\section{3) Confidentiality of HIV test results}

a. A patient's HIV positive result shall be informed directly to his/her attending physician by a relevant staff of the Testing Department. The attending physician shall inform the patient's consultant and other health workers who are directly involved in taking care of and treating the patient.

b. The consultant shall inform the patient of his/her test result through after-test counseling and encourage the patient to ask his/her partner to see the consultant for consultation of the patient's positive result.

c. Head of the Department and attending physician shall be responsible for managing patients' case records and keeping the patient's HIV test results confidential.

d. Hospital staff shall not notify HIV positive results to anyone else.

e. HIV infected patient's wards, beds, medical records, clothes and other stuff shall not have any mark so that his/her infection is unable to be recognized.

f. The Administration Room shall be responsible for monitoring the implementation of these regulations.

\section{4) Infection Prevention and Control}

a) All hospital staff shall always take universal prevention measures.

b) Hospital staff shall wash their hands in the following situations:

Before:

- putting on gloves;

- having contact with each patient;

- preparing medical instruments and medication;

- processing and distributing food;

After:

- being exposed to patient's blood, fluid or waste;

- having direct contact with patients;

- leaving contaminated areas for clean areas;

- having contact with stuff closed to patients; and,

- taking off gloves. 


\section{Hgrizons}

c) Hospital staff shall wear clean gloves when:

- being exposed to patient's blood, fluid and waste;

- having contact with contaminated tools; and,

- their skin is grazed.

d) Hospital staff shall wear sterilized gloves:

- during a surgical operation; and,

- during incision care of a patient.

e) Needles and pointed and sharp instruments shall be disposed of according to the regulation.

f) All used needles shall be disposed of.

g) In case of occupational exposure to HIV, hospital staff shall inform the Anti-infection Department for timely handling.

h) All hospital staff shall be vaccinated against super-bacterial hepatitis.

i) The hospital shall supply sufficient equipment and facilities for the practice of universal prevention, including:

- Running water taps or solution for quick hand sterilization to wash hands in all the situations prescribed in this Convention.

- Clean and sterilized gloves to be used in all the situations prescribed in this Convention.

- Safety goggles for health care workers carrying out operations in Surgical Department and Obstetric Department.

- Sterilizing chemicals packaged in the size convenient for use.

- Tools for cleaning and collecting cloth stuff.

- Anti-infection Department, Care Assistance Department and Pharmacy Department shall be responsible for monitoring the implementation of these regulations.

\section{2) Training on HIV}

a. A group of nurses, doctors and care assistants shall be responsible for learning and updating knowledge of anti-infection and HIV and disseminating that knowledge timely to other hospital staff.

b. All hospital staff shall be trained on basic knowledge of HIV and universal prevention. 
c. Administration room - Anti-infection Department, Care Assistance Department shall be responsible for organizing training courses.

\section{3) Popularizing HIV related regulations and policies}

a. Legal and professional regulations shall be popularized timely to concerning individuals in the hospital through regular meetings and written documents shall be sent to departments.

b. Patient related written regulations shall be popularized weekly in the patients meetings in wards and made public in health check rooms, waiting areas and treatment rooms.

c. The Administration Room shall be responsible for monitoring the implementation of these regulations. 


\section{Convention on a Safe and Friendly Hospital \\ General Hospital of Thốt Nốt district \\ $\cos \cos \cos 800080$}

\section{1) Reception, health care and treatment of HIV infected patients}

a) HIV infected patients shall be admitted to and given care and treatment by the specialized ward.

b) HIV infected patients shall be counseled, health checked, out-treated and provided with free medicine in out-patient health check rooms for HIV/AIDS infected people on voluntary basis.

c) HIV infected patients shall have the same rights and duties as other patients.

d) Regarding care, care assistants shall have to strictly follow the regulations on providing the same care in food, hygiene... for HIV infected patients as for other patients.

e) In terms of treatment: Doctors shall examine and treat patients according to the provided treatment regime.

f) Health care workers shall have to carry out sufficient necessary tasks for care and treatment for patients.

\section{2) Counseling and HIV tests}

a) All tests for HIV shall be carried out on patients' willingness.

b) All cases subject to HIV tests shall be counseled before and after being tested.

c) All tests for HIV shall be carried out according to the regulations of the Ministry of Health.

d) HIV test results shall have to be kept confidential as prescribed by the law.

e) Tests for HIV for people less than 16 years old and those without civil behaviors shall be carried out only upon the written agreement of their parents or trustees.

\section{3) Confidentiality of HIV test results}

a) Basing on the test result from the Center for Preventive Medicine of Can Tho, the hospital Management Board shall inform it to the counselor, treatment doctor and other health care workers who directly provide care and treatment for the patients.

b) The health care workers who are informed the patients' HIV test results shall have to keep the information completely confidential. 
c) There shall not be any discrimination in care and treatment between HIV patients and other ones.

\section{4) Infection Prevention and Control}

a) Hospital staff shall have to wash their hands in the following situations:

-Before...

- putting on gloves;

- having contact with every patient;

- preparing medical tools and medicine;

- processing and distributing food;

After...

- being exposed to patient's blood, fluid or waste;

- having direct contact with patients;

- leaving contaminated areas for clean areas;

- having contact with stuff closed to patients; and,

- taking off gloves.

b) Hospital staff shall wear clean gloves when:

- being exposed to patient's blood, fluid and waste;

- having contact with contaminated tools; and,

- their skin is grazed.

c) Hospital staff shall wear sterilized gloves:

- during a surgical operation; and,

- during incision care of a patient.

d) Medical and domestic waste shall be sorted and disposed of according to the regulations of the health industry. 


\section{Hgrizons}

e) After being exposed to patient's blood or fluid, hospital staff shall let their head of department be informed immediately and a report shall be made according to the regulations.

f) The hospital shall supply sufficient equipment and facilities for the practice of universal prevention.

\section{5) Training on HIV}

a) All hospital staff shall be trained on basic knowledge of HIV and basic prevention.

b) From 1-2 staff in each ward shall be trained on HIV counseling and testing.

c) The hospital shall provide updated information and knowledge of HIV/AIDS to its staff every six months.

d) A group of specialized health care workers shall be established and trained on treatment and prevention in each ward.

\section{6) Popularizing HIV related regulations and policies}

a) All patients shall be educated about the rights and duties of HIV infected patients.

b) Legal and professional regulations shall be communicated in a timely manner to relevant individuals in the hospital through regular meetings, and written documents shall be sent to departments.

c) HIV related regulations shall be displayed in public spaces in the hospital and announced periodically on the hospital's internal loudspeaker system.

7) The Administration Room, Care Assistance Room and Anti-infection Ward shall be responsible for organizing and monitoring the implementation of this convention. 


\section{Regulations for a Safe and Friendly Hospital Tuberculosis and Lung Hospital of Hai Phong}

\section{Receive and provide care and treatment for HIV/AIDS patients}

\section{Hospital's responsibilities}

1. All the patients coming to the hospital shall be received warmly and suffer no discrimination and stigma.

2. Patients shall be examined and counseled to have HIV test and other tests according to their illness status. They shall be informed about their rights and duties as patients as prescribed by the Ministry of Health.

3. HIV infected patients shall be taken care of and lent individual necessities (blankets, mosquito nets, clothing, mugs...) like other patients.

4. Patients shall be treated for tuberculosis and if they meet the requirements, shall receive ARV treatment according to the treatment regime of the Ministry of Health and National AntiTuberculosis Program.

5. Patients shall be counseled about treatment and self-care, ways to prevent opportunistic infection and to prevent the transmission of their disease to their relatives and the community.

6. Patients shall be treated with free tuberculosis drugs and anti-HIV drugs depending on the amount of drugs provided for the hospital.

7. Patients shall receive care and treatment in a separate department after being counseled and providing their consent.

\section{Patients' and their relatives' responsibilities:}

Following the hospital's regulations

1. Patients have to follow strictly the doctors' medical instructions.

2. Patients and their relatives have to respect doctors, health care workers and other patients.

\section{Counseling and Testing}

1. All patients coming to the hospital to have their health checked and to receive treatment shall be counseled to have voluntary HIV testing. Those with positive HIV test results carried out in competent health institutions shall not have to be retested.

2. Mandatory HIV testing (for the purpose of diagnosis and treatment) must be carried out in accordance with the law and the regulations of the health ministry. 


\section{Hgrizons}

3. Counselors and health workers directly providing health examinations, care and treatment for patients must be trained in counseling skills, knowledge of HIV/AIDS and anti-HIV/AIDS law.

4. Counseling rooms must be equipped with sufficient equipment for convenient and high-quality counseling service.

\section{Keeping testing results confidential}

1. $\operatorname{HIV}(+)$ testing results must be kept confidential

2. HIV $(+)$ test results are only informed directly by the testing technician to the health worker requesting the test and to the treating doctor.

3. The health worker requesting the testing and treating doctor are responsible for informing the test results to the following people:

- Counselors

- Patients

- Health workers directly providing care and treatment for the patients and members of consultation board.

- Patient's wife or husband, guardians (if the patient is a minor)

\section{Universal prevention}

1. The hospital's health workers shall have to follow standard universal prevention procedures when working with all patients, regardless of having HIV or not, to ensure safety for themselves and for the patients. All the hospital health care workers and staff ought to abide by the following universal prevention procedures:

- Washing hands regularly and before carrying out surgeries,

- Using protective clothing such as boots, gloves, glasses, masks...according to the guidelines,

- Practicing safe injection,

- Handling medical tools safely: cleaning, sterilizing,

- Safely disposing waste, especially sharp and pointed things,

- Carefully handling linens and clothing.

2. Handling HIV exposure in accordance with the determined process. An appropriate amount of drugs for the treatment of post-exposure to HIV must be always available in stock in the Pharmacy Department to have timely prevention treatment for the HIV exposed staff.

3. Providing sufficient necessary equipment for universal prevention. 
4. Setting up a hospital anti-infection committee which supervises the regular practice of hospital infection prevention.

5. Providing documents and guidelines about universal prevention for all departments and rooms so that every health care worker in the hospital can have access to them.

\section{Training}

1. Training all the staff in the hospital on anti-HIV/AIDS law.

2. Organizing annual training classes on counseling, care and treatment for HIV/AIDS patients for all related staff.

3. Updating knowledge of HIV transmission prevention, post-exposure treatment and universal prevention for all the hospital staff every year.

\section{Disseminating regulations related to HIV}

\section{As for hospital staff:}

All the law documents, underlaw documents and regulations of the health industry related to HIV/AIDS shall be disseminated in a timely manner to all hospital staff via daily meetings or sending them to the departments.

\section{As for patients:}

Regulations related to patients shall be disseminated to them via monthly patient meetings, loudspeaker system in the hospital or notices hung in health check rooms, treatment rooms and departments.

\section{Steering Board for Comprehensive Care for Patients shall be responsible for implementing all these regulations.}




\section{Convention on a Safe and Friendly Hospital Quang Ninh Hospital of Tuberculosis and Pulmonary Disease}

\section{Reception, health care and treatment of HIV infected patients}

a. The hospital shall ensure equality in the reception, health care and treatment of HIV infected patients.

b. The quality of services provided to HIV infected patients or patients suspected with HIV infection shall be the same as the quality of services provided to other patients.

c. HIV infected patients shall not be arranged to stay in a separated ward or department.

d. The hospital shall guarantee to provide contact address of and introduce HIV infected patients to organisations and institutions that offer health care assistance and services to HIV positive people in their locality.

e. The hospital shall set up a unit to deal with patient's inquiry and complaint. Its address, telephone number and work schedule shall be made available in waiting areas and other public areas within the hospital. Its staff shall be available in the office during scheduled hours.

\section{Consultation and HIV tests}

a. All cases shall be tested for HIV based on patient's willingness (according to patient's request or doctor's assignment and patient's permission). Compulsory cases subject to diagnosis and treatment shall be the cases under Ministry of Health's regulations.

b. Those patients that have had HIV tests with positive results certified by a functional institution shall not require retesting.

c. All cases subject to HIV tests shall be counselled before being tested by a professionally trained counselor.

d. HIV test results shall be informed to patients by a professional trained counselor.

\section{Confidentiality of HIV test results}

a. A patient's HIV positive result shall be informed directly to his/her attending physician by a relevant staff of the Testing Department. The attending physician shall inform the patient's counselor and other health workers who are directly involved in taking care of and treating the patient.

b. The counselor shall inform the patient of his/her test result and encourage the patient to ask his/her partner to see the counselor for consultation of the patient's positive result.

c. Hospital staff shall not notify HIV positive results to anyone else.

d. HIV infected patient's wards, beds, medical records, clothes and other stuff shall not have any mark so that his/her infection is unable to be recognised. 


\section{Contamination Prevention and Control}

a. Hospital staff shall apply basic preventative measures to all patients, whether they are HIV infected or not, to ensure hospital staff and patient's safety; particularly

i. Hospital staff shall wash their hands with clean water and soap or surgical spirit in the following situations:

1. before putting on gloves;

2. before having contact with every patient;

3. before preparing medical tools and medicine;

4. before processing and distributing food;

5. after being exposed to patient's blood, fluid or waste;

6. after having direct contact with patients;

7. after leaving contaminated areas for clean areas;

8. after having contact with stuff closed to patients;

9. after taking off gloves.

ii. Hospital staff shall wear clean gloves when:

1. being exposed to patient's blood, fluid and waste;

2. having contact with contaminated tools;

3. their skin is grazed.

iii. Hospital staff shall wear sterilised gloves:

1. during a surgical operation; and,

2. during incision care of a patient.

iv. Contaminated needles and sharps shall be put in unpenetratable containers. Medical waste shall be put in yellow bags and domestic waste shall be put in blue bags. Medical waste shall be treated according to the procedure stipulated by Ministry of Health.

b. After having exposure to HIV infected patient's blood and fluid, hospital staff shall report it to the Department of Planning and Administration and comply with the post-exposure procedure stipulated by Ministry of Health.

c. The hospital encourages those staff that have contact with HIV infected patients to have vaccination against hepatitis $B$.

d. The hospital shall guarantee to provide sufficient facilities for basic prevention in the hospital.

\section{Training on HIV}

a. All hospital staff shall be trained with basic knowledge of HIV and basic prevention.

b. The hospital shall provide updated information and knowledge of HIV/AIDS to its staff through professional meetings quarterly. 


\section{Hgrizons}

6. Popularising HIV related regulations and policies

a. Legal and professional regulations shall be popularised to concerning individuals in the hospital through regular meetings at hospital and department levels and written documents shall be sent to departments.

b. Patient related written regulations shall be made public in waiting areas and wards.

7. The Steering Committee for Comprehensive Health Care shall be responsible for organising and monitoring the implementation of this convention. 


\section{Hgrizons}

Horizons is a global operations research program designed to:

- Identify and test potential strategies to improve HIV/AIDS prevention, care, and support programs and service delivery.

- Disseminate best practices and utilize findings with a view toward scaling up successful interventions.

\section{(2) Population Council}

Horizons is implemented by the Population Council in collaboration with

- International Center for Research on Women (ICRW)

- International HIV/AIDS Alliance

- PATH

- Tulane University

- Family Health International (FHI)

- Johns Hopkins University

For more information, please contact:

Horizons Program, Communications Unit 4301 Connecticut Avenue, NW Suite 280 Washington, DC 20008 USA

Tel: 202-237-9400

Fax: 202-237-8410

Email: horizons@popcouncil.org www.popcouncil.org/horizons 